
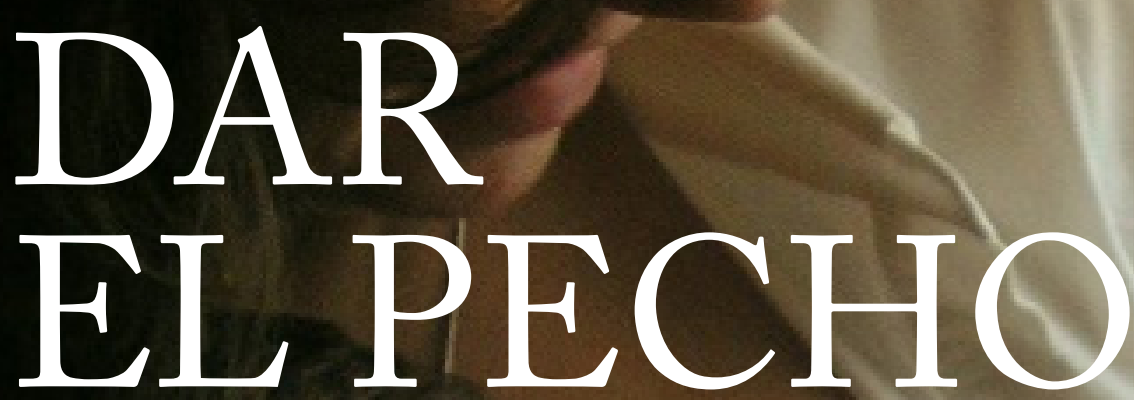

Estudio cualitativo sobre los grupos de promoción de la lactancia materna en la provincia de Toledo

Gonzalo Melgar de Corral Mercedes de Dios Aguado M. ${ }^{a}$ Concepción Villar de la Fuente María Fátima Gallego Moreno 



\section{Dar el pecho}

Estudio cualitativo sobre los grupos de promoción de la lactancia materna en la provincia de Toledo 



\title{
Dar el pecho \\ Estudio cualitativo sobre los grupos de promoción de la lactancia materna en la provincia de Toledo
}

\author{
Gonzalo Melgar de Corral \\ Mercedes de Dios Aguado \\ M. ${ }^{a}$ Concepción Villar de la Fuente \\ María Fátima Gallego Moreno
}

Ediciones de la Universidad

Cuenca, 202I 
(C) de los textos e imágenes: sus autores.

(C) de la edición: Universidad de Castilla-La Mancha.

Edita: Ediciones de la Universidad de Castilla-La Mancha

Colección ATENEA no 24

Diseño de cubierta: Servicio de Publicaciones (UCLM).

ulie Editoriales

Esta editorial es miembro de la UNE, lo que garantiza la difusión y ESPAÑolas

comercialización de sus publicaciones a nivel nacional e internacional.

I.S.B.N.: 978-84-9044-468-9 (Edición electrónica)

D.O.I.: http://doi.org/10.18239/atenea_2021.24.00

Composición: Compobell

Hecho en España (U.E.) - Made in Spain (U.E.)

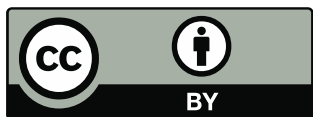

Esta obra se encuentra bajo una licencia internacional Creative Commons CC BY 4.0. Cualquier forma de reproducción, distribución, comunicación pública o transformación de esta obra no incluida en la licencia Creative Commons CC BY 4.0 solo puede ser realizada con la autorización expresa de los titulares, salvo excepción prevista por la ley. Puede Vd. acceder al texto completo de la licencia en este enlace: https://creativecommons.org/licenses/by/4.0/deed.es 


\section{AGRADECIMIENTOS}

A las mujeres participantes en las entrevistas grupales de Yepes, Fuensalida y Toledo. A las enfermeras que participaron en las entrevistas a profesionales. A las personas que apoyaron en la organización de las entrevistas. A María Jesús García, Luis San Antonio y Gema Fuertes, profesionales de enfermería que colaboraron inicialmente en la realización de este estudio. A las personas que colaboraron en la trascripción de las entrevistas. Y finalmente a Idoia Ugarte que revisó el texto final.

\section{ACLARACIONES}

Los nombres que aparecen en los textos se han alterado para conservar el anonimato. 



\section{Índice}

1. INTRODUCCIÓN …...................................................... 13

1.1. Aspectos sociales y culturales de la L.M............................. 14

1.1.1. Lactancia materna y feminismo ................................... 17

1.1.2. Condicionantes de la L.M.......................................... 20

1.1.2.1.. Factores socio-demográficos relacionados con la madre y el hijo o la hija .................................................. 20

1.1.2.2. Información prenatal sobre lactancia materna y su influencia en la decisión de amamantar...................... 21

1.1.2.3. Prácticas hospitalarias perinatales ...................... 22

1.2. Promoción de la L.M....................................................... 22

1.3. Origen y desarrollo de los talleres de apoyo a la L.M.......... 25

1.3.1. Antecedentes de los grupos de apoyo.......................... 25

1.3.2. Historia de los talleres o grupos de apoyo en Toledo... 26

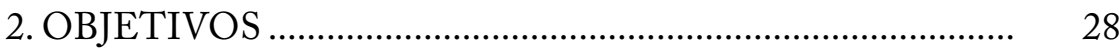

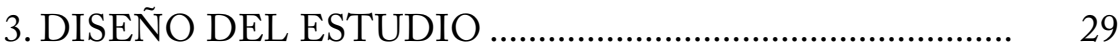

3.1. Enfoque metodológico y método........................................... 29

3.2. Tipo de estudio ................................................................ 30

3.3. Población. Características de las informantes....................... 30

3.3.1. Características poblacionales de la zona básica de Yepes $\quad 30$

3.3.2. Características poblacionales de la zona básica de Santa María de Benquerencia: ................................................ 32

3.3.3. Características poblacionales de la zona básica de Fuensalida 
3.4. Diseño muestral: características del muestreo ...................... 34

3.5. Técnicas de generación de la información ........................... 36

3.5.1. Grupos de discusión. Entrevistas grupales .................. 37

3.5.2. Forma de captación..................................................... 37

3.5.3. Entrevistas en profundidad ....................................... 38

3.6. Análisis .............................................................................. 39

3.7. Plan de ejecución ................................................................ 41

3.7.1. Fases ...................................................................... 41

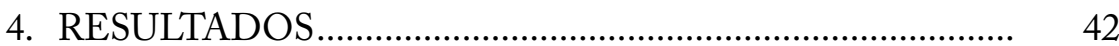

4.1. La experiencia del taller de lactancia materna.................... 42

4.1.1. La utilidad del taller: "no me esperaba... tanto"............. 44

4.1.2. Espacio de relación y autoayuda: "Si la familia no te ayuda, para eso están las reuniones"

4.1.3. Dificultades para acceder: "¿para qué vas a ir a esa tonteria?".

La dificultad del pudor............................................... 52

Las dificultades debidas al entorno social..................... 53

Las dificultades familiares ............................................ 55

4.1.4. Los/las profesionales que lo coordinan: "Mis pañuelos de lágrimas".

2

4

4.1.5. Valoración de recursos, estructura, espacio y propuestas de mejora: "Un poquito antes".

4.1.6. Momento de abandonar el taller: "Que me puse a trabajar"

4.1.7. Expectativas no cumplidas: "y yo esperando a que empezara aquello".

4.2. La lactancia materna

4.2.1. La práctica de la lactancia materna: "El tiempo más feliz" 67

La leche materna: "lo mejor del mundo"

Técnica de lactancia materna y el lactante: "Si no te ayuda nadie, tú no sabes"

Condicionantes para el inicio y el mantenimiento de la lactancia materna: "Mucha paciencia y tenerlo muy claro" Condicionantes para el inicio de la lactancia materna.. Condicionantes para el mantenimiento de la lactancia materna: "yo cuando lo quite mi hija".

Beneficios e inconvenientes de la lactancia materna: "muy enriquecedora para los dos, pero... muy dura"............ Beneficios

Inconvenientes

4.2.2. La esfera privada o psico y relacional .......................... 95

Afectividad: ¿Ternura o Esclavitud? ............................... 96 
Dependencia: el apego.................................................. 103

Familia: Mi madre, mi marido, mi suegra .................... 105

Pareja: "Mi marido" .................................................... 111

4.2.3. Papel de los y las profesionales de la salud. "Pero no se dan cuenta de que tú no sabes".

En el hospital: "No saben guiarte".

En Atención Primaria: "Incluso es que te atienden a otros horarios"

Otros profesionales

124

Contradicciones: "Entre ellos no están coordinados"...... 124

4.2.4. La esfera socio cultural: "no está bien visto"

129

La imagen de la mujer lactante: "Nadie te mira, nadie te ve".

El rechazo social a la lactancia materna: "Todo el mundo en contra de la lactancia".

El rechazo a la participación en los grupos de apoyo a la lactancia

El rechazo a la lactancia materna en sí misma

Reivindicación de la lactancia en el plano social: " $A$ contracorriente de todo el mundo".

$\mathrm{La}$ "estrategia" de los grupos de apoyo

La "estrategia" del apoyo de los y las profesionales de la salud

La "estrategia" de visibilizar la lactancia materna........

7. ANEXOS

7.1. Anexo 1. Perfil tipo de las entrevistas grupales

7.2. Anexo 2. Modelo de "ficha de captador final".....

7.3. Nexo 3. Guía de discusión de las entrevistas grupales..........

7.4. Anexo 4. Guía de entrevista a profesionales

7.4.1. Guía de entrevista a profesional de enfermería en Atención Primaria con experiencia en talleres de L.M. 161

7.4.2. Guía de entrevista a profesional de enfermería en

Atención Hospitalaria. Neonatología

7.5. Anexo 5. Estrategia de análisis de los datos

7.6. Anexo 6. Libro de códigos inductivos (iniciales)................. 165

7.7. Anexo 7. Libro de códigos y matriz de análisis ................... 167

7.8. Anexo 8. Tabla de ilustraciones 



\section{Dar el pecho \\ Estudio cualitativo sobre los grupos de promoción de la lactancia materna en la provincia de Toledo}

\section{INTRODUCCIÓN}

La lactancia materna (L.M.) es la alimentación a través de la leche de la madre, siendo la forma ideal de transmitir los nutrientes necesarios al hijo o a la hija para su crecimiento y desarrollo saludable.

La OMS (Organización Mundial de la Salud) y el UNICEF (Fondo de Naciones Unidas para la Infancia) recomiendan:

- La lactancia materna debe comenzar en la primera hora de vida. El calostro (leche amarilla y espesa que se produce al final del embarazo) es el alimento idóneo para el recién nacido o la recién nacida.

- La lactancia materna exclusiva durante los seis primeros meses del recién nacido o de la recién nacida.

- Seguir amamantando al hijo o a la hija a partir de los seis meses, al mismo tiempo que se le van ofreciendo otros alimentos complementarios, hasta un mínimo de dos años.

Según la OMS y el UNICEF, a partir de los dos primeros años la lactancia materna debería mantenerse hasta que el niño, la niña o la madre decidan, sin que exista ningún límite de tiempo. Se desconoce cuál es la duración "normal" de la lactancia materna en la especie humana.

La Asociación Española de Pediatría (AEPED) apoya sin ambages la lactancia materna porque promueve la salud y previene numerosas enfermedades.

1 http://www.unicef.org.co/Lactancia/historia.htm 
(Pediatria, 2008) Según afirma en sus Recomendaciones: "el vinculo afectivo que se establece entre una madre y su bebé amamantado constituye una experiencia especial, singular e intensa. Existen sólidas bases cientificas que demuestran que la lactancia materna es beneficiosa para el niño, para la madre y para la sociedad, en todos los países del mundo y además favorece el desarrollo intelectual'. Desde el punto de vista sanitario la leche materna protege al lactante de muchas enfermedades tales como catarros, bronquiolitis, neumonía, diarreas, otitis, meningitis, infecciones de orina, enterocolitis necrotizante o síndrome de muerte súbita del lactante, pero también de enfermedades futuras como asma, alergia, obesidad, enfermedades inmunitarias como la diabetes, la enfermedad de Crohn o la colitis ulcerosa y arterioesclerosis o infarto de miocardio en la edad adulta.

La L.M. aporta muchas ventajas saludables para la mujer: favorece la recuperación posparto ayudando a la contracción del útero, disminuyendo los loquios, la anemia y la mortalidad materna. Mejora el vínculo madre-hijo/a, el contacto físico proporciona al bebé abrigo y protección. Amamantar de forma exclusiva retrasa el establecimiento de la ovulación y los periodos menstruales (con una menor pérdida de hierro). Ahorro de tiempo y dinero (no hay que comprar leche ni preparar biberones). Hay estudios de los cuales se deduce que las madres que amamantan tienen menos probabilidad de padecer cáncer de mama, de útero o de ovario. Durante la menopausia el riesgo de sufrir osteoporosis es más reducido. Al tener mayor gasto calórico la recuperación del peso es mucho más rápida. Aumenta la autoestima como mujer y como madre. (Macadam \& Dettwyler, 1995; Zamora Pasadas \& Cañamero Pascual, 2008)

Las ventajas de la lactancia materna se extienden a toda la sociedad y al planeta en general, supone un ahorro ya que no consume energía ni en su elaboración, ni en su preparación (salvo la alimentación de la madre), ni después lavando o esterilizando utensilios, tampoco contamina ni deja residuos. (Dettwyler, 1987)

Además de todo lo ya expuesto, en palabras de Carlos González: “...la lactancia no es una herramienta para conseguir la salud, sino una parte de la salud misma. No es un medio sino un fin [...]. Ahora sé que la lactancia no es un esfuerzo, y mucho menos un sacrificio, que la mujer hace por el bien de su hijo, sino una parte de su propia vida, de su ciclo sexual y reproductivo. Un derecho que nadie le puede arrebatar". (González, 2006)

\subsection{ASPECTOS SOCLALES Y CULTURALES DE LA L.M.}

La leche materna, durante la existencia del ser humano, ha sido el único alimento que el recién nacido o la recién nacida podía recibir para sobrevivir. 
Así pues, desde la aparición del ser humano en la tierra no se ha concebido otro tipo de alimento para la primera etapa de la vida humana (Macadam \& Dettwyler, 1995); por lo tanto, la lactancia materna como proceso biológico es una actividad cultural que afectará a las mujeres dependiendo, entre otros factores, de sus creencias, clase social, etnia, lugar de procedencia, acceso a la educación y trabajo fuera de casa. (Wilhelm, Flanders Stepans, Hertzog, Callahan Rodehorst, \& Gardner, 2006) Todo ello evidentemente tiene relación con los procesos de socialización y condiciones sociales que hacen que se asuman determinados conceptos sobre el hecho de amamantar.

La historia de la L.M. es tan antigua como la historia de la humanidad siendo los beneficios documentados durante siglos; descubrimientos recientes en este tema, combinados con las tendencias mundiales actuales en relación con la lactancia han provocado un renovado interés en esta práctica antigua. (Macadam \& Dettwyler, 1995)

En España, como en otros países de nuestro entorno, la estructura de la familia ha cambiado hacia unidades más pequeñas, desplazadas de su zona de origen por motivos laborales, en ocasiones desarraigadas y por tanto ante la llegada de un nuevo ser se encuentran sin apoyo familiar ni red social a quien recurrir. El nacimiento de un hijo o una hija es un acontecimiento crucial en la vida de cualquier mujer; tradicionalmente durante el puerperio los familiares apoyaban y cuidaban a la madre, y ella solo se ocupaba del cuidado del recién nacido o de la recién nacida. Sin embargo, hoy en día una mujer tras el parto sigue asumiendo todas sus responsabilidades junto con los cuidados de su hijo o hija y en muchos casos sin ayuda adicional, lo que puede repercutir negativamente en la salud de la madre y/o del/la lactante.

En los últimos años se percibe un cambio en el protagonismo en la maternidad: antes se decía que una mujer había "dado a luz" mientras que ahora se dice que "ha nacido un niño o una niña", con lo que la mujer ha pasado a un segundo plano, centrándose todas las atenciones en el niño o en la niña. Todas estas circunstancias contribuyen a dificultar la lactancia materna.

En la actualidad, la mujer ha añadido al papel de madre y esposa, el de trabajadora y se ha introducido en el mercado laboral con pocas políticas de protección a la conciliación familiar y escasísimas para la lactancia: permisos maternales de 16 semanas, jornadas partidas, situaciones de inestabilidad laboral. Aparte de su jornada laboral, dentro de casa, por regla general, debe añadir horas "extras" para la realización de las labores domésticas y cuidado del resto de los hijos y de las hijas, con casi nula colaboración de la pareja. 
No existe conciencia de compartir tareas. (Alba Romero, Aler Gay, \& Olza Fernández, 20II)

Más de una generación de mujeres no han amamantado a sus hijos/as, interrumpiéndose la transmisión de conocimientos intergeneracional y perdiéndose una cultura, la cultura del amamantamiento, de la crianza natural y posiblemente el vínculo natural entre madres e hijos/as. Varios factores han influido en esta pérdida:

- Cambios sociológicos ocurridos en la era moderna de la sociedad industrial a lo largo de los siglos XIX y XX: la incorporación de la mujer al trabajo asalariado que hace ver el amamantamiento como un problema. Un espíritu de modernidad con creencia ciega en avances científicos hace que el pensamiento dominante acepte que todo lo artificial es mejor que lo natural: "maternidad científica".

- Los intereses económicos industriales. (Barriuso, De Miguel, \& Sánchez, 2007)

- El pensamiento feminista: "la lactancia artificial es considerada como una liberación”. (Didierjean-Jouveau, 2003)

- Una participación activa de la clase sanitaria, fundamentalmente médica, convencida inicialmente de la maternidad científica, unida a una cierta prepotencia que negaba cualquier posibilidad de intervención de las propias mujeres en su parto y en la crianza de sus hijos e hijas.

Además, nos encontramos en una sociedad de bienestar donde se puede acceder a una gran cantidad de preparados lácteos, que, introducidos en el mercado con agresivas campañas publicitarias, restan importancia a la crianza natural.

Según el Instituto Nacional de Estadística (INE) en el año 2012 en España el porcentaje de niños/as de mes y medio con L.M. era de $72.4 \%$, a los tres meses era de $66.6 \%$ y a los 6 meses $46.9 \%$.

Por tanto, a pesar del apoyo que los y las profesionales de la salud daban a las madres, abogando por los beneficios de la lactancia materna, se objetivaban resultados bajos de prevalencia de L.M. Este escenario provocó un cambio sustancial en la manera de enfocar el apoyo necesario para promover el amamantamiento. De ahí, surgió la necesidad de crear grupos de apoyo a la lactancia materna liderados por profesionales de la salud (matrón, matrona, enfermera/o) y con apoyo de otros/as profesionales comprometidos/as con la lactancia materna (pediatras, médicos/as de familia,...), que dieran un apoyo 
formal a las mujeres con deseos de amamantar, que a su vez reunidas con sus respectivos pares pudieran verbalizar sus dudas, temores, experiencias, se enriquecieran con la vivencia de la crianza de las otras mujeres, y sintieran la vivencia de dar de mamar a sus hijos/as entre iguales.

\subsubsection{LACTANCIA MATERNA Y FEMINISMO}

La relación maternidad, lactancia y feminismo no ha sido nunca sencilla, ha variado mucho a lo largo de la historia. En Francia entre 1960 y 1970 predominaba una corriente de pensamiento que rechazaba la maternidad. Un artículo de la época comparaba el hecho de ocuparse durante una jornada completa del cuidado de un bebé, como pasarse todo el día con la única compañía de un enfermo mental incontinente (Didierjean-Jouveau, 2003) En los países escandinavos, el movimiento feminista luchó para que se reconociera la función social de la maternidad (permisos de maternidad, ayudas, etc.). Sin embargo, en Estados Unidos surgieron los grupos self-help ("grupos de apoyo") precursores del movimiento de "liberación de la mujer".

Siguiendo a Didierjean-Jouveau, el feminismo se divide en dos corrientes:

a) El Feminismo de la Igualdad, ve el origen de la opresión de la mujer en su cuerpo y sus capacidades reproductivas; acepta que la tecnología (como el biberón) es liberadora, toda información sobre la lactancia es vista como un riesgo de "culpabilización" de las mujeres e insiste en la libertad de elegir la maternidad y la lactancia. Esta corriente feminista busca la igualdad estricta entre hombres y mujeres, compartir las tareas domésticas; incluido el cuidado de la descendencia y considera la maternidad, así como la lactancia una servidumbre, una esclavitud "lugar de la dominación masculina”. En Francia Simone de Beauvoir y en nuestro país Lidia Falcón consideran que hay que prescindir de la maternidad para lograr la verdadera emancipación de la mujer.

b) E1 Feminismo Existencial defiende que la maternidad y la lactancia se viven con ternura por tanto, ser mujer es motivo de alegría y de orgullo. Critica la visión tecnológica y capitalista de la gestación; denuncia la dicotomía pecho lactante/pecho erótico, así como la reducción de los pechos a meros objetos sexuales; percibe el cuerpo de la mujer como fuente de espiritualidad y de poder y no de opresión. En 1970 grupos de mujeres se movilizan contra la destrucción de la naturaleza y los desastres ecológicos, (d'Eaubonne, Merchant, \& Hottell, 1974; García, Lainez, \& Coarasa, 2006; Vilalonga, 2010) se comienza hablar de ecofeminismo cuyo exponente máximo es Vandana Shiva; este concepto supera la descalificación de la 
maternidad como servidumbre y encuentra en la maternidad un signo de empoderamiento y autodeterminación de la mujer. La maternidad implica un retorno a nuestra condición de mamíferos y considera la lactancia natural como un reencuentro con el propio cuerpo. En relación con esta última tendencia, la incorporación de la mujer a la universidad, facilitó y potenció el acceso al mundo laboral. Estos hechos supusieron un cambio en el concepto de familia y paternidad. Actualmente, se puede elegir el número de descendientes y el momento de tener un hijo o una hija, la maternidad puede ser una elección. Todos estos cambios han propiciado nuevos conceptos en relación con el modo de sentir y vivir la maternidad y por ende la lactancia. A finales del siglo XX surgió el término "Madres insumisas",(Alba Romero et al., 20II) estas mujeres proclaman y viven la maternidad alejadas de vinculaciones institucionales (matrimonio, familia). Cada vez es más frecuente un tipo de madre, soltera, cercana a los cuarenta años donde el varón ha tenido un papel accidental. En palabras de Isabel $\mathrm{Aler}^{2}$ reivindicar "la lactancia materna es un acto político de insumisión". "La recuperación del poder creador de las mujeres, de sus obras y de sus criaturas, es la llave para iniciarnos de raíz, que no de golpe, en la sanación del conjunto de sintomas y procesos morbosos que padece nuestra civilización. Es el antídoto para la misoginia que con distintas consecuencias o intensidades nos afecta a mujeres $y$ hombres. La misoginia entendida como el miedo que en forma de odio, desprecio, infravaloración, marginación o negación de forma contenida o expresa se siente hacia el poder creador de las mujeres y hacia sus obras y sus criaturas, es decir, hacia el poder de dar la vida en toda su integridad y potencialidad, que no es otro que el poder de concebir, gestar y alumbrar biológica, social y culturalmente".

Elisabeth Badinter sostiene que las dos corrientes feministas mantienen un discurso tan opuesto que se anulan mutuamente, el único tema sobre el que se han puesto de acuerdo es sobre la idea de "la mujer como víctima". Piensa que las mujeres en los años 6o, peleaban con afán por liberarse del determinismo natural y en cambio, a partir de los años 8o, las hijas de aquellas mujeres se rebelan y reivindican un retorno al origen; al cuerpo femenino donde reposaría el arquetipo de lo sagrado. Promueven un estilo de crianza simbiótica, practican la lactancia a demanda, abandonan el trabajo, algunas se hacen adeptas al colecho e incluso para proteger el planeta, vuelven a utilizar pañales lavables. El "lo quiero todo" es reemplazado por "le debo todo a mi hijo: mi leche, mi tiempo, mi energía”. Además, Badinter, sostiene que el dis-

2 http://www.holistika.net/parto_natural/lactancia_materna/ecofeminismo_y_lactancia.asp 
curso que existía en los años 70 y 80 frente a los hombres, había engendrado un fenómeno que fue el llamado padre gallina, con frases como "no es justo", "ustedes deben compartir las tareas cotidianas con nosotras". Esas pequeñas frases representaban la culpa moral, factor de cambio en la mentalidad de la sociedad. Sin embargo, el nuevo modelo naturalista, de simbiosis maternofilial, deja necesariamente al padre afuera, en el exterior de la relación. Y, sin que haya hecho nada para lograrlo, el hombre se encuentra así liberado de toda coacción para hacerse cargo, de manera igualitaria, de los hijos e hijas y de las tareas domésticas. (Badinter, 2003, 2010)

Edurne Uriarte defiende en España, la opinión de la filósofa Badinter, ésta denuncia precisamente, "el retorno del naturalismo y la tremenda presión que se ejerce sobre las mujeres para que sean madres perfectas, para que sacrifiquen sus deseos de libertad, sus impulsos individualistas, sus metas profesionales, para que sean madres antes que mujeres. Además, los naturalistas cuentan con un arma incomparable: los sentimientos de culpabilidad que sufren las madres, ironías de la historia, escribe Badinter, en el momento en que las mujeres occidentales han conseguido librarse del patriarcado se encuentran con un nuevo dueño en el hogar al que deben sacrificarlo todo: el niño. La maternidad se vuelve más exigente que nunca, la buena madre es la que condiciona su vida y sus objetivos a los niños. Lo que desmonta, a su vez, décadas de trabajo para desarrollar un cuidado de los niños compartido con las parejas"3.

La periodista Carmen Machado con su artículo "Madre o vaca"4 sin sospecharlo consiguió destapar y hacer aflorar el interés del público por un asunto considerado hasta entonces de interés "menor", la lactancia materna, además resultó ser muy relevante, sensible e importante, para la opinión pública. Colaboró en la organización del activismo prolactancia español, a través de los diferentes movimientos de apoyo a la lactancia materna. (Nieto del Mármol, 20I2) Los nombres de estos grupos oscilan a menudo entre la abierta confrontación y reivindicación política ("La liga de la leche", "El parto es nuestro", "Que no os separen"), el desafío provocativo en nombres de blogs ("Tenemos tetas. Maternidad impúdica", "Úteros de guerrilla", "Madres insumisas") o las imágenes metafóricas o cuasipoéticas relacionadas con la leche en sí ("Vía láctea", "Génesis", "Ocean", "Mamantial”) y de ternura maternofilial ("Mamilactancia”, "Entremamás”). Además, gracias a este artículo se conocen las

3 Artículo "Las mamíferas" de Edurne Uriarte, en: http://www.mujerhoy.com/comuni$\mathrm{dad} /$ opinion/mamiferas,124574,09,2010.html

4 MAGAZINE EL MUNDO de 17 de octubre 2010 en www.elmundo.es/ papel/2010/10/17/magazine/ 
opiniones y actitudes de quienes practican el "lactivismo"s. (Massó Guijarro, 20I3) Las lactivistas generan redes de cooperación, altruismo y solidaridad recíproca, ponen de manifiesto que la casa y la calle pueden conjugarse; que su distinción no es substancial sino coyuntural en el marco del sistema capitalista que necesitó de tal dicotomía para materializarse, estas madres comparten sus creencias a través de las redes sociales. Sin embargo, las mujeres que defienden el lactivismo se sienten perseguidas por la industria alimenticia, por la sociedad y por los medios de comunicación.

Esta corriente también se relaciona con el ecofeminismo en su visión esencialista, sin embargo, este enfoque ha sido muy criticado por atribuir opiniones, ideas, sentimientos y papeles sociales al hecho en sí mismo de ser mujer, sin tomar en consideración los procesos históricos y sociales acontecidos en relación al hecho de lactar. (Jackson \& Pearson, 1998)

\subsubsection{CONDICIONANTES DE LA L.M.}

El inicio de la lactancia materna, así como su mantenimiento en el tiempo no depende solamente de la decisión de la madre, muchos son los factores que condicionan tanto el inicio como la duración.

A lo largo del tiempo se pensó que con la educación perinatal sobre las ventajas de la lactancia materna se conseguirían altas tasas de inicio y duración prolongada de la misma. Sin embargo, muchas han sido las mujeres que aun queriendo amamantar a sus hijos e hijas no lo han logrado.

Los factores condicionantes de la lactancia materna se pueden clasificar en tres tipos:

\subsubsection{Factores socio-demográficos relacionados con la madre y el hijo o la hija}

- El peso del neonato/a: Aquellos/as que pesan más de 3000 tienen mayor probabilidad de ser amamantados/as que quienes pesan menos de 3000 g. También hay que tener en cuenta que la prematuridad es un factor que dificulta a veces el desarrollo de la lactancia.

- El tabaquismo materno: las madres fumadoras tienen menor probabilidad de amamantar a sus hijos/as, así como un mayor riesgo de mastitis.

5 El "Lactivismo" se define como la defensa del derecho del bebé/niño a ser amamantado y de la madre a amamantar, a demanda, en cualquier lugar, sin miradas ni comentarios de desaprobación y hasta que el niño lo desee" véase: (Massó Guijarro, 2013; Nieto del Mármol, 2012). 
- La edad de la madre: las madres menores de 20-25 años y mayores de 37 años registran menor adherencia al amamantamiento.

- El nivel de estudios de la madre es un factor no significativo, aunque se observa que un mayor nivel cultural favorece la decisión amamantar.

- Experiencia previa de lactancia materna exclusiva es un factor favorecedor.

- El trabajo fuera del hogar, podría considerarse como un factor limitador por tener que incorporarse la madre al trabajo antes de los 6 meses. Por lo tanto, el tipo de contrato, el sector donde trabaje púbico o privado, ser asalariada o autónoma, puede influir en el mantenimiento o instauración de la lactancia. Las madres autónomas o asalariadas con contratos precarios e inestables abandonan de forma muy temprana el amamantamiento.

- Presiones familiares: madres, suegras, otras madres que realizan lactancia artificial, etc, pueden repercutir en un abandono del amamantamiento, ya que la madre se encuentra sometida a dichas presiones, y si en el entorno no está establecida la "cultura de la lactancia materna" ${ }^{6}$, esta mujer corre el riesgo de abandonar el amamantamiento.

- Las madres de origen magrebí, así como las de origen sudamericano tienden a una lactancia materna prolongada en el tiempo, sin embargo, la madre de etnia gitana tiende a una menor durabilidad.

- La falta de espacio público para poder dar el pecho (en algunos centros comerciales ya hay salas de lactancia, aunque estas se encuentran normalmente señalizadas con un biberón o un chupete), o el rechazo que produce en algunas personas el hecho de ver a una madre amamantar a su hijo/a.

\subsubsection{Información prenatal sobre lactancia materna y su influencia en la decisión de amamantar}

- La educación prenatal influye en el inicio de la lactancia materna, pero no en su mantenimiento. Luego es imprescindible tomar el relevo del hospital citando en atención primaria al neonato/a al alta hospitalaria. Por tanto, la primera visita en su centro de salud será una consulta de lactancia, y no solo de realización de pruebas metabólicas.

6 Entendemos por cultura de la lactancia materna todo un conjunto de experiencias vividas por la madre tanto en su infancia, adolescencia o juventud con mujeres y niños que hayan practicado dicha lactancia (Macadam \& Dettwyler, 1995). 
- Los grupos de apoyo a la lactancia materna, tanto los coordinados por profesionales sanitarios/as como los "grupos de madre a madre" son un factor favorecedor.

\subsubsection{Prácticas hospitalarias perinatales}

- El tipo de parto: los/as neonatos/as procedentes de un parto eutócico recibieron lactancia materna exclusiva con mayor frecuencia que los y las procedentes de parto distócico o cesárea. Este hecho se explica no por razones biológicas sino por prácticas hospitalarias inadecuadas que impiden y condicionan el contacto piel con piel tanto en el paritorio como en las unidades de reanimación post-anestésica.

- El uso de determinados analgésicos durante el parto dificulta el inicio de la lactancia así como la posición que debe mantener el/la neonato/a en el pecho.

- El separar al niño o a la niña de la madre, aunque sólo sea por la noche, para que la mujer descanse, así como el ofrecimiento precoz de biberones y chupetes dificulta la instauración de la lactancia materna.

- Por otro lado, algunas patologías maternas o enfermedades neonatales pueden retrasar la instauración de la lactancia.

\subsection{PROMOCIÓN DE LA L.M.}

En la segunda mitad del siglo XX existe un renovado movimiento por la lactancia materna, motivado por las altas tasas de morbilidad y mortalidad. La visión a nivel de Salud Pública era la de informar a las madres sobre los beneficios nutricionales e inmunológicos de la leche materna, pero sin realizar una valoración integral del significado de la lactancia materna como práctica de crianza; se seguía promocionando este método de crianza de forma individual con el pensamiento de que la madre es el único interviniente en la decisión del amamantamiento, sin tener en cuenta al cónyuge o pareja, abuelas, grupo de pares, el/la pediatra, medios de comunicación, así como las propias creencias de la madre y su experiencia de vida. Se puede decir que, aunque sí consta un discurso de promoción y apoyo social a la lactancia materna, no existe un escenario social que apoye a la mujer que decide amamantar.

En los países empobrecidos la morbilidad y mortalidad infantil relacionadas con la lactancia artificial son aún mayores. Ante las dificultades económicas para la adquisición de la leche de fórmula los padres y las 
madres suelen prepararla más diluida, contribuyendo a crear problemas de desnutrición. Además, la falta de agua potable, sobre todo en las zonas rurales, impide que se puedan preparar los biberones en las condiciones higiénicas adecuadas.

Los esfuerzos para promover la lactancia materna constituyen para la OMS un elemento clave de los sistemas sanitarios dentro de su plan de salud para todos en el año 2000. En 1979 se celebra la reunión OMS/UNICEF sobre alimentación del y la lactante y del niño/a pequeño/a. Siendo finalmente, en I98I cuando se aprueba el Código Internacional de Comercialización de sucedáneos de la leche materna, éste regula la publicidad de dichos productos en los medios de comunicación, en los obsequios facilitados a las mujeres embarazadas o las puérperas, así como la publicidad en los centros sanitarios. El Gobierno Español I2 años más tarde, se adhirió a dicho Código por medio de Real Decreto (RD r408/92 en BOE 13.0r.93). En 1989 OMS/UNICEF realiza una declaración conjunta sobre Protección, Promoción y Apoyo de la Lactancia Materna:" Diez pasos hacia una feliz lactancia exitosa" que se recomienda cumplir a los hospitales y maternidades:

I. Disponer de una política sobre lactancia materna.

2. Capacitar a todo el personal.

3. Capacitar a las gestantes sobre la lactancia materna.

4. Iniciar la lactancia durante la media hora siguiente al parto.

5. Enseñar a las madres técnicas y cómo mantener la lactancia.

6. Dar a las criaturas recién nacidas leche materna en forma exclusiva.

7. Facilitar el alojamiento conjunto.

8. Fomentar la lactancia materna a libre demanda.

9. No dar a los niños/as biberones y chupos.

Io. Fomentar el establecimiento de grupos de apoyo.

Sobre el último punto OMS-UNICEF dice:

"En muchos países las mujeres han constituido grupos sociales de apoyo que ayudan a las madres que desean amamantar a sus hijos. Los agentes de salud apoyarán la creación y funcionamiento de estos grupos y remitirán a ellos a las madres, sobre todo a las jóvenes inexpertas, al ser dadas de alta del hospital o clínica. Los consejos individuales, la educación sanitaria y los materiales informativos que facilitan estos grupos pueden servir de complemento importante a los esfuerzos de los agentes de la salud. Se fomentará la distribución de este material mediante el sistema sanitario.” 
En 1990 de la reunión OMS-UNICEF llevada a cabo en Florencia (Italia) nace la Declaración de Innocenti, aquí se establece que cada instalación que otorgue servicios de maternidad practique completamente "los diez pasos para una feliz lactancia exitosa".(García, 2006).

La Iniciativa para la Humanización de la Asistencia al Nacimiento y la lactancia (IHAN) fue lanzada por la OMS-UNICEF en I99I-I992, para animar a los hospitales y en particular a las salas de maternidad a adoptar las prácticas que protejan, promuevan y apoyen la lactancia materna exclusiva desde el nacimiento. Todos los hospitales que acrediten cumplir" los diez pasos hacia una feliz lactancia exitosa" y los principios del Código Internacional de Comercialización de Sucedáneos, así como las resoluciones de la Asamblea Mundial de la Salud (AMS) relacionadas con el mismo, recibirán el galardón: hospital IHAN.

Instaurada por OMS-UNICEF, desde 1992 se viene celebrando la semana mundial de la lactancia materna del i al 7 de agosto, aniversario de la Declaración de Innocenti. Siendo en la actualidad el movimiento social más extendido en defensa de la lactancia materna y en él participan más de I7o países.

Desde 2005 durante el mes de octubre en Toledo se celebra la semana de la lactancia materna. Organizada por la Gerencia de Atención Primaria de Toledo participan las mujeres y profesionales de la salud responsables de los talleres de apoyo a la lactancia del área sanitaria de Toledo.

A pesar de estas iniciativas los datos sobre la prevalencia de lactancia materna a los 6 meses siguen siendo bajos, por lo que ya en el siglo XXI, la iniciativa IHAN, consciente de la importancia que tiene la Atención Primaria en el mantenimiento de la lactancia materna, lanza el proyecto de Centro de Salud IHAN. Para recibir el galardón como CS-IHAN se han de cumplir siete pasos: Los siete pasos para una feliz lactancia natural en la Comunidad:

I. Disponer de una Normativa de lactancia materna, escrita, adaptada a su realidad laboral y social y consensuada entre profesionales, autoridades y usuarios y usuarias. La Normativa debe ser conocida por todo el personal del Centro de Salud y deben habilitarse las medidas para ello.

2. Tener un Plan de Formación para el personal con el que se les capacita para poner en práctica la Normativa de lactancia.

3. Ofrecer información a todas las mujeres embarazadas y sus familias sobre el amamantamiento y la mejor manera de ponerlo en práctica tras el parto.

4. Apoyar a la madre que amamanta en el inicio de la lactancia y asegurarse de que es atendida en las primeras $48 \mathrm{~h}-72 \mathrm{~h}$ tras el alta de la Maternidad, con especial atención a las madres de riesgo. 
5. Apoyar a las madres para mantener la lactancia materna exclusiva durante los seis primeros meses (o 26 semanas) y continuar amamantando, tras introducir la alimentación complementaria adecuada, a partir de entonces hasta los dos años o más.

6. Favorecer y apoyar las mejores prácticas de alimentación. Proporcionar una atmósfera receptiva y de acogida a las madres y familias de los y las lactantes amamantados.

7. Fomentar la colaboración entre los y las profesionales de la salud y la Comunidad a través de los Talleres de Lactancia y el contacto con los grupos de apoyo locales.

Además, y como requisito de obligado cumplimiento el Centro de Salud deberá cumplir los principios del Código Internacional de Comercialización de Sucedáneos y las resoluciones de la Asamblea Mundial de la Salud (AMS) relacionadas con el mismo.

\subsection{ORIGENY DESARROLLO DE LOS TALLERES DE APOYO A LA L.M.}

\subsubsection{ANTECEDENTES DE LOS GRUPOS DE APOYO}

Se denomina Grupos de apoyo a la lactancia materna (GALM) a un movimiento social, surgido a mediados del siglo XX, formado por asociaciones que brindan apoyo a mujeres que desean amamantar. (Materna, 2005) Los grupos se formaron a iniciativa de madres que consideran que si bien amamantar, posee un componente fisiológico e instintivo, también requiere aprendizaje y que, en ocasiones, las mujeres necesitan el apoyo de otras mujeres con experiencia para poder amamantar con éxito a sus hijos e hijas (de la Salud, 2003).

Los grupos de apoyo vienen a sustituir a la red de mujeres con que contaban las madres en el pasado. La idea era que las madres necesitaban, además de información, compartir la crianza con otras madres para tener un sentimiento de normalidad. La liga de la leche fundada en Chicago en 1956 y los grupos de madres de los países nórdicos fueron los primeros en iniciar esta labor.

En España la historia de los grupos de madres comienza a mediados de los años 80, con la asociación "Vía Láctea” en Aragón, "La Liga de la Leche” en Euskadi y el grupo "Gala” en Barcelona.

Los grupos de apoyo a la L.M., se reúnen periódicamente para compartir experiencias, apoyo e información adecuada sobre la L.M. Son grupos abier- 
tos a nuevas participantes y están dirigidos por una o más consejeras con más antigüedad y experiencia.

Los grupos de apoyo a la lactancia materna, como servicio, básicamente funcionan de dos formas:

- Grupos de apoyo para madres

- Grupos de apoyo de "madre a madre"

En muchos casos los "grupos de apoyo para madres" son coordinados por profesionales de la salud, generalmente mujeres, aunque no tengan experiencia propia de lactancia materna. Esta persona puede que no sea madre ni que tampoco pertenezca culturalmente al grupo, y aparece frente al resto de los integrantes en la figura de experta. Aunque pueden ser grupos de voluntariado por parte de profesionales de la salud motivadas por el tema, es más frecuente que se trate de un proyecto o servicio que desarrolla un centro de salud u hospital. Este tipo de grupo no se considera parte de este movimiento social, sino un servicio profesional.

Los "grupos de apoyo de madre a madre" se pueden considerar en general como formados por personas que se encuentran en una misma situación "conflictiva" (iniciar y mantener la lactancia materna) y que se juntan libremente para ayudarse y satisfacer unas necesidades comunes, para superar dudas o dificultades, compartir experiencias o bien conseguir cambios sociales o personales. En ocasiones están coordinados por madres y son ellas quienes dirigen las reuniones. En algunos movimientos (como la Liga de la Leche) es indispensable que haya amamantado personalmente con éxito. En nuestro ámbito existen grupos de "madre a madre" en algunas localidades que funcionan como asociaciones independientes formadas por madres sin vinculación formal con profesionales sanitarios/as.

En general el motivo que lleva a cada madre a incorporarse a un grupo de ayuda puede ser muy diferente de una a otra. Las participantes de un grupo tienen oportunidad, no solo de hablar de los motivos, los deseos y las expectativas que las han llevado a reunirse, sino también de sus preocupaciones, angustias, dudas y dificultades.

\subsubsection{HISTORIA DE LOS TALLERES O GRUPOS DE APOYO EN TOLEDO}

El primer taller de apoyo a la L.M. del Área Sanitaria de Toledo se creó en 1999 gracias a una enfermera del centro de salud de Fuensalida, muy 
implicada en la promoción de la L.M. En el año 2000 y también a cargo de una enfermera se organiza un nuevo taller en el centro de salud de Illescas. Entre 2005 y 2008 se crean seis grupos de apoyo en distintas zonas básicas de salud tanto urbanas, como rurales.

Pero es a raíz de un curso multidisciplinar organizado en diciembre de 2008, por la Gerencia de Atención Primaria de Toledo (GAPTO), cuando se forman la mayoría de los talleres existentes. Muchos profesionales sanitarios: enfermeros/as, médicos/as, pediatras... se formaron para asesorar y apoyar a las mujeres que quieren dar de mamar a sus hijos o hijas. A lo largo de 2009 se crearon doce talleres en diferentes zonas básicas de salud, entre ellos los de Yepes y Santa M.a de Benquerencia.

En los años sucesivos se siguen impartiendo cursos sobre L.M. por parte de la GAPTO, y en el periodo comprendido entre 20IO - 20II, se forman otros doce grupos de apoyo a la lactancia natural en distintos centros de salud del Área Sanitaria.

En la actualidad existen un total de treinta y un talleres, repartidos por los centros de salud tanto urbanos como rurales, de la provincia de Toledo llegando incluso a estar presentes en algunos consultorios locales.

El objetivo general de esta actividad es ofrecer asesoramiento profesional a las mujeres que quieran dar de mamar a sus hijos o hijas, así como formar a las madres en L.M., prevenir y detectar precozmente problemas en las mamas y facilitar un lugar de reunión para compartir sus experiencias. En todos los talleres se dispone de un peso para vigilar la ganancia ponderal de los y las recién nacidos/as, que también está a disposición de todas las madres que quieran usarlo para pesar a sus bebés. Se suele hacer un registro de las asistentes y de los pesos de los niños y las niñas para su seguimiento en las sucesivas sesiones.

Los/las profesionales que coordinan estos grupos son principalmente enfermeras/os, aunque también colaboran matrones/as y pediatras, por tanto, son "grupos de apoyo para madres". En muchos de estos talleres los/las responsables, tratan temas relacionados con la L.M. en sesiones formativas con exposiciones en PowerPoint, charlas, debates, etc. Otra actividad que se realiza periódicamente en alguno de los grupos de apoyo en colaboración con la fisioterapeuta, es un taller de masaje al bebé.

Normalmente tienen lugar una vez a la semana con una duración de hora y media o dos horas. Los lugares de reunión suelen ser salas del propio centro de salud o locales de uso comunitario pertenecientes a los ayuntamientos de las distintas localidades. 
Cualquier mujer puede acudir al grupo de apoyo sin previa cita ni inscripción. Generalmente acuden por recomendación de algún/a profesional del centro de salud, del hospital o de otras mujeres que conocen el taller. Pueden acudir acompañadas de otras personas: pareja, madre, hijos, hijas, amigas, amigos. También pueden acudir durante el embarazo.

Además, algunas mujeres, antiguas participantes en estos talleres han constituido asociaciones en defensa de la lactancia materna, por ejemplo: "Mamá teta” en Polán, "Son-Risa Maternal" en Sonseca.

\section{OBJETIVOS}

El estudio pretende valorar de forma cualitativa los talleres de apoyo a la lactancia en las ZBS de Fuensalida, Santa María de Benquerencia (Toledo) y Yepes, lo que proporcionará una aproximación a la visión diferencial que sobre este tema se pudiera tener desde un entorno rural o urbano. La intención del estudio no es tanto comparar los resultados entre sí sino descubrir los mitos, las creencias y las experiencias de las madres que pertenecen a poblaciones con diferentes características socioculturales y realidad social. Por otro lado, al afrontar aspectos fenomenológicos se plantea realizar una aproximación a la representación social actual de la L.M. para las participantes en este tipo de talleres.

Por tanto, los objetivos son:

\section{I.-CONOCER LA VALORACIÓN QUE HACEN LAS MUJERES QUE ASISTEN A LOS TALLERES DE APOYO A LA LACTANCIA MATERNA.}

I.I.-La utilidad del taller.

I.2.- Espacio de relación y autoayuda.

I.3.- Dificultades para acceder al taller.

I.4.- Los y las profesionales que los coordinan.

I.5.-Valoración de recursos, estructura, espacio y propuestas de mejora.

r.6.-El momento de abandonar el taller.

I.7.-Expectativas no cumplidas.

2.-CONOCER LA REPRESENTACIÓN SOBRE LA L.M. QUE TIENEN LAS MUJERES QUE ACUDEN A LOS TALLERES DE APOYO A LA LACTANCIA MATERNA

2.I.-La práctica de la lactancia materna. 
2.I.I.-La leche materna.

2.I.2. -La técnica de la lactancia y el/la lactante.

2.I.3.-Condicionantes para el inicio y mantenimiento de la lactancia materna.

2.I.4.-Beneficios e inconvenientes de la lactancia materna.

2.2.-La esfera privada, psicológica y relacional.

2.2.I.-Afectividad.

2.2.2.-Dependencia.

2.2.3.-La familia.

2.3.-El papel de los y las profesionales de la salud.

2.3.I.-En el hospital.

2.3.2.-En atención primaria.

2.3.3.-Otros y otras profesionales.

2.3.4.-Contradicciones.

2.4.- La esfera sociocultural.

2.4.I.-La imagen de la mujer que amamanta.

2.4.2.-El rechazo social a la lactancia materna

2.4.3.-Reivindicación de la lactancia materna en el plano social.

\section{DISEÑO DEL ESTUDIO}

En la investigación cualitativa el diseño se entiende como flexible para permitir la necesaria circularidad en la investigación, por lo que la realización y el resultado de cada fase han modificado en ocasiones el diseño inicial de las fases posteriores.

\subsection{ENFOQUE METODOLÓGICO Y MÉTODO}

$\mathrm{El}$ interés del estudio se centra en conocer los discursos de las madres que amamantan, por tanto, el estudio se plantea con una metodología cualitativa dados los objetivos a alcanzar, la investigación permitirá describir representaciones, vivencias y expectativas desde la perspectiva de la población y a partir de sus propias categorías.

En concreto pretende conocer qué cosas dicen las participantes en los talleres acerca de su experiencia en ellos y respecto a su concepción de la L.M. Estos intereses de investigación ponen un cierto veto a las técnicas 
cuantitativas que, por su naturaleza, permiten sobre todo constatar lo que previamente ha sido supuesto por el/la investigador/a. (Fernández de Sanmamed Santos, 2000)

\subsection{TIPO DE ESTUDIO}

Se trata de un estudio principalmente de carácter explicativo respecto al primero de los objetivos y fenomenológico de carácter exploratorio respecto al segundo, que se orienta hacia las representaciones colectivas sobre la L.M. de las mujeres participantes en los talleres. Sobre todo, en este último objetivo pretende acceder tanto a la "significación" (el plano semántico de los discursos), como al "sentido" (el plano pragmático de esa enunciación).

\subsection{POBLACIÓN. CARACTERÍSTICAS DE LAS INFORMANTES}

- Mujeres participantes en los talleres de Yepes, Sta.M. a de Benquerencia y Fuensalida, todos ellos en la provincia de Toledo.

- Rural/urbana

Por lo tanto, el universo de la población de estudio (mujeres participantes en los talleres de promoción de L.M.) se divide en tres poblaciones. Se trata de una experiencia similar, pero para poblaciones con características demográficas y sociales diferenciadas.

\subsubsection{CARACTERÍSTICAS POBLACIONALES DE LA ZONA BÁSICA DE YEPES}

La zona básica de Yepes comprende los municipios de Yepes, Ciruelos, Huerta de Valdecarábanos, Villasequilla y Villamuelas. En total con datos del padrón de fecha oI-OI-20Io se trataría de una población de II.238 habitantes empadronados.

Con datos del INE de una revisión de la población del año 2000, nos encontraríamos la siguiente pirámide poblacional conjunta de todos los municipios: 


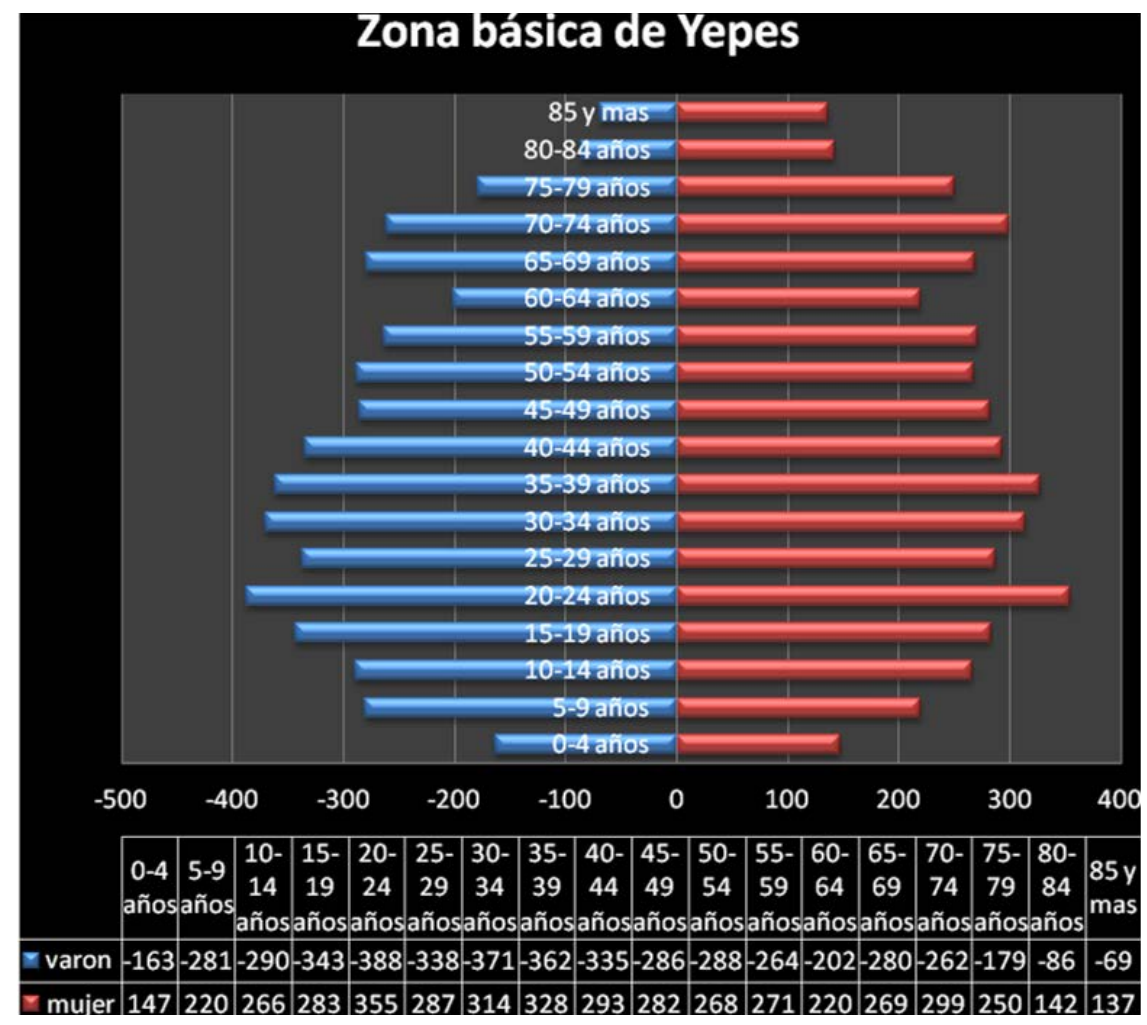

Ilustración I. Pirámide de Población de ZBS Yepes (Toledo).

Se trataría por tanto de un modelo demográfico denominado regresivo por su forma de bulbo, debido a que en la base existe menos población que en los tramos intermedios, mientras que en la cumbre existe un número importante de efectivos. Se trata de un modelo muy característico de las zonas rurales de Castilla-La Mancha. Son las típicas de los países desarrollados, en los que la natalidad ha descendido rápidamente, y sin embargo las tasas de mortalidad llevan mucho tiempo controladas, siendo la esperanza de vida cada vez mayor. Son poblaciones muy envejecidas y donde no se garantiza el relevo generacional.

Puede tener relevancia en esta población la tradición y el modelo de crianza que han tenido las madres que asisten a dicho taller de lactancia, ya que son mujeres que normalmente están arraigadas al lugar con familiares, sobre todo progenitores, que son los principales educadores informales de la sociedad. 


\subsubsection{CARACTERÍSTICAS POBLACIONALES DE LA ZONA BÁSICA DE SANTA MARÍA DE BENQUERENCIA:}

El distrito de Santa M. ${ }^{a}$ de Benquerencia según el análisis demográfico del municipio de Toledo que hizo la revisión del padrón municipal el i de enero de 2010, muestra que es un barrio que alberga 19.246 residentes por lo que supone ser el distrito más poblado de Toledo.

A continuación, se ha elaborado una pirámide de población a partir de datos recogidos por el INE y un segundo gráfico obtenido a partir del estudio demográfico de Toledo, incluido en el plan de servicios sociales. En él se puede observar que es un barrio joven. El índice de dependencia que se define como el porcentaje de población menor de 15 años y mayor de 64 años sobre la población de 15 años a 64 años, muestra poseer un índice reducido. Todo ello unido estrechamente a que el barrio de Santa M. ${ }^{a}$ de Benquerencia es un barrio residencial, obrero, que aumenta en crecimiento poblacional joven, debido a la adquisición de nuevas construcciones de vivienda social protegida, mostrando a su vez un indicador socioeconómico medio-bajo ${ }^{7,89}$.

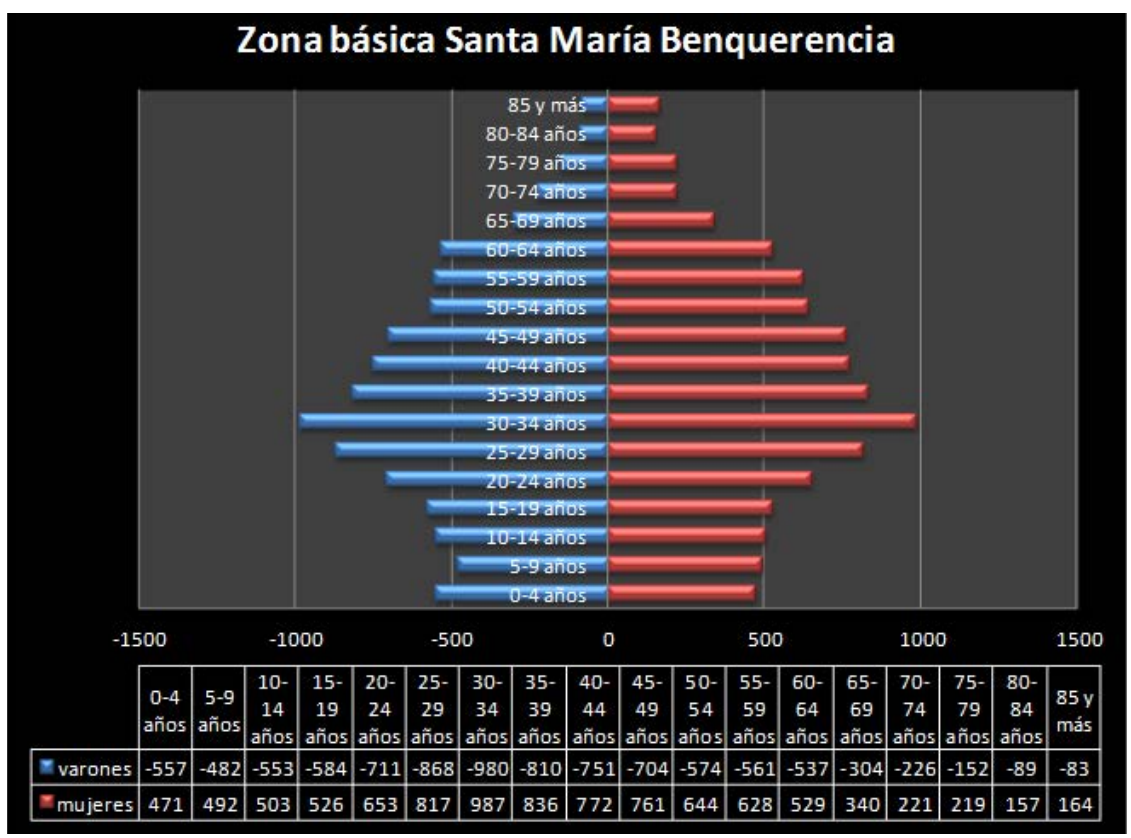

Ilustración 2. Pirámide de Población de ZBS Sta. M. a de Benquerencia (Toledo).

7 www.ine.es/

8 http://www.ayto-toledo.org/padron/dissecm.pdf

9 http://www.ayto-toledo.org/ssoc/s_planssoc.asp 
La pirámide de población de la zona básica de Santa María Benquerencia, al igual que en la zona básica de salud de Yepes tiene forma de bulbo, o sea, es regresiva.Por tanto, muestra un descenso de nacimientos y grandes efectivos en tramos intermedios, pero a diferencia de la zona básica de Yepes, hay menos efectivos en los tramos más altos. Esto es debido no tanto a que haya una menor esperanza de vida: ya que los efectivos sanitarios son idénticos (Atención primaria accesible y atención especializada cubierta con el Complejo Hospitalario de Toledo, en las dos zonas básicas de salud), sino a que se trata de un barrio relativamente de nueva creación, aparece en la década de I970. Luego, es un barrio joven con gente que habita en él en edades jóvenes y fértiles, aunque con un índice de fecundidad bajo como suele ser habitual actualmente en la sociedad española.

\subsubsection{CARACTERÍSTICAS POBLACIONALES ZONA BÁSICA DE FUENSALIDA:}

La zona básica de Fuensalida comprende los municipios de Fuensalida, Huecas, Portillo de Toledo, Santa Cruz de Retamar y Villamiel. En total con datos del padrón de fecha oI-OI-20Io se trataría de una población de I7.689 habitantes empadronados. Las poblaciones se encuentran relativamente bien comunicadas con la capital.

A continuación, se ha elaborado una pirámide de población a partir de datos recogidos por el INE. En él se puede observar que la población tiene características intermedias entre las otras dos poblaciones.

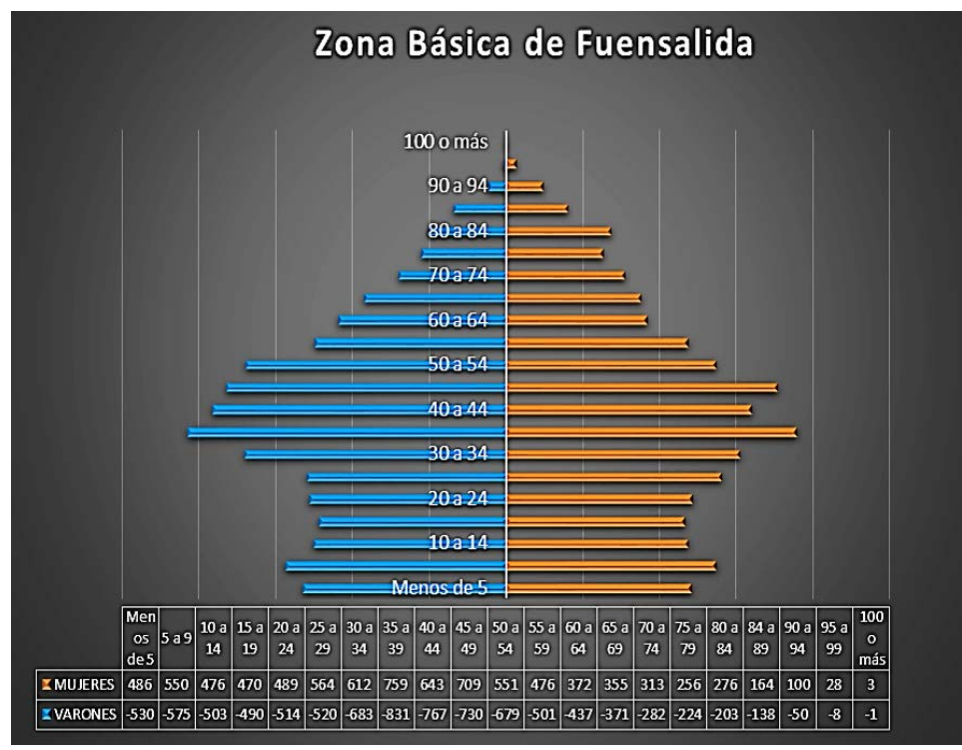

Ilustración 3. Pirámide de Población de ZBS de Fuensalida (Toledo). 
La población posee una buena proporción de población infantil y joven que posiblemente se debe a ciertas oportunidades laborales, sobre todo de tipo industrial y de servicios. En conjunto la pirámide de población tiene forma de bulbo, aunque en menor proporción que las otras dos zonas estudiadas. El descenso de los nacimientos no es tan acusado y hay grandes efectivos en los tramos intermedios.

\subsection{DISEÑO MUESTRAL: CARACTERÍSTICAS DEL MUESTREO}

Dado que no ha interesado la representatividad estadística de los datos recogidos, sino la representatividad estructural de los mismos, la muestra pretende reflejar la heterogeneidad de la población de estudio para que afloren todas las posibilidades de discurso presentes en la misma.

En función de los objetivos la muestra incluye a las mujeres lactantes que acuden a los talleres, siendo imprescindible el dominio de la lengua en la que se realizarán los grupos o entrevistas. Por tanto, las variables son:

- Variables de inclusión: mujeres que acuden al taller al menos tres veces y que hayan lactado al menos i5 días.

- Variables de Exclusión: madres que no dominen el castellano, mujeres que sólo acudieron durante la gestación y/o profesionales sanitarias.

Las variables de estudio se centran en garantizar diferentes grados de participación en los grupos, así como las diferentes experiencias sobre la lactancia materna en las mujeres. Las muestras se dividen para las tres zonas de estudio y por tanto la participación en cada uno de los talleres actúa como variable de segmentación.

Variables de estudio:

- Permanencia en el taller medida en número de sesiones:

o "Permanencia r": más de 5 sesiones de asistencia.

o "Permanencia 2" (o "efímeras"): 3 a 5 ;

o Origen: en la zona básica de salud de Yepes se distribuirá la variable origen en tres categorías:

- "Origen I" ("Foráneas") mujeres españolas que se han trasladado a vivir a la ZBS de Yepes desde otras localidades;

o "Origen 2" ("oriundas") mujeres nacidas en la Zona de Yepes

o "Origen 3 ” inmigrantes extranjeras. 
En la zona básica de salud de Santa María de Benquerencia se distribuirá esta variable sólo en dos categorías: españolas e inmigrantes. Ya que la categoría "origen I" ("foránea") no presenta relevancia en la población. En la zona básica de salud de Fuensalida no se consideraron estas categorías.

- "Paridad": con dos categorías: Multípara y primípara.

- "Rural-Urbano", que será variable de segmentación para los grupos de Yepes y Fuensalida como rurales, y de Santa María de Benquerencia como urbano.

- "Duración de la lactancia" (que se tomará hasta el momento de ser entrevistada) será dividida en dos categorías: "Corta" (de menos de 4 meses) y "larga” (de más de 4 meses). El motivo de establecer los perfiles de esta forma se debe a que a partir de los cuatro meses de lactancia suelen aparecer factores que puedan favorecer el abandono de la práctica, como son:

o La mujer trabajadora debe incorporarse a su puesto de trabajo tras el descanso de 16 semanas por maternidad, teniendo en cuenta las excepciones que marca la ley: gestación múltiple, compartir el descanso maternal con la pareja, etc.

o Durante esos cuatro meses ya se suele haber producido algún bache de lactancia, generados por fases de crecimiento del o la lactante donde la madre tiene que adecuar la producción de leche materna a las necesidades y demanda de su hijo/a.

o Además, a los cuatros meses de edad, el/la lactante ha perdido los reflejos arcaicos: reflejo de Moro, de la marcha, etc., y el niño o niña empieza a interesarse por el entorno, dando la impresión que ha perdido interés por el pecho. (Pediatria, 2008)

o A todo esto, se suma que algunas mujeres carecen de confianza en su capacidad de lactar, lo que se suele verbalizar por frases como "mi leche no es buena", "no sé lo que toma realmente". Esto contribuye a abandonar la lactancia de forma temprana.

o La presión del entorno por la excesiva importancia que se da al incremento ponderal de los/las lactantes.

o Factores asociados a la lactancia: grietas, ingurgitaciones mamarias, mastitis, dolor en la tetada, mal agarre... que inducen al abandono de la lactancia materna.

Sin embargo, una vez superados estos factores y pasado el tiempo estimado de cuatro meses, es cuando realmente se puede hablar de "lactancia mater- 
na eficaz", diagnóstico NANDA de enfermería definido como "La familia o la diada madre-lactante demuestran una habilidad adecuada y satisfacción en el proceso de lactancia materna". Este tiempo de cuatro meses se acerca algo a la propuesta de la OMS de seis meses de lactancia materna exclusiva.

Los miembros del equipo de investigación creen que otras variables de control habituales, tales como la edad, clase social o nivel de estudios no son relevantes para el estudio ya que estas variables no se toman en cuenta en la organización de los talleres y las participantes se relacionan habitualmente entre sí en los grupos. Por otro lado, la variable edad queda acotada suficientemente para toda la población de estudio al estar todas ellas en edad reproductiva.

En un momento posterior, hacia el final del estudio se propuso realizar dos entrevistas a profesionales con actividades relacionadas con la promoción de la lactancia materna, no con la intención de aportar datos al estudio sino más bien con la intención de triangular la información, incorporando el punto de vista de los y las profesionales de la salud en algunas de las cuestiones. Para ello se entrevistó a dos enfermeras una del ámbito hospitalario y otra de atención primaria.

\subsection{TÉCNICAS DE GENERACIÓN DE LA INFORMACIÓN}

Dentro de la metodología cualitativa se utilizaron técnicas que permitieron recoger los discursos en todas sus dimensiones, incluidas las aparentes contradicciones, ruidos etc. y ponerlos en relación con las condiciones sociales de producción de esos discursos, asignándoles un sentido.

De entre estos instrumentos o técnicas de generación de información, se optó por el grupo de discusión. Esta técnica permite que los discursos se desplieguen en toda su amplitud, recogiendo todo lo que se dice y cómo se dice, buscado la diversidad y la heterogeneidad en cuanto a representatividad estructural de un discurso.(Báez \& de Tudela, 2007) En general se suele afirmar que el grupo de discusión hace emerger en el nivel microsocial la estructura discursiva de las personas investigadas tal como suele producirse en el plano macrosocial y permite identificar realidades con relevancia explicativa. (Ibáñez, 1979)

No obstante, resultó imposible garantizar alguno de los requisitos teóricos de los Grupos de Discusión, en particular que los miembros de los grupos no hayan tenido contacto previo entre sí. Por este motivo en rigor, la técnica empleada fue la de Entrevista Grupal, en todos sus aspectos, similar a la del Grupo de Discusión, aunque de más difícil interpretación, dado que la posible relación previa puede condicionar algunos aspectos del discurso de los/las participantes. 


\subsubsection{GRUPOS DE DISCUSIÓN. ENTREVISTAS GRUPALES}

Inicialmente se realizaron Entrevistas Grupales (EG) para cada variable de segregación (rural-urbano) en las zonas de Yepes y Santa María de Benquerencia, hasta considerar que se había producido la saturación del discurso. Posteriormente se realizó una quinta Entrevista Grupal en la zona básica de Fuensalida con la intención de triangular la información, sobre todo la relacionada con la representación social de la lactancia.

Las EG contaron con al menos ocho miembros convocados y se realizaron cuando el número de asistentes fue superior a seis.

Como espacio para la realización de las Entrevistas Grupales, se intentó que no resultase significativo para las mujeres participantes, de forma que en principio no se condicionase el discurso. Los espacios fueron: unas instalaciones cedidas por el Ayuntamiento de Yepes y el Centro Cívico de Santa María de Benquerencia. En la zona básica de Fuensalida se realizó en el aula habitual donde se realizan los talleres (en el centro de salud) por considerar que el espacio ya no suponía ningún tipo de condicionamiento, dado que venía a ser el espacio natural del grupo.

La duración de las entrevistas se limitó a dos horas como máximo.

Actuaron como preceptores de las EG, mujeres miembros del equipo de investigación y colaboradoras en la investigación que no fueran conocidas por las participantes de los grupos. Aun a pesar de que el taller de Yepes está codirigido por un enfermero, las EG fueron siempre dirigidas por mujeres para evitar que cuestiones relacionadas con el género pudieran condicionar el discurso.

El diseño de las Entrevistas Grupales se muestra en el Anexo i: Perfil tipo de las Entrevistas Grupales.

\subsubsection{FORMA DE CAPTACIÓN}

$\mathrm{El}$ proceso de captación se realizó a través de redes informales del equipo de investigación mediante método de pasos de contactación sucesivos, (Mateo Rodríguez, 2000) incluyendo de forma inicial personas previamente conocidas por los/las investigadores/as, entre ellas:

o Algunas de las mujeres excluidas.

o Trabajadoras sociales de los centros de salud.

o Matronas de las ZBS. 
o Sanitarios/as que no trabajan en el programa o que pertenecen a otra ZBS.

Los captadores/as fueron informados de manera similar, no incluyendo la información de los principales contenidos de la investigación. Así la información que se les dio a los/as captadores/as iniciales y finales fue:

"Estudio de la Universidad de Castilla-La Mancha sobre la lactancia materna"

Para facilitar el proceso de captación se realizaron fichas de captadores/ as finales, donde figuraba, en la parte superior, el perfil de cada una de las personas con la que contactar (de acuerdo con la composición de cada grupo) y los criterios de inclusión y exclusión, redactados de forma sencilla. En la parte inferior se incluían las indicaciones para la persona que asistiría al grupo, sobre el lugar, la hora, la duración y el motivo de la reunión. El modelo de fichas de captación se presenta en el anexo $\mathrm{n}^{\mathrm{o}} 2$.

Para cada EG planificada se nombró una persona responsable de su organización, miembro del equipo de investigación. Éste trató de garantizar que el grupo se formase en las mejores condiciones.

El horario de los grupos se ajustó al momento más adecuado para las participantes, en horario de tarde. En la ZBS de Yepes los grupos se realizaron muy próximos en el tiempo dada la posibilidad de interacción de las participantes en el espacio rural.

Cada sesión se registró en audio y posteriormente se trascribió literal e íntegramente.

Para el diseño de las guías de discusión, se elaboró un guion previo, tomando los objetivos del estudio y algunos temas que de forma espontánea pudieran aparecer en la discusión. Esta guía de discusión se diseñó en forma de preguntas y también en forma sintética para facilitar la labor a la preceptora de cada grupo. Esta guía se muestra en el Anexo 3.

\subsubsection{ENTREVISTAS EN PROFUNDIDAD}

Como ya se ha expuesto, en la fase final de la investigación se realizaron dos entrevistas individuales a enfermeras del ámbito hospitalario y atención primaria, cuya actividad estaba estrechamente relacionada con la lactancia materna. Estas entrevistas se concibieron como triangulación de los datos aportados por los grupos de mujeres. En particular una de las enfermeras 
desarrolló su labor de promoción de la lactancia materna en el taller de Fuensalida, siendo una referencia a nivel regional y nacional.

En estos casos se desarrolló una entrevista abierta (denominada "entrevista en profundidad"), aunque focalizada a la experiencia de los informantes sobre la lactancia. La entrevista se concibe como un proceso comunicativo directo, personalizado y flexible mediante el que es posible explorar "los porqués" y "los cómos" de los discursos de los sujetos de estudio. Efectivamente, la entrevista permite acceder al discurso a través de las descripciones y categorizaciones de la experiencia de los informantes (Santamarina Campos, 2005, p. 23).

Igualmente, para las entrevistas se elaboró una guía de entrevista, un guion previo que reflejaba los objetivos del estudio y algunos temas que de forma espontánea pudieran aparecer en la conversación. La guía de entrevista se muestra en el Anexo 4.

Las entrevistas se registraron en audio y posteriormente se trascribieron literal e íntegramente, exactamente igual que las entrevistas grupales.

\subsection{ANÁLISIS}

Las transcripciones de las entrevistas fueron sometidas a varios tiempos de lectura diferenciados: En un primer momento se procedió a una lectura rápida con el fin de captar las líneas argumentales principales para cada objetivo y posteriormente se orientó a obtener las categorías principales.

La interpretación se realizó como un proceso inductivo basado en el marco teórico propuesto y la revisión de la literatura. Así, tras la lectura inicial de todos los materiales se tomó nota de las primeras impresiones y se realizó un esquema de codificación (véase Anexo 6: libro de códigos inductivos) que sirviera para marcar los pasajes interesantes para cada objetivo y resultado esperado.

Así se comenzó el proceso de segmentación y codificación en el que se seleccionaron y rescataron los fragmentos de texto relevantes, atendiendo al criterio de ser representativos para las líneas del discurso y asignándoles un código de categoría inductiva.

Las notas de análisis se diferenciaron en cuatro tipologías: teóricas (donde se registraba la estructura teórica), metodológicas (donde se reflexionaba sobre la técnica de obtención de datos), conceptuales (para los detalles referidos a los "códigos") y analíticas o de reflexión que constituían las notas de análisis propiamente dichas. 
Estos fragmentos se volcaron en una planilla de hoja de cálculo, para poder ser manejados informáticamente (selección y ordenación según códigos, origen de los textos, anotaciones, etc.) y se les incorporó una nota de análisis que orientaba la posible línea de estudio posterior.

A medida que avanzaba el proceso se pudo comenzar la reelaboración del libro de códigos incluyendo las categorías emergidas de los discursos y de las notas de análisis. A partir del libro de códigos definitivo se pudo generar la matriz de análisis, que reflejaba las líneas discursivas presentes y las reflexiones de análisis que sugerían (véase anexo 7. Libro de códigos y matriz de análisis). De esta forma se recodificaron los textos.

La codificación se realizó por tres codificadoras miembros del equipo de investigación, resolviéndose las discrepancias surgidas mediante consenso y volcándose en un solo documento.

Las temáticas, inicialmente agrupadas por los códigos iniciales inductivos (esto es relacionados con los objetivos iniciales), finalmente se agruparon en "familias" de códigos, como protocategorías, que coincidirían con los capítulos o temas del informe de resultados.

Posteriormente se procedió a la redacción de cada capítulo, en forma de narración teórica apoyada en las citas literales. El equipo investigador incluyó las citas literales, ordenándolas por códigos y subcódigos, seleccionó aquellas más representativas e ilustrativas y procedió a interpretar su sentido a partir de las notas de análisis. Los capítulos se presentaron y discutieron por el grupo de investigación admitiéndose los contenidos por consenso.

A la postre se trató de esquematizar las relaciones entre las diferentes categorías (o diferentes capítulos) redactándose en forma de resultados generales $\mathrm{y}$ conclusiones.

Por último, se llevó a cabo la triangulación del análisis del discurso de las EG con el análisis de las entrevistas a profesionales y la Entrevista Grupal de Fuensalida. Además, el estudio de investigación se completó contrastándolo con personas con sobrada experiencia en el tema, para garantizar así la fiabilidad del mismo.

Los resultados preliminares referidos al objetivo primero fueron presentados en VIII Congreso Español de Lactancia Materna de Bilbao ${ }^{\mathrm{Io}}$. Igualmente, parte de los resultados se presentaron en el VII Congreso Iberoamericano de Investigación Cualitativa en Salud en Barcelona y en el X Congreso Nacional de FAECAP, I Congreso de ACAMEC y VII

10 VIII Congreso Español de Lactancia Materna de la IHAN se celebró en la ciudad de Bilbao, en febrero de 2015. 
Encuentro Nacional de EIR y de Tutores en Toledo (y recogidos en el libro de actas del mismo (De Dios Aguado \& Gallego Moreno, 20I7). Otros aspectos fueron recogidos en forma de artículo científico de carácter internacional (Melgar del Corral, Villar de la Fuente, de Dios Aguado, \& Gallego Moreno, 2017).

\subsection{PLAN DE EJECUCIÓN}

\subsubsection{FASES}

a) Fase exploratoria: Construcción del marco teórico y redacción del diseño proyectado del estudio:

Durante la fase exploratoria el equipo investigador procedió a estudiar la documentación existente sobre el tema en diversas fuentes documentales (libros, artículos, páginas web). Además, se realizaron búsquedas bibliográficas en las siguientes líneas o ejes:

- Otros estudios sobre grupos de apoyo a la lactancia.

- Representaciones sobre la L.M. (Visión de la L.M.)

- Estudios de los condicionantes de la lactancia materna.

- Justificación de uso de investigación cualitativa para el tema de estudio.

La búsqueda bibliográfica se realizó en las siguientes bases de datos: PubMed - indexed for MEDLINE y http://www.bibliotecacochrane. com.

Utilizando como lapso de tiempo en PubMed sin límite y en Cochrane acotado desde 2000 al 201 y utilizando como palabras clave entre otras las siguientes: Breastfeeding workshop, maternal breastfeeding, breastfeeding duration, randomized controlled trial.

Finalmente se procedió a la redacción del marco teórico del trabajo de investigación tratando de reflejar de manera general la información relevante para el estudio. Se justificó el estudio mediante una argumentación de la pertinencia de la investigación y se reflejó la situación de los Talleres

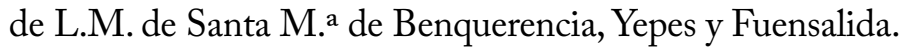

Posteriormente se procedió a la discusión de los propósitos de la investigación y redacción de los objetivos. En el diseño proyectado por el estu- 
dio se valoró la metodología de investigación y la instrumentalización de las técnicas y metodologías.

En este punto se ordenan en el tiempo las actividades relevantes para el desarrollo de la investigación mediante un cronograma. Finalmente se recogió la bibliografía, los anexos y las tablas.

Esta fase se desarrolló durante 6 meses.

b) Fase de campo: recogida y análisis preliminar de la información.

La fase de campo se prolongó durante 8 meses en los que se realizaron las Entrevistas Grupales simultáneamente en las dos zonas de estudio iniciales. Posteriormente se realizó la EG de Fuensalida y las entrevistas a profesionales.

c) Fase de redacción: en esta fase se procedió a la codificación, análisis y redacción de los capítulos del informe. Se prolongó durante un año.

d) Fase Verificación de resultados: triangulación de métodos y fuentes y elaboración del informe final. Esta fase se desarrolló durante un año, culminando con la redacción del Informe Final.

e) Fase de difusión de resultados:

Se prolongará durante 6 u 8 meses y en ella se elaborarán informes de la investigación de diversos aspectos de la misma, para ser presentados a eventos científicos nacionales e internacionales o diferentes publicaciones.

\section{RESULTADOS}

\subsection{LA EXPERIENCIA DEL TALLER DE LACTANCLA MATERNA}

En este capítulo se analizan en profundidad los aspectos relacionados con la asistencia de las madres a los talleres para dar respuesta al primer objetivo del estudio, la utilidad del grupo de apoyo desde el punto de vista de las mujeres participantes y corroborado por profesionales responsables de los mismos, para ello se analizan los comentarios sobre: participación en el taller y ayuda a resolver dudas, asesoramiento sobre lactancia materna, apoyo de los/las profesionales responsables de dicho taller, así como de otras madres.

"Es donde realmente me enseñaron a dar el pecho [...] lo pasé muy mal, si no hubiese sido por el taller de lactancia, que me enseñaron realmente a que el niño, sin pezones podía engancharse [...] quizás no hubiera acabado dándole el pecho." GDPi I7-I 
Está en línea con lo que señalan los/as profesionales:

"[el Taller] es un sitio donde efectivamente [...] hay una formación, hay gente que lo respalda, un profesional que lo respalda y unas madres que están bien formadas, que han ayudado a otras madres y funciona."

$\mathrm{EP}_{2} 55^{\prime} 55^{\prime \prime}$

"Hay solvencia" $\mathrm{EP}_{2} 5_{6}{ }^{4} 8^{\prime \prime}$

"No he trabajado en Atención Primaria, pero sé que tienen talleres de Lactancia Materna y tienen la educación pre y post, preparto, y sé que es súper importante porque ellas llegan con conceptos". EPr. 24’49"

El estudio muestra las opiniones de las madres acerca del taller como espacio donde: se comparten experiencias y se establecen relaciones madremadre, se acompaña su decisión de amamantar y se forma un vínculo entre ellas, siendo por tanto el lugar donde se atienden sus necesidades y se resuelven sus dudas.

"Aunque sólo sea por la reunión de madres [...] cuando eres primeriza, [] te tranquilizabas mucho." GDP2 6-3

En sus discursos las mujeres comentan las dificultades que encuentran para acudir al taller: pudor, oposición del entorno familiar y social para su asistencia al grupo de madres y profesionales sanitarios/as que tiene por objetivo el apoyo a la lactancia materna.

"en el pueblo influye mucho la familia, y si la madre dice: ¿Para qué vas a ir a esa tontería? Si te das cuenta...Yo porque soy de Madrid, tú eres de Madrid, ella es de..." GDYI 25-2

Afloran sus opiniones sobre: los/las profesionales responsables, el horario, el lugar y los días establecidos para el taller, las actividades que se realizan, el material disponible y la utilidad.

"En el taller de lactancia te ayudaban, a mí por ejemplo me ayudaron a que se enganchara bien el pequeño y fenomenal” GDPi 9-ז3

Aparecen discursos relacionados con el cese de asistencia al grupo de apoyo y la reincorporación de la mujer a su jornada laboral.

"Cuando empecé a trabajar porque ya había terminado la baja maternal y ya no tenía tiempo." GDY2 I7-I2 
Al final del capítulo, se analizan las expectativas no cumplidas y la decepción que perciben algunas madres con relación al taller.

"Cada uno preguntaba sus cosas y yo esperando a que empezara aquello, ¿no? (Se ríe)

yo: ¡Pero esto no empieza!” GDY2 9-I8

Por otro lado, conviene señalar que no se aprecian diferencias en el discurso entre las variables de estudio respecto a este primer objetivo. Así, las verbalizaciones son similares entre las mujeres procedentes del medio rural o urbano; entre las primíparas o multíparas; las inmigrantes, las oriundas y las foráneas; no se aprecian ni entre las que han asistido a más o menos sesiones, ni tampoco aparecen entre quienes han dado una lactancia más o menos larga. Solo en el subcapítulo 4.I.7 Expectativas no cumplidas, aparecen diferencias entre el taller rural y el urbano.

En general las citas para este objetivo son abundantes, con la excepción de lo referido al subcapítulo 4.I.5 Valoración de recursos, estructura, espacio y propuestas de mejora, que son escasas.

\subsubsection{LA UTILIDAD DEL TALLER:"NOME ESPERABA...TANTO"}

$\mathrm{E} 1$ análisis de las entrevistas grupales revela que las mujeres tienen dos posiciones discursivas opuestas sobre las expectativas a los talleres de apoyo a la lactancia. Por un lado, afloran citas en las que se refleja su decepción al no encontrar lo que esperan: imaginaban un curso más o menos organizado y encuentran un taller que funciona como grupo de autoayuda con asesoramiento individual o colectivo por un o una profesional según las necesidades de las madres, siendo además un lugar de relación entre iguales.

"Yo, sinceramente me quedé un poco decepcionada el primer día. Porque pensaba que era algo temático. [...]

- Sí, eso es lo que me pasaba a mí." GDY2 9-זo Y II

Y, por otro lado, aparece la línea discursiva en la que las mujeres reconocen que el taller les ha proporcionado más de lo que esperaban, superando sus expectativas:

"Bueno, no me esperaba... tanto. Aprender tanto como he aprendido. [...] No me imaginaba eso" GDYI II-8

Cabe señalar en cuanto al grupo de apoyo, que son muchas más las citas en las que las mujeres hablan de satisfacción, que las citas que reflejan decepción 
o expectativas no cumplidas. Una vez que entienden cómo funciona el taller la satisfacción parece generalizada.

Algunas mujeres acuden al taller antes de dar a luz, sin embargo, la mayoría acuden cuando son amamantadoras, estas mujeres van buscando apoyo a la lactancia materna y esperan encontrar asesoramiento en diferentes aspectos: ayuda para que se agarre al pecho, para solucionar problemas de postura, para resolver dudas sobre la crianza del recién nacido, etc.

"Porque es que, desde los seis, siete meses de embarazo yo ya estaba yendo al Taller siempre que podía, porque yo quería que me ayudaran.” GDYI 6-I

Cuando surgen problemas y la madre se siente insegura sobre su capacidad para amamantar a su hijo o hija, en el taller, encuentran el apoyo necesario para continuar.

"Iba haciendo el mínimo peso, y entonces me desanimé y quise dejar la lactancia. Como con el primer niño se me retiró a los dos meses [...], yo veía que no hacía nada...pues me desanimé. En el Taller me apoyaron, me dijeron que no pasaba nada, que era cuestión de tiempo, de la adaptación, que no tenía por qué salir como con el otro niño, que cada bebé es un mundo [...]. Y entonces lo seguí intentando" GDY I II-8

Muchas mujeres consiguen que el niño o la niña aprenda a mamar gracias al asesoramiento recibido al inicio de la lactancia. En los talleres se les asesora en: posición correcta, utilización de pezoneras, enganche, signos de buena mamada, etc.

"al final María, la enfermera que me atendía en lactancia: ¡venga insiste! y yo mientras no me digan que mi hijo peligra voy a seguir intentando y al final a la tercera semana ya el niño se enganchó bien" GDPI $5^{-1}$

"Me ayudaron mucho a coger las posturas, las posiciones porque ella no... no chupaba directamente, chupa con pezonera. Y para que no cogiese aire [...], la forma de expulsar los gases [...].Y ellos me ayudaron en eso." GDYI 4-I

Las mujeres participantes del estudio reconocen, en sus verbalizaciones, que en los grupos de ayuda han aprendido mucho, pero lo más valorado de ellos es la ayuda que reciben, incluso en algunos casos parece que el taller ha superado sus expectativas.

"Me pensaba que bueno, era un Taller donde se juntaban varias madres, daban el pecho, charlaban de sus cosas...Pero no me esperaba la ayuda. 
Yo no sabía que te pesan al niño cada semana, yo no me imaginaba... no me imaginaba eso" GDYI II-8

Es habitual que la madre se preocupe por el peso de su hijo/a, históricamente la ganancia de peso está asociada a un signo de salud y bienestar, por ello el hecho de pesar al lactante en el taller les parece muy útil. La ganancia de peso del bebé motiva a la madre a seguir con la lactancia, le proporciona seguridad y le anima a permanecer en el taller.

"La verdad es que eso está muy bien, que te pesen al niño cada semana. Y luego eso, pues la ayuda que te dan..." GDYI II-4

"mira, pesa doscientos gramos más. Y te vas: Muy bien, muy bien." $\mathrm{GDP}_{2}$ 6-9

"Te dicen: No te preocupes. Vas ahí, te le pesan... [Pone otra voz] Es suficiente, tú tranquila, tú esto. Biberón olvídate" GDY2 I3-4

Sin embargo, el peso también puede llegar a obsesionar a la madre, tal y como revela alguna verbalización y se puede convertir en arma de doble filo, como lo reconocen los/as profesionales responsables de los talleres y las madres:

"el peso que después se ha cuestionado mucho a mí me parece que tiene que seguir estando, aunque lo relativices mucho" $\mathrm{EP}_{2} 2 \mathrm{I}^{\prime} \mathrm{I}^{\prime \prime}$

"Cuando tú haces lo del peso con el fin de avalar, como testificar que lo que estás haciendo funciona, las madres desde fuera [...] lo que quieren no es 150 que está muy bien si no 280 que ha dicho la otra que es lo que tiene [su hijo]" $\mathrm{EP}_{2}$ 9'5"

"Yo, para mí, creo que... [Te pesen al niño] incluso te llegan a obsesionar un poco." GDP2 6-io Y II

"Y la mía, ¿por qué no coge tanto? [...] Y... yo, a mí, me llegaba un poco a obsesionar, luego, ya al final, ya no. Ya decía: Pues si está tranquila, está tranquila" GDP2 6-I4

Como ya se comentó en la introducción durante los años 6o-80 muchas mujeres no amamantaron a sus hijos e hijas, por tanto, ahora no pueden o no saben ayudar a sus hijas a iniciar la lactancia natural. Además, en la actualidad la estructura de la familia ha cambiado, muchas mujeres viven alejadas de su familia o desplazadas de su zona de origen por motivos laborales y no cuentan con el apoyo suficiente para asesorarles en la lactancia. En estas circunstancias el taller suple la carencia de "cultura de la lactancia materna" que hay en nuestra sociedad. Efectivamente, como se analizó en la introducción, la OMS, en su momento, respondió a esta pérdida de "sabiduría familiar" pro- 
moviendo la lactancia materna, a través de los grupos de apoyo a la lactancia, estos grupos debían ser liderados por profesionales sanitarios/as expertos/as en lactancia materna, para que las mujeres con deseos de amamantar a sus hijos/as, tuvieran un apoyo formal.

"Yo no tengo madre entonces me ayudaron ellas un poco a colocar al niño en el pecho, a que se enganchara" GDPI 4-I

En el grupo de apoyo a la L.M. se realiza un asesoramiento personalizado a cada madre, los/las profesionales expertos/as en lactancia, responsables de los talleres, ayudan a la madre a resolver sus inseguridades sobre la crianza de su hijo/a y sobre la lactancia materna.

"todo el tiempo que yo necesité estuvo conmigo, a ver si el niño se enganchaba y tal, y al final se enganchó" GDY 2-I

"Lo bueno que tiene es que yo por ejemplo, [...] las dudas que tenía se las preguntaba" GDY2 9-I4

Además, se lleva a cabo un asesoramiento genérico en lactancia y crianza de los/as hijos/as a través de sesiones formativas con material audiovisual, hecho valorado de forma muy positiva y siendo muy útil para resolver las dudas que les surgen durante el periodo del amamantamiento.

"vas allí y lo mismo te ponen un video con alguna cosa interesante pues de cómo dar la leche, o las papillas, [...] dar masajes..." GDPI 8-I4

"Las dudas que tienes te las resuelven, te ayudan" GDPI I3-5

Según se desprende de sus discursos, aunque son muchos los conceptos y las habilidades que se trabajan en el taller relacionados con la lactancia, también encuentran otros beneficios distintos de lo que puede ser el apoyo a la lactancia materna como tal.

"todos los meses se ve lo que van engordando, que va bien la lactancia a pesar de haber sido una cesárea, las dudas que tienes te las resuelven, te ayudan, lloras porque estás de las hormonas hasta aquí, no duermes y hablas con otras mujeres que están en tu misma situación, estuve yendo ocho meses y me gustaba mucho, dos horas a la semana que sales de casa" GDP1 13-5

"Pero yo lo del Taller, a mí sí que me gustó mucho. Aunque sólo fuera por tranquilizarme." GDP2 7-5 
En ocasiones, los talleres aparecen en sus discursos como: tiempo de libertad, una "excusa para salir de casa". Así, la asistencia al grupo de apoyo les permite salir a la calle, en un momento en el que se sienten retenidas, encerradas, enclaustradas en sus hogares.

"A mí el taller de lactancia me ayudo un montón, primero le comentaba las dudas que podía tener sobre la lactancia y salir unas horas a la semana a la calle (murmullo) Los primeros dos meses es nada más que teta y teta, no podía salir a la calle." GDPr 9-16

"Sobre todo, para mí una válvula de escape para salir un poco del encierro que supone los primeros tiempos y luego el compartir la experiencia" GDPI $14-5$

También, les proporciona tranquilidad al estar con otras madres en su misma situación (como ya veremos más a delante) y disponer de una persona profesional experto/a en lactancia a quién consultar.

"En el taller de lactancia te ayudaban, a mí por ejemplo me ayudaron a que se enganchara bien el pequeño y fenomenal, luego vas haciendo grupos que te pone en contacto con gente de la lactancia." GDPr 9-ז3

En general los sentimientos de las mujeres que asisten a los talleres son muy parecidos e independientemente de dónde esté ubicado este grupo de apoyo, las mujeres se sienten seguras y apoyadas entre iguales.

"Hay más grupos de apoyo a la lactancia en Toledo [...] a otras madres que han asistido a otros grupos de lactancia, les ha pasado un poco lo mismo, que han sentido ese apoyo más entre los propios" GDY 3-3

La madre debido a su inexperiencia busca apoyo físico, psicológico y moral. Será a partir de una relación de confianza con el/la profesional cuando la madre se sentirá segura y relajada, mejorando su autoestima con relación a su rol de madre.

"Estuvo conmigo, yo iba con mi hija [a la consulta]. Y ponía a la niña [a mamar] y me decía [la enfermera]: Tranquila, [...] no tienes que hacer nada [para amamantar] Y estuvo así, por lo menos...casi quince días conmigo" GDY2 8-7

"Le miraban $[\ldots]$ e incluso $[\ldots]$ les pasaban al pediatra si hiciera falta" GDPi 9-8 
Como ya se describió en la introducción, los grupos de apoyo a la lactancia materna, tanto los coordinados por profesionales sanitarios como los "grupos de madre a madre" son un factor favorecedor de la lactancia materna.

Se establece así una relación de empatía con otras mujeres amamantadoras. Este hecho no sólo prolonga en el tiempo el grupo, si no que provoca cierto sentimiento de pertenencia a un colectivo que se construye en torno a la lactancia y que podríamos llamar "de mujeres amamantadoras".

Además, la lactancia materna, al igual que el parto, aunque es un proceso natural no está exenta de complicaciones y/o problemas que necesiten de profesionales sanitarios/as expertos/as, para solventarlos. El taller de apoyo a la lactancia vendría a realizar este papel de ayuda, apoyo y asesoramiento.

Dar las gracias al Taller, que es un apoyo muy grande [...] Digo: $\mathrm{Si}$ quieres dar el pecho infórmate, porque es lo mejor. Que te asesoren, que te ayuden. Que, aunque es una cosa natural, a veces no es tan natural. GDYI 26-8

\subsubsection{ESPACIO DE RELACIÓN Y AUTOAYUDA: "SI L $\boldsymbol{A} \boldsymbol{F} \boldsymbol{A M I L I \boldsymbol { A }}$ NO TE AYUDA, PARA ESO ESTÁN LAS REUNIONES"}

La gerencia de atención primaria de Toledo, durante el año 2008, impartió cursos sobre lactancia materna, con la finalidad de promover la creación de talleres de apoyo a la lactancia natural; adhiriéndose así a las políticas internacionales de la OMS / UNICEF en materia de lactancia materna. Estas políticas defienden un cambio en la manera de promover la lactancia y recomiendan la creación de grupos de apoyo a la lactancia liderados por profesionales sanitarios (matrón/a, enfermero/a) y apoyados por otros profesionales (pediatra, médico/a de familia, etc.). Estos grupos de apoyo a la lactancia deben proporcionar asesoramiento formal a las madres, que a su vez reunidas con sus respectivos pares puedan verbalizar sus dudas, temores y experiencias, sintiendo, a la vez, el enriquecimiento de la crianza de sus hijos e hijas.

Gracias a esta iniciativa entre 2009 y 201 se crearon veinticuatro grupos de apoyo a la lactancia materna en el área de salud de Toledo.

"Es un Taller que dan nuestras enfermeras de Pediatría [...], pesan a los niños, te informan, cada día se trata un tema. Pues, cómo puedes conservar la leche, cada madre se pone a darle de mamar y te enseñan si está bien la postura, si no está bien" GDP 2 6-2 
El taller facilita un espacio donde las mujeres pueden: hablar entre iguales, compartir experiencias, manifestar sus preocupaciones y exponer sus miedos. En este espacio no sólo se relacionan con los y las profesionales de la salud responsables del mismo, sino que, al relacionarse entre ellas, les permite comprender que tienen miedos, dudas y preocupaciones muy parecidas, además crean relaciones de amistad, cariño y confianza, lo que les hace sentirse como en familia.

"Yo creo que creas una complicidad y te sientes allí como [...] tu familia. [...] Allí las preguntas surgen, o simplemente vas a preguntar algo y lo acaba de preguntar tu compañera [...], yo sí que creo que ha sido, para mí [...] muy enriquecedor. Siempre positivo." GDYI II-I2 y I2-I

"Yo creo que creas una complicidad y te sientes allí como...como si... Haces un grupo y prácticamente es en ese momento como tu familia." GDYI II-I2

Todas estas circunstancias favorecen que las mujeres se sientan motivadas e ilusionadas para seguir con la lactancia, esperando con deseo el día del taller para acudir a él.

"Te animas a ir, que te gusta ir y [...] que llegue el día para ir." GDP2 6-6 "yo lo dejo todo por ese ratito [dicen las madres] necesitan llenarse de esa energía que hay alli" $\mathrm{EP}_{2} 6 \mathrm{r}^{\prime} 28^{\prime \prime}$

$\mathrm{Al}$ asistir, encuentran que el grupo de apoyo es un espacio abierto y dinámico que favorece las relaciones humanas, que pueden relacionarse con otras mujeres en su misma situación y descubren que los talleres están dirigidos por profesionales expertos/as en lactancia materna que solucionan sus dudas. Estas circunstancias ofrecen a la madre seguridad, favorecen el desarrollo de las habilidades necesarias para amamantar a su hijo o hija, consiguiendo que la madre acuda al taller de forma periódica.

"Un apoyo muy eficaz. Si la familia no te ayuda, para eso están los grupos, ¿no? Para... la gente que tiene experiencia, profesionales que te empujan y te apoyan y todo. O sea, a mí me parece estupendo" GDY2 I3-4

Aunque las mujeres hablan con sus parejas o familiares, no siempre se sienten comprendidas por ellos/as en esta etapa tan importante y especial de su vida. Sin embargo, en el taller se encuentran con otras mujeres que han pasado o están pasando por lo mismo. 
"Yo podía hablar con mi marido como me sentía, pero mi marido no entendía que a lo mejor a mi me entraban ganas de llorar, en cambio hablabas con otras y te decían a mi me pasa igual." GDPI I3-7

"Ya voy con las pilas puestas para otra semana, porque sé que me voy a encontrar con mi marido con mi suegra [...] estaba deseando llegar aquí para aliviarme de toda la carga que traigo" $\mathrm{EP}_{2} 38^{\prime} 28^{\prime \prime}$

Por todo lo comentado con anterioridad parece que el taller adquiere una nueva dimensión, no es sólo un lugar donde: encontrar asesoramiento profesional, adquirir conocimientos sobre el tema, entablar nuevas amistades o una excusa para salir de casa; sino que, para las mujeres del estudio de investigación, el taller es un grupo de autoayuda.

"Es un poco terapia de grupo [...] salir de mi casa, olvidarme de todo, $[\ldots]$ hablar con las madres, relajarme y olvidarme, darme cuenta de que no soy rara, que todas tenemos el mismo problema"GDF oo' 29 "

Los grupos de autoayuda según Mario Campuzano "son organizaciones de personas que comparten similares problemas psicológicos, físicos o existenciales, pueden ser grupos orientados al crecimiento personal y auto actualización tales como la liga de la leche"(Campuzano, 2004) son iniciados por personas asertivas que invitan a otras a encontrarse de forma periódica y frecuente para discutir su problema común y buscar formas de resolverlo o de manejarlo de la mejor manera posible."

Cabe destacar, por tanto, que las mujeres en el taller de lactancia se sienten entre iguales, esto les invita a comunicar libremente sus sentimientos, prejuicios, creencias, temores, miedos, etc. y no se sienten presionadas, criticadas, cuestionadas, juzgadas, etc. En este entorno de seguridad progresivamente van mejorando sus habilidades y se van adaptando a su nuevo rol de madre.

"Compartir la experiencia [...], vas y ves que a la de al lado le pasa lo mismo que a ti (murmullo) y entonces al final es casi un taller un poco psicológico" GDPI I4-6

"Yo iba nada más que para desahogo" GDY 2 I3-5

“¿qué traéis en la mochila esta semana? Vamos a descargarla." EP2 27'ıо”

Aunque las mujeres participantes en las entrevistas grupales valoran muy positivamente el apoyo brindado por el personal sanitario responsable de los grupos de apoyo, dan una importancia especial a los consejos que reciben de otras madres, de sus pares. 
"Tiene que haber madres por allí que te digan: Mira [...] es así, ten paciencia." GDY2 5-3

"Van a ayudar las madres que es muy importante...las mismas madres les van a solucionar el tema, mi papel ahí es saber que eso funciona". $\mathrm{EP}_{2} 37^{\prime} 49^{\prime \prime}$

Este soporte emocional que consigue la mujer en el taller de lactancia, favorece la asistencia, facilita los lazos de amistad entre las asistentes, la madre siente fidelidad y pertenencia al grupo y con el tiempo introduce el taller en su rutina de actividades.

"Aparte de la obligación de salir un día a la semana [...], das un paseo, te juntas con otras mamás, te sientes que no estás sola, [...] además, nos dábamos consejos unas a otras [...] y éramos un coloquio (murmullo) éramos una piña." GDPI I4-5

\subsubsection{DIFICULTADES PARA ACCEDER: “¿PARA QUÉ VAS $\boldsymbol{A} I \boldsymbol{I} \boldsymbol{A}$ ESATONTERIA?"}

Si como se ha visto, el taller de lactancia proporciona a la madre un entorno abierto y dinámico que favorece las relaciones humanas, por otro lado, existen distintas circunstancias que dificultan la asistencia de las mujeres al taller, tanto a nivel personal (sobre todo el pudor), como a nivel familiar o social (sobre todo las críticas por asistir al taller).

\section{La dificultad del pudor}

El taller para algunas mujeres, según se desprende de las entrevistas grupales, es un lugar donde se sienten expuestas tanto físicamente, al tener que descubrirse el pecho para dar de mamar, como emocionalmente al comentar con otras mujeres sus sentimientos.

Como se analizará en el capítulo 4.2.4.I La imagen de la mujer lactante, hay madres que manifiestan su malestar o vergüenza al tener que descubrir su pecho en el grupo o en otros espacios públicos, aunque según algunas mujeres, esto ocurre al principio de la lactancia y después se va superando.

"Exponer mi pecho $[\ldots]$ a mi no me gustaba" GDY2 I-5

"yo no le quería dar en ningún sitio, de vergüenza.

Luego ya no, luego ya..." GDY2 r7-3

Estos sentimientos parece que condicionan, en algunos casos, la asistencia al taller y algunas mujeres irían si no tuvieran que dar el pecho delante de personas extrañas. 
"Mi cuñada $[\ldots]$ no va a venir al Taller para que nadie la vea las tetas. Por ejemplo, yo le he dicho: Es que yo no voy al Taller y me saco las tetas. Hay días que mi hijo necesita mamar y mama, y hay días que no." GDYI

El hecho de que las madres asistentes al grupo de apoyo manifiesten haber sentido pudor, durante la lactancia, puede explicar por qué, aunque la lactancia materna es algo natural, en nuestra sociedad y sobre todo en algunas zonas rurales, no parece bien vista si se practica en público.

"Aquí en la plaza, aunque me mira la gente como si fuese un bicho raro [alguien ríe], porque es que, además, la propia gente me dice que cómo se me ocurre en la plaza darle de mamar. Como si es que yo le estuviese haciendo un daño." GDYI I5-7

Parece ser que el cuerpo de la mujer puede mostrarse en privado o en situaciones muy concretas, pero no exhibirse en público, ni siquiera para dar de mamar ${ }^{\text {II }}$.

Por otro lado, resulta curioso que no se hagan referencias al hecho de exponerse delante de un enfermero varón. Esto quizá pueda deberse a que el pudor frente al personal sanitario se vence en los momentos de la preparación al parto o durante el parto.

\section{Las dificultades debidas al entorno social}

El entorno familiar de la mujer que asiste al taller de forma periódica, en muchos casos, no entiende por qué acude al taller para relacionarse con otras madres lactantes.

Las participantes del taller de Yepes tienen la impresión de que sólo acuden mujeres "foráneas" y no las que pertenecen a familias tradicionales del pueblo. Esto puede estar relacionado con la idiosincrasia del pueblo que ejerce de barrera, en las mujeres, para que acudan libremente al taller de lactancia (al margen de la explicación de que el taller estuviera mal considerado). Un poco de historia sobre la localidad de Yepes ayudará a comprender su idiosincrasia ${ }^{\text {r2 }}$. Incluso, en

11 Esto lo trataremos más profundamente en el capítulo 2.4 La esfera socio cultural cuando hablemos de las connotaciones socioculturales de la lactancia materna.

12 Las primeras noticias documentadas son del siglo XII, Alfonso VIII donó la jurisdicción a los arzobispos de Toledo y se mantuvo bajo el señorío de la catedral primada de Toledo hasta que el papa Gregorio XIII otorgó bula de enajenación al rey Felipe II y vendió la villa en 1.576. Los siglos XVI y XVII fueron los de mayor esplendor de la villa, autores como San Juan de La Cruz, Santa Teresa de Jesús o Calderón de la Barca dedicaron obras a la localidad, En ese momento histórico la vida religiosa estaba muy presente en la sociedad, tanto que la villa, contaba con: un convento de 
la actualidad, persisten las diferencias sociales que hacen que algunas mujeres no se sientan cómodas compartiendo espacios públicos con otras mujeres.

"en el pueblo influye mucho la familia, y si la madre dice: ¿Para qué vas a ir a esa tontería? Si te das cuenta...Yo porque soy de Madrid, tú eres de Madrid, ella es de..." GDYI 25-2

Si se considera, tal y como se hizo en la metodología, que la población de Yepes en el estudio aparece "segregada" por la variable "procedencia" (entre "oriundas" y "foráneas") se entiende que el taller, como espacio de relación, lo estará también. Así, el hecho de que las "oriundas" no asistan nunca a los grupos de apoyo se explica porque es un espacio exclusivo de relación de "foráneas", al parecer casi único en el pueblo. Efectivamente muchos de los espacios de relación aparecen limitados para las que no pertenecen a las familias antiguas del pueblo. Cabe considerar que tanto el carácter horizontal de las relaciones intragrupo (por ser gratuito, de acceso libre y público) como el hecho de que se organice por enfermeros/as que proceden de fuera del pueblo, contribuye a que las mujeres procedentes de las familias "oriundas" del lugar tengan dificultades para acceder.

Sin embargo, ese caso no se da en sociedades o barrios "más abiertos" tales como el barrio Santa María de Benquerencia de Toledo un "barrio de aluvión" y de origen principalmente obrero o en la localidad de Fuensalida.

Esto lleva a afirmar que, a la hora de organizar talles o actividades grupales que presenten características de autoayuda y de espacio de relación, se debe estudiar con cuidado las características sociales de la población diana, pues estas pueden influir en la asistencia.

monjas carmelitas descalzas, uno de monjas bernardas, uno de frailes dominicos y otro de frailes franciscanos, contaba con la iglesia del hospital de San Nicolás, la iglesia del hospital de la Concepción y la iglesia parroquial de San Benito Abad, edificio singular para la época por sus excelentes pinturas. Los arzobispos de Toledo ostentaban tanto poder, que los gobernadores eran puestos por ellos para que gobernaran en su nombre, además, tenían su residencia en la plaza mayor de la que llamaban su villa. En aquella época las clases sociales estaban muy marcadas, no solían compartir espacios públicos y no era habitual que se mezclasen sus integrantes. La decadencia se produjo en el siglo XVIII con la desamortización de Mendizábal.

Hoy en día existe en funcionamiento el convento de clausura de monjas carmelitas descalzas, su iglesia parroquial sigue siendo un edificio singular y la religión católica marca el ritmo de las actividades del pueblo, estando muy presente en sus festividades, así como en la vida diaria de los yeperinos. (Trillo Siaba, 1982) 


\section{Las dificultades familiares}

En general las participantes en las entrevistas grupales, refieren que algún/a familiar tiene un concepto negativo de la lactancia. Por otro lado, con cierta frecuencia expresan también que alguno/a de sus familiares considera la asistencia al taller como "un adoctrinamiento". Esto hace que en muchos casos intenten evitar la asistencia al taller.

Efectivamente, algunas participantes perciben en los grupos de apoyo a la L.M. una connotación incluso excluyente, es decir, como un grupo social constituido, lo que se interpreta a partir de la expresión "gente de la lactancia" para referirse a las participantes en estos grupos.

"En el taller de lactancia te ayudaban, a mí por ejemplo me ayudaron a que se enganchara bien el pequeño y fenomenal, luego vas haciendo grupos que te pone en contacto con gente de la lactancia." GDPi 9-I3

Estas expresiones son excepcionales en el marco de la atención sanitaria ya que no se aplican a otras actividades grupales de la atención a la salud. Más aún, incluso tampoco se aplican a grupos que se conciben y se organizan como grupos de autoayuda. Parecería que nos encontráramos ante una visión de los talleres y por tanto del concepto mismo de promoción de la lactancia como un "movimiento social".

Este hecho puede explicar que algún/a familiar tenga una visión negativa del taller, llegando a denotarse por alguno de ellos "como una secta" o considerarse como un "movimiento integrista".

"Mi ex [se refiere a su pareja] fue una vez a ver a Carmen, fue a la consulta para decirle que si éramos un tipo de secta o algo así" GDPI 19-6

El rechazo (expresado por la palabra secta y otras) se debe a una serie de causas que ahora se esbozan, pero que se desarrollan con más amplitud en el capítulo 4.2.4.2 El rechazo social de la lactancia materna:

- El problema generacional: la visión negativa de los talleres por parte de las mujeres de la generación anterior (la correspondiente a las madres de las participantes), posiblemente puede deberse a que la lactancia materna fue mucho menos frecuente, menos duradera y más reservada a clases sociales bajas.

"Mi madre, [...] era de la época en que estaban de moda los biberones.

Dice: Yo iba al pediatra y me sacaba la teta, la gente me miraba mal." GDP2 II-IO, I2-I 
- La oposición de las mujeres que no dan el pecho. Ya que el énfasis en que la lactancia materna mejora la salud del hijo/a, cuestiona el rol de madre de las mujeres que no lactan.

"Hay muchas más mujeres que en el fondo están frustradas por no haber dado el pecho." GDPi ig-7

- La oposición de la pareja. En ocasiones para algunos padres, el hecho de lactar puede aparecer como excluyente, porque reduce las posibilidades de participación en la crianza. Sin embargo, otros padres pueden sentir celos hacia el nuevo miembro de la unidad familiar.

"Yo creo que lo de [la lactancia materna] es el privilegio que tenemos las mujeres." GDY 2 2I-2

"El mío es por un poquito de celos [...] sí, contigo se calla y conmigo no [...] $\mathrm{GFD}_{3 \mathrm{I}^{\prime}} 25^{\prime \prime}$

- La oposición desde la igualdad de género. Otro aspecto que explicaría el rechazo social a los talleres puede estar relacionado con las reivindicaciones de igualdad entre géneros. Además, dado el escaso margen de conciliación de la vida laboral y del cuidado de los hijos e hijas en España, la lactancia materna podría sentirse como una dificultad para el desarrollo profesional de las mujeres.

"En la plantilla de mi trabajo si somos el $95 \%$ mujeres y no tienes una sala o un lugar determinado para poderte sacar el pecho [...] yo me iba al servicio y había compañeras que me decían yo en el servicio no lo haría, yo por mi niño lo hago en un servicio" GDPI II-2

\subsubsection{LOS/LAS PROFESIONALES QUE LO COORDINAN: "MIS PAÑUELOS DE LÁGRIMAS"}

El personal sanitario tiene un papel importante en la promoción y apoyo a la lactancia materna, está formado y capacitado para: transmitir seguridad $\mathrm{y}$ ofrecer confianza a las madres amamantadoras, asesorar durante todo el periodo de la lactancia en el comienzo, mantenimiento y destete, a través de la resolución de dudas y apoyo emocional, demostrando así la empatía necesaria para generar confianza en la madre.

"Estoy aquí sola, no tengo a una madre, una suegra ni nadie, me apoyé mucho en el Taller [...]. Estuvo la enfermera conmigo todo el tiempo 
[...] estuvimos lactando meses, que fueron muy duros, $[\ldots]$ después de dos meses tan duros, luego me rechazó el pecho y la verdad es que lo pasé muy mal [...] fue un trabajo; tanto mío como del Taller, porque ya te digo que me dedicaron mucho tiempo y mucho apoyo." GDYI 6-I

"Yo no tengo madre entonces me ayudaron ellas un poco a colocar al niño en el pecho, a que se enganchara, era muy chiquitín y le costaba mucho" GDPr 3-I4

Las madres participantes del estudio, en sus discursos, agradecen a los/ las profesionales su: implicación, dedicación, empatía. Además, agradecen el apoyo y el ánimo recibido, aportándoles seguridad y confianza en sí mismas. Destacan de forma muy positiva la relación que se establece entre las madres y los/las profesionales responsables del taller.

"Iba nada más que para desahogo porque para mí Lola y Javier han sido mis pañuelos de lágrimas." GDY 2 I3-6

"Carmen la enfermera del taller de lactancia, me animó a ir al taller". GDPi 19-I

"María, la enfermera que me atendía en lactancia "venga insiste " y yo mientras no me digan que mi hijo peligra voy a seguir intentando y al final a la tercera semana ya el niño se enganchó" GDPI $5^{-1}$

También reconocen que los/as enfermeros/as responsables del grupo de apoyo tienen, por un lado, los conocimientos teóricos necesarios, la formación precisa para desarrollar sus habilidades y resolver sus dudas y, por otro lado, tienen la experiencia imprescindible para conseguir que el o la lactante aprenda a mamar, se agarre y se coloque bien al pecho.

"Las dudas que tienes te las resuelven, te ayudan" GDPI I3-5

"Es que no mamaba bien con [...] y sí que te ayudan mucho, de cómo te los tienes que poner, de muchos conceptos" GDP 2 5-15

"En el taller de lactancia te ayudaban, a mí por ejemplo me ayudaron a que se enganchara bien el pequeño y fenomenal" GDPI 9-I3

"Fui a Lola y me dijo: Vente, te vienes un día y te lo soluciono. Y así fue. Yo iba a la toma con ella, ella me daba masajes, me ponía paños, me dijo cómo hacerlo en casa. Y gracias a ella." GDY2 6-ıо

Refieren que los/las responsables de los talleres están muy implicados/as en la defensa de la lactancia natural y se muestran disponibles a sus demandas e incluso adaptan su horario para poder atenderlas. Esto tiene un valor añadido para ellas, porque sienten que la madre y la lactancia son muy importantes. 
"Incluso es que te atienden a otros horarios" GDYI I2-2

Los/as profesionales se implican para resolver cuanto antes las dudas de las mujeres en beneficio de la lactancia materna:

"porque sabes que lo que solucionas inmediatamente va a ser bueno a la larga, lo que dejas a una semana... ya viene con biberón. Es inmediato [el apoyo que necesitan]" $\mathrm{EP}_{2} 68^{\prime} 38^{\prime \prime}$

"Necesitan venir cuando surge la duda" $\mathrm{EP}_{2}$ 6I' 15 "

Y hacen hincapié en el esfuerzo que realiza el/la profesional hasta que se instaura la lactancia materna, en la confianza que trasmite a la madre en sus capacidades para lactar, dedicándole el tiempo necesario hasta que se siente segura:

"todo el tiempo que yo necesité estuvo conmigo, a ver si el niño se enganchaba y tal, y al final se enganchó" GDY 2 -I

"Estuvo conmigo, yo iba con mi hija [a la consulta]. Y ponía a la niña [a mamar] y me decía [la enfermera]: Tranquila, [...] no tienes que hacer nada [para amamantar] Y estuvo así, por lo menos...casi quince días conmigo" GDY2 8-7

"había hecho un sacrificio, que para mí no fue sacrificio, pero oye, que fue un trabajo; tanto mío como del Taller, [...] y me dedicaron mucho tiempo y mucho apoyo" GDYi 6-I

Otro aspecto que aflora en sus verbalizaciones sobre los/las responsables de los talleres, es la confianza que sienten en ellos/ellas como profesionales de Enfermeria, les consultan sus dudas y si ellos/ellas lo consideran oportuno derivan a su hijo/a al pediatra y esto parece dar mucha seguridad a las madres.

"Le miraban $[\ldots]$ e incluso $[\ldots]$ le pasaban al pediatra si hiciera falta " GDPi 9-8

Cabe por tanto creer que se establece una relación de especial confianza entre las mujeres asistentes y los/las profesionales responsables de los grupos. Aun así, algunas madres manifiestan que quien mejor las puede ayudar es otra madre que ha pasado por su misma experiencia.

"Una prima mía [...] me dijo: la teta tienes que metérsela entera en la boca [...] en el taller sí me decían, pero no llegaba, es que tiene que ser alguien que le haya dado el pecho y además recientemente [...] las enfermeras te ayudan mucho, pero algunas no han dado el pecho porque no han sido madres y otras son más mayores[...] el que acaba de dar te dice esto es así 
[se refiere al cuidado de las grietas] eso te lo dice alguien que lo ha pasado y que ha llorado y le ha dolido" GDPI I4-6 Y I5-I

Esto legitimaría a los grupos de ayuda a la lactancia materna que se basan en este método para fomentar la lactancia materna, los grupos denominados "madre a madre", como "La liga de la leche" o "La vía láctea".

Por todo lo analizado anteriormente, el taller de apoyo a la lactancia materna tendría dos vertientes: una sería el taller de formación y asesoramiento dirigido por un/a profesional experto/a en lactancia, donde se resuelven dudas, se asesora en la técnica de amamantar, se ponen vídeos, se dan charlas y la otra vertiente sería la de un grupo de autoayuda en el que las mujeres son las protagonistas, ellas se apoyan y asesoran según sus propias experiencias vividas en primera persona.

Los resultados de la investigación desvelan que los/las profesionales responsables de los talleres objeto de estudio son conscientes de estas dos dimensiones del taller y favorecen las relaciones de ayuda mutua entre las participantes más que entre el personal sanitario y las participantes (lo que convertiría el grupo de apoyo a la L.M. en un curso de formación); aspecto que como se desgranará es una de las expectativas frustradas: el no encontrar un curso formal sobre lactancia natural.

"Cada uno preguntaba sus cosas y yo esperando a que empezara aquello, ¿no? (Se ríe) yo: ¡Pero esto no empieza!” GDY 2 9-I8

En todos los grupos de apoyo a la lactancia es necesaria una persona experta que coordine el grupo, tanto si es un grupo de "madre a madre" como si es de "apoyo para madres" que es el caso de la investigación. Dicho coordinador/a o responsable debería ser consciente de la relación especial de confianza que establecen las madres con él/ella, pero siendo capaz de pasar a un segundo plano en un momento dado, para favorecer la comunicación entre las mujeres y dar la oportunidad de que aparezca ese grupo de autoayuda con efectos tan positivos para las madres.

\subsubsection{VALORACIÓN DE RECURSOS, ESTRUCTURA, ESPACIO Y PROPUESTAS DE MEJORA: "UNPOQUITO ANTES"}

Como ya es sabido, el taller de lactancia materna urbano y el de Fuensalida se desarrollan en un espacio del Centro de Salud y, en el caso del taller de Yepes en una sala del Centro Cultural. Las reuniones se realizan una vez a 
la semana y los/las responsables de los talleres y las madres disponen de una serie de material, mobiliario o impresos para realizar las actividades previstas ${ }^{13}$.

En las entrevistas grupales aparecen muy pocas citas con respecto a este tema. En el caso del grupo de apoyo de Benquerencia, sólo una madre, haciendo referencia a las causas para dejar de asistir, comenta que la sala donde se desarrollaba el taller era pequeña para el número de asistentes ${ }^{14}$.

"O hay mucha gente, también. Cuando hay mucha gente tienes que dejarle un poco más a la gente... más pequeñines.” GDP 2 8-19 y 20

En el taller de Yepes, las escasas opiniones sobre los recursos, estructura u organización se centran exclusivamente en el horario.

"Yo dejé de ir porque mi hija se despierta a lo mejor a las diez y cuarto o las diez y media [...]. Cuando quiero llegar allí digo:

Anda, si ya...ya ha terminado." GDY2 I8-2

"Yo lo planteé: ¿ No se puede poner un poquito más tarde? Es que las diez de la mañana es un poco pronto. $Y$ me dijeron: No, es que la gente no quiere venir más tarde." GDY2 2 19-8

También se encuentra alguna cita referida a la duración del taller:

"Era muy poco el tiempo que daban [se refiere al taller de lactancia]". GDY2 I8-I

El hecho de que las propuestas obedezcan a cuestiones particulares, junto con la escasez de citas, sugiere que en general, las madres están satisfechas con estos aspectos.

Respecto a la idea de promocionar o informar sobre los grupos de apoyo, sí se encuentran algunas citas que hacen referencia al hecho de proporcionar más información durante el embarazo, e incluso desarrollar alguna sesión durante este periodo.

"Cuando estás embarazada tienes mucho tiempo [...]. Pues entonces es cuando te tienen que dar la información: los DVD, los libros, las charlas, lo que haya: Entonces." GDYI $32-$ II

Incluso alguna mujer expone que se debería informar del taller de lactancia antes del parto.

13 Materiales previstos según la "Guía de lactancia materna" de la gerencia de Atención Primaria de Toledo.

14 Por este motivo desde el año 2011 se pasó a utilizar una sala más amplia. 
"Antes de dar a luz te tienen que hablar del Taller. Y hablar de los beneficios de la leche materna para que se vayan concienciando esas madres. Durante el embarazo." GDY2 20-9

"Nos las pusieron demasiado tarde las películas." GDY 2 IO-I

Sorprende que las mujeres primíparas que acuden a los talleres confiesen tener poca formación sobre lactancia materna antes de iniciarla, ya que este tema se introduce en los Cursos de Preparación al parto, de manera explícita. Además, en el medio rural, son los mismos profesionales que desarrollan el taller, quienes les hablan de la lactancia durante el embarazo.

Las posibles causas, que motivan este hecho, pueden ser debidas a que, durante el embarazo, especialmente en los últimos meses, las mujeres se centran en prepararse adecuadamente para el parto, por lo que el tema de la lactancia queda en segundo plano. Posteriormente, en el puerperio inmediato, la lactancia se inicia coincidiendo con múltiples cambios en la mujer, en un momento de estrés para la pareja y donde la madre no dispone de tiempo para informarse (por ejemplo, leer o ver vídeos). De esta forma, la lactancia materna suele iniciare con inseguridad, miedo a lo desconocido y con carencia de información teórica.

Incluso es posible llegar a comprender este hecho, si se examinan las representaciones sociales del parto que tiene la mujer, estas establecen dos tiempos claros: antes y después del parto, por lo que pretender que la mujer tenga en cuenta cuestiones posteriores al parto antes de haberlo pasado, resulta ilusorio.

En este sentido, aunque parezca paradójico, podría ser conveniente incorporar los temas relacionados con la promoción de la lactancia materna al inicio del embarazo (en los primeros meses) y no como suele hacerse al final del mismo (próxima al parto), así estaría lo suficientemente alejada de la inmediatez del parto y la mujer tendría tiempo para formarse. Además, es posible pensar que la lactancia materna debería tratase en los Cursos de Preparación al parto, de forma participativa y contando con madres que hayan lactado.

Una estrategia empleada en la zona básica de salud de Yepes, con escaso éxito, es invitar a las embarazadas a que asistan a los talleres. Sin embargo, la realidad es que ellas no suelen acudir, posiblemente porque se sienten "fuera de lugar" participando en talleres de lactancia antes de haber dado a luz. Y, por otro lado, se rompe la condición necesaria de actividad entendida como "grupo de autoayuda": desarrollarse entre iguales ya analizado en el apartado 4.I.2. Espacio de relación y autoayuda. 
“...por favor que se nos dé más apoyo, es que es tan importante... ese primer contacto..." GDF 68'29"

\subsubsection{MOMENTO DE ABANDONAR EL TALLER: “QUE ME PUSE ATRABAJAR"}

Dado que la asistencia al taller es libre sin un momento determinado para abandonarlo y puesto que las madres manifiestan estar muy satisfechas con él, parece muy interesante investigar los motivos que llevan a las mujeres a abandonar la asistencia al mismo. Aunque las causas para abandonar el taller pueden ser múltiples, el motivo que más se repite es la reincorporación de la mujer al trabajo.

"Cuando empecé a trabajar porque ya había terminado la baja maternal y ya no tenía tiempo." GDY2 I7-I2

Efectivamente, la mayoría de las mujeres entrevistadas refieren haber dejado de asistir al grupo de apoyo cuando se les acabó el descanso por maternidad, cuando se reincorporaron al trabajo,

"Pues yo lo decidí, vamos, no decidí, sino que eso, que me puse a trabajar" GDYI I3-I

"Iba todos, todos los días, hasta que me puse a trabajar. Todas las semanas estuve yendo. Durante los cuatro primeros meses" GDP2 2 -I

En otros casos se deja de asistir al taller cuando el biorritmo del bebé es incompatible con el horario en el que se desarrolla el taller.

"Yo dejé de ir porque mi hija se despierta a lo mejor a las diez y cuarto o las diez y media. Y ahora tengo que darle en mi casa el desayuno. Cuando quiero llegar allí digo: Anda, si ya...ya ha terminado." GDY2 I8-2

En el caso del Taller urbano, alguna madre expone que la falta de espacio puede ser motivo para abandonar su asistencia. Parece que el espacio era pequeño para el número de madres asistentes y pensó que las mujeres más veteranas están en la obligación de dejar espacio a las madres con lactantes más pequeños, reconociendo que quizás lo necesitan más ellas, ya que, al ser su hijo o hija más mayor, tiene menos dificultades para lactar.

"O hay mucha gente, también. Cuando hay mucha gente tienes que dejarle un poco más a la gente... Más pequeñines. Tú ya bueno, pues vas...” $\mathrm{GDP}_{2}$ 8-19 y 20 
Algunas madres manifiestan que les cuesta dejar de asistir y reconocen que les da pena abandonarlo. Llega hasta tal punto su implicación que, aunque no den de mamar a su hijo/a siguen yendo, sienten nostalgia y esporádicamente se acercan para saludar.

"Yo, de hecho, luego he estado un año y pico yendo ya sin dar el pecho [...] Porque a mí me da mucha pena porque yo vengo con mi niño, y yo qué sé. Dice: Sí, sí, porque seguimos dando apoyo, aunque tú no puedas darle el pecho" GDYI I2-7

"me puse a trabajar, un trabajo de cuatro meses que ya se ha terminado, desgraciadamente. Pero bueno, tuve que meter al niño en la guardería. Porque como he comentado no tengo aquí familia ni nada, lo metí en la guardería. Entonces, claro, ya...aunque he ido algún día, porque he trabajado aquí en Yepes, algún miércoles he pasado a saludar, pero ya sin el niño." GDY I I2-ıo

En la investigación se descubre que existen razones objetivas para abandonar el taller: horarios, trabajo, pero también pueden existir razones subjetivas para dejar de asistir: el momento de abandonar un grupo de autoayuda, como es éste, llegaría cuando ya no se necesita la ayuda o cuando se percibe que ya no se es útil al grupo, bien porque sus iguales y amigas no van, o porque al no dar el pecho la madre ha cambiado su rol y ya no sirve de referente para otras mujeres, además la madre suele vivir el destete como algo complicado lo que podría justificar los sentimientos de "pena" al abandonar el taller. Para las mujeres que no trabajan el momento de abandonar el grupo, puede ser difícil, llegando a sentir un vacío si no tienen otras actividades con qué sustituirlo.

"El destete $[. .$.$] es algo traumático para ti y para el niño" GDF o6 49"$

En este punto se pueden proponer algunas recomendaciones a los/las responsables de los talleres para que el abandono de las participantes sea menos traumático:

Llegado el momento de abandonar el grupo de apoyo se podría hacer algo especial como despedida: un diploma de asistencia reconociendo el aprovechamiento por parte de la madre y el niño o la niña.

Para algunas mujeres que llevan mucho tiempo asistiendo al taller se podría crear la figura de "facilitadora" para difundir el taller entre las mujeres de la zona. En algunos Centros de Salud las antiguas participantes han formado asociaciones para la defensa de la lactancia materna, una forma de sentirse útiles y mantener la relación entre ellas. Se les podría proponer unirse a dichas asociaciones o formar una propia. 
Podría organizarse alguna actividad, como en la Semana de la Lactancia que se celebra en el Área Sanitaria de Toledo; en esta actividad también podrían participar las mujeres que han asistido al taller con anterioridad.

\subsubsection{EXPECTATIVAS NO CUMPLIDAS: "Y YO ESPERANDO $\boldsymbol{A}$ QUE EMPEZARA AQUELLO"}

Cabe mencionar que las citas encontradas sobre expectativas no cumplidas aparecen exclusivamente en el taller de Yepes; aunque, como se ve más adelante, la satisfacción es generalizada entre las mujeres del estudio de investigación. Sin embargo, algunas mujeres se sintieron decepcionadas los primeros días que acudieron a dicho taller rural, pero tan sólo al inicio de la asistencia hasta que comprendieron que la dinámica de los grupos de apoyo es diferente a la esperada. Estas mujeres buscaban algo como un curso, en donde cada sesión aportase conocimientos teóricos con un programa previamente establecido.

"Hoy toca este tema, ¿no?, Y yo me siento, y cada una hablaba de lo suyo, de su rollo, de su problema y tal, empieza la reunión. Y así una hora y ya: Vámonos." GDY2 9-I2

Muchas de las mujeres que asisten por primera vez al taller, lo hacen sin saber qué se van a encontrar o en qué consiste. Algunas de ellas refieren que esperaban una formación teórica, más académica y siguiendo un guion o programa preestablecido.

"Cada una hablaba de lo suyo, de su rollo, de su problema [...]. Ese es el fallo enorme que tiene" [se refiere al taller de lactancia] GDY2 9-1o

$\mathrm{Al}$ acudir al taller se encuentran con un espacio que funciona como un grupo de autoayuda, donde cada mujer puede expresar sus preocupaciones $\mathrm{y}$ sus emociones, puede relacionarse entre iguales y hablar de sus problemas. Esto en ocasiones no les parece suficiente, ya que esperan que se impartan conocimientos teóricos y se les forme en lactancia materna.

"Porque supuestamente el taller de la lactancia es eso. Para que te digan: Pues mira, hay que coger a la niña, pues mejor toma esto [...], más contenidos." GDY 2 10-7Y8

Las madres reconocen tener poca formación en este tema por varios motivos: durante el embarazo sus esfuerzos se centran en formarse para el parto; cuando nace su hijo/a e inician la lactancia están demasiado ocupadas y no 
tiene tiempo para leer, ver vídeos, etc. y cuando se da información teórica parece que ésta llega tarde.

"Nos las pusieron demasiado tarde las películas." GDY2 IO-I

“iAhora me ponen el video!" GDY2 ro-8

Muchas mujeres asisten a los grupos de educación para la salud llamados de educación maternal, (antes denominados de preparación al parto). Éstos, generalmente son impartidos por matronas/es y suelen estar estructurados y organizados como un curso, en ocasiones, esta es la única referencia que tienen las mujeres cuando acuden al taller de apoyo a la lactancia materna y seguramente esperan encontrar algo parecido.

"Cada uno preguntaba sus cosas y yo esperando a que empezara aquello, ¿no? (Se ríe) yo: ¡Pero esto no empieza!” GDY2 9-18

\subsection{LA LACTANCIA MATERNA}

En este capítulo se aborda el segundo objetivo del estudio de investigación, con él se pretende conocer: las representaciones sobre la lactancia materna que tienen las mujeres que acuden a los talleres, sus opiniones, sus actitudes, sus creencias y sus conocimientos sobre la lactancia materna.

Para ahondar en estas cuestiones se recurre al concepto de Representaciones Sociales que desde la psicología social introduce Moscovici. Para este autor son "una modalidad particular de conocimiento cuya función es la elaboración de los comportamientos y la comunicación entre los individuos". Las representaciones "un corpus organizado de conocimientos y una de las actividades psíquicas gracias a las cuales los hombres hacen inteligible la realidad física y social, se integran en un grupo o en una relación cotidiana de intercambios [...] son sistemas de valores, nociones y prácticas que proporcionan a los individuos los medios para orientarse en el contexto social y material, para dominarlo" (Moscovici, I986, p. 79). Según Jodelet, las representaciones sociales siempre representan un objeto y tiene por tanto el carácter de "imagen" y "la propiedad de poder intercambiar lo sensible y la idea, la percepción y el concepto” desde un carácter simbólico (Moscovici, I986, p. 478) En términos de contenido las Representaciones están integradas por otras formaciones subjetivas como son opiniones, actitudes, creencias, informaciones y conocimientos (Pérez, 1999). 
Estas representaciones sociales, en la vida cotidiana se articulan entre sí y cubren toda la realidad y la experiencia a la que se enfrentan los sujetos, transformándolas en asuntos sociales y psicológicos (Moscovici, 1986, pp.708-709).

Las representaciones aparecen como formas de pensamiento natural informal, no científico, que en el interior de los grupos humanos tiene la utilidad práctica de guiar la acción social de los sujetos. En este sentido se trata, por así decir: ideas para la acción.

Para Berger y Luckman, las representaciones sociales se asumen por los procesos de socialización primaria, sobre todo en la infancia. Para estos autores, la realidad de la vida cotidiana aparece como "una construcción intersubjetiva", que mediante procesos de interacción y comunicación se comparten y se experimentan con los demás como "un mundo dado, naturalizado", "común a muchos hombres". (Berger \& Luckmann, 2003, p. 39). Por otro lado, la socialización secundaria, actúa cuando las personas nos introducimos en "submundos", que son realidades parciales frecuentemente formales o institucionalizadas, y que contrastan con "el mundo de base" adquirido en la socialización primaria. Es interesante señalar que, si mediante la socialización se asumen las representaciones sociales, éstas se desempeñan en la práctica cuando la persona tiene que "ejercer" los "roles sociales" con los que estas representaciones se relacionan (Berger \& Luckmann, 2003, p. 76).

En el estudio, también se analizan las opiniones, actitudes, creencias, informaciones y conocimientos que determinan las prácticas de las mujeres, entendiendo que el hecho de la lactancia (como el de la maternidad) descansa en un conjunto de representaciones sociales compartidas en gran medida en nuestras sociedades, que se asumen como naturales en la socialización primaria y que se ponen en práctica en el desempeño concreto del rol de madre. Siguiendo este esquema, los talleres de lactancia materna, en cierta medida, operan mediante procesos de socialización secundaria, matizando o cuestionando estas "representaciones base" sobre la lactancia, con el fin de favorecerla.

Tomando este marco de referencia para el análisis, esta segunda parte del trabajo estudia las representaciones sobre el hecho de lactar organizándolo en cuatro grandes capítulos:

2.I.- LA LACTANCIA MATERNA, centrada en la práctica del amamantamiento y la representación social de la leche materna.

2.2- LA ESFERA PRIVADA, analiza la lactancia materna en el ámbito psicosocial inmediato: familia y pareja y en el ámbito emocional y relacional. 


\section{3.- EL PAPEL DE LOS Y LAS PROFESIONALES DE LA}

SALUD, examina la visión que tienen las madres del personal sanitario con relación a la lactancia.

2.4.- LA ESFERA SOCIO CULTURAL, estudia las verbalizaciones entorno a los problemas sociales y culturales de la lactancia.

A partir de los discursos de las mujeres, se descubre: cómo conciben el hecho mismo de dar el pecho, las vivencias que experimentan al hacerlo, su relación con el sistema sanitario durante el amamantamiento y los discursos que reflejan sus problemas en la esfera social.

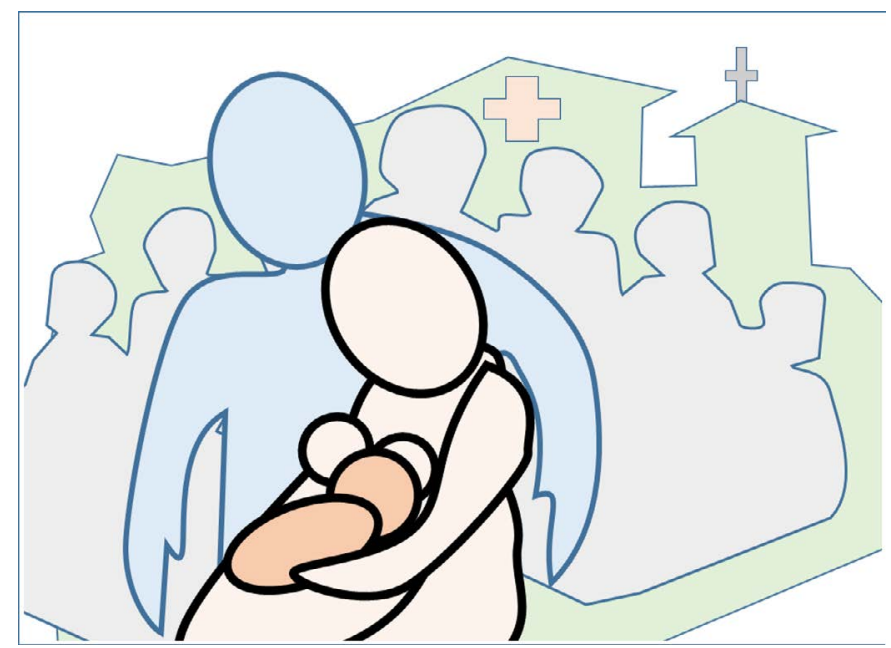

Ilustración 4. Esferas de la L.M.

\subsubsection{LA PRÁCTICA DE LA LACTANCIA MATERNA: "EL TIEMPO MÁS FELIZ"}

En este capítulo se analizan las opiniones sobre la lactancia materna desde el punto de vista de la esfera personal de la mujer, como una actividad que deben realizar la madre y el niño/a básicamente y en la que ellos son los protagonistas, aunque existen otros actores secundarios/as: sanitarios/as, familia, pareja, comunidad en la que viven ${ }^{15}$; y muchas circunstancias que influyen sobre todo en el inicio y el mantenimiento de dicha actividad.

En concreto se analizan los siguientes aspectos:

15 Analizado en los apartados referidos a la esfera psicosocial, el papel de los/las profesionales y la esfera sociocultural. 
La visión que las madres participantes en el estudio tienen sobre la leche como producto, sus características de calidad y cantidad, los beneficios sobre el bebé y cómo ha cambiado el concepto sobre la leche materna y el hecho de amamantar en los últimos años.

"Todo positivo, la verdad es que mi niña no coge ninguna gripe, no coge nada, hasta el día de hoy está muy sana." GDPi 2-ıo

"Yo doy fe que un niño con L.M. se pone mucho menos malo" GDF2'r7"

Sus opiniones sobre: la práctica y la técnica en sí de amamantar, el/la lactante y su sabiduría innata para mamar y cómo en algunas ocasiones se necesita aprendizaje y en otras no.

"Parece como que hubieras dado toda la vida de mamar a [...]. Como si hubieras...y era la primera". GDY2 23-I2

A través de sus discursos se estudian los condicionantes para iniciar la lactancia: la ayuda prestada desde el sistema sanitario, las complicaciones en el parto, etc.

"Depende de cómo vengas del parto, [...] cuando vienes con los cambios hormonales, muchísimos puntos, dolor [...] tú ya estás agotada, porque no duermes." GDY2 3-זо

Además, se analizan los factores que influyen para mantener la lactancia y se examinan sus beneficios, comodidad, vínculo afectivo, etc. siempre desde el punto de vista de las mujeres.

"es incompatible porque te aconsejan seis meses de lactancia y luego te dan cuatro de baja. Y digo: No me salen las cuentas." GDY2 23-I

"Yo creo que es cómodo, también. [...] Porque puedes ir a cualquier sitio y no necesitas llevar nada." GDY I I-4Y6

"creo que se crea como un vínculo [...] las madres que han dado de mamar mucho tiempo a su hijo." GDP2 4-7

Y por último se averiguan los inconvenientes para amamantar, siendo el cambio de estilo de vida, el citado con más frecuencia.

"A mí me encantaba el picante y lo tuve que dejar." GDY2 2I-II

Muchas de las opiniones aportadas por las mujeres coinciden con lo recogido en estudios anteriores sobre la lactancia natural, pero en algunas ocasio- 
nes, difieren y aportan otras ideas u opiniones, que ayudarán a enriquecer el conocimiento global sobre el tema.

Las cinco entrevistas grupales proporcionan muchas citas sobre este tema, no se observan diferencias con respecto a las variables marcadas por el estudio, tan solo en el subcapítulo 4.2.I.3 Condicionantes para el inicio de la lactancia materna: se encuentran citas que relacionan a la madre primeriza con mayores dificultades para iniciar la lactancia. Y en el subcapítulo 4.2.I.4 Beneficios de la lactancia materna donde aparece alguna cita sobre el vínculo emocional relacionado con multípara, como se analizará.

\section{La leche materna: "lo mejor del mundo"}

Aún hoy en día, se desconoce la composición exacta de la leche materna, es un producto biológico tan complejo, que la leche de cada mujer tiene su propia composición. En dicha composición influyen variables como: el clima, la región del mundo donde viva la mujer, el día o la noche; además cambia a lo largo de la toma, en cada mamada y a lo largo de la lactancia adaptándose a las necesidades del/la bebé en cada etapa de su desarrollo. En definitiva, la leche de la madre "no se puede copiar" o fabricar artificialmente. Lo ideal para el ser humano es la alimentación al pecho hasta los seis meses de edad de forma exclusiva y se aconseja mantenerla, por lo menos, hasta los dos años de edad, junto con otros alimentos.

Las mujeres del estudio son conscientes de ello y así lo expresan.

"Vi la compensación, que es lo que estáis hablando que es una cosa tan... muy bonita y un orgullo muy grande para mí el poder alimentar a mi hijo con lo mejor del mundo" GDY2 I-8

Muchas mujeres y también profesionales reconocen que la leche materna es "especial", entre otras cosas, porque ayuda a sus hijos e hijas a estar sanos/ as y no enfermar en comparación con las "leches de fórmula".

"Y sano. Porque le aportas las...las defensas que una leche de fórmula no le puede dar." GDYi i-8

"compañeras del trabajo que sus niños no han tomado el pecho se ponen malos y los recuperan peor." GDPI I-4

"Los seis primeros meses de vida mi hijo no tuvo nada, pero es que ni un moco $[\ldots]$ le veo un niño sano, fuerte, vital $[\ldots]$ yo estoy segura que eso es la lactancia $[\ldots]$ es beneficiosa por todo." GDP $5^{-1}$ 
“Tiene tres años y medio, y habrá ido a la pediatra...como tú dices, una vez. [...] Es una niña sanísima [...]. Y yo creo que algo tiene que ver la lactancia." GDP2 $3^{-2}$

“A los grandes prematuros es que tiene que ser leche materna” EPr 9' 49 "[en prematuros] algunas no lo consiguen [...] entonces se les propone, si hay leche de donante, si la mamá quiere, dar esa leche de donante" EPI 9'o9"

Además, al igual que es una fuente de salud y evita patologías en el niño o niña, también les parece que puede ayudarle a curarse, cuando ha sufrido alguna infección.

"Ha estado malito, [...] durante el virus no quería nada más que el pecho. Nada. Ni biberón ni nada [...] sólo quería pecho.” GDY2 23-I

"Fíjate cómo él sabe que esto le está ayudando a curarse [...] dentro de su intuición cómo sabe que es lo mejor para él, para curarse" GDY2 23-II

Es interesante reflejar que, según sus opiniones, del mismo modo que la madre pasa a su hijo/a por la leche las defensas para ayudarle a curarse, también puede pasarle sustancias perjudiciales cuando la madre las ingiere o tiene algún problema, aunque sea de origen emocional, llegando incluso a enfermarse el/la bebé.

"Y tomarte una cerveza no es que te... vaya a salir tu hija...alcohólica" GDY2 2I-6

"con cinco meses tuvo una neumonía, pero fue por la leche que yo tenía, porque mi marido se fue de casa [...] por eso se puso enfermo." GDPI $5^{-1}$

No todas las madres están seguras del efecto beneficioso de la lactancia, no relacionan la leche materna con que la criatura, se ponga menos enferma. Y si existe ese beneficio, les parece que éste se acaba cuando se deja la lactancia.

"Ha tenido de todo, estomatitis vírica, neumonía y fueron 15 meses de pecho, $[\ldots]$ sí que es verdad que mientras le di el pecho no cogió nada, pero no lo relaciono." GDPi $3^{-1}$

Algunas madres no confían en las leches artificiales y denominan a la leche de fórmula "eso de farmacia", denotando desprecio o asco al referirse a las leches de vaca modificadas para adaptarlas al consumo de los/las bebés. Algunos familiares incluso, insisten a las mujeres para que den el pecho al hijo/a, pues la leche de fórmula no les parece un alimento válido para el niño/a. 
"Yo he tenido muy claro que no le iba a dar nunca "de eso de farmacia"." $\mathrm{GDP}_{2}$ I3-IO

"Dale la teta, teta, teta. Las leches [artificiales] no valen para nada, dice, y tienes que darle el pecho." GDP2 II-I

Las mujeres, participantes en la investigación, reconocen que existen muchas ideas falsas sobre la leche materna y que estas han calado en nuestra sociedad. La más extendida es que los niños y las niñas que se alimentan a pecho no engordan lo suficiente, al contrario que los/as alimentados/as con leche de fórmula, en cuya publicidad siempre aparecen niños/as rollizos/as. Otra idea falsa puede ser que un pecho de tamaño pequeño no puede producir toda la leche que el niño/a necesita y la última idea es que puede existir leche materna "de mala calidad".

"Cuando veían que mi niño sí engordaba, se ponía hermoso y se ponía bien y enganchó, me lo dijeron: anda yo pensé... ¡hay madre mía! no pensábamos que ibas a poder darle leche y menos que se pusiera tan hermoso ${ }^{\mathrm{I}}$. Dije anda, mira." GDPi io-9

"Aunque se tenga poco pecho, pero a lo mejor la leche es de primera calidad." GDY2 I2-I

"No creo que sea eso, a lo mejor no mama lo suficiente, toda la leche vale, puede ser que no mame lo suficiente [...]; si duerme mucho y son lactantes, tienen el estómago muy pequeño, comen muy poquito y enseguida se vacía y tiene que volver a mamar" GDPi 9-I2

En la actualidad, no solo el embarazo y el parto están controlados por el sistema sanitario, la lactancia natural también está comenzando a sufrir ese proceso. Por ejemplo, algunas mujeres opinan que es necesario analizar la leche de la madre para dar confianza a la mujer respecto a su capacidad para alimentar correctamente a su hijo/a. Sin embargo, no todas las mujeres están de acuerdo con esta afirmación.

"El bebé si no engorda es que no le estás dando suficiente alimento, entonces es que tu leche, lo que dicen, te la tienen que analizar para saber si es buena o mala." GDPi 9-II

Algunas madres reconocen que tenían idealizada la lactancia natural antes de dar a luz y en algunos casos no se consigue producir toda la leche que el niño o la niña necesita, con lo que la madre se siente decepcionada:

16 En Castilla-La Mancha “hermoso", cuando se refiere a persona, es sinónimo de rollizo. 
"yo, la verdad es que tenía como un mito de lo de la lactancia. De que iba a ir todo muy bien y que... [...] no sé si por la naturaleza mía o por lo que sea, no llegué nunca a producir todo lo que ella deseaba [...] Mi niña casi siempre se quedaba llorando en la toma." GDP 2 I-3

Los discursos de las mujeres parecen reflejar la evolución que el concepto de "leche materna" ha tenido en el último siglo. Hasta mediados del siglo XX la leche materna era la única opción para alimentar a los niños y niñas pequeños, era lo natural, cabe destacar que en aquellos momentos el personal sanitario apenas intervenía en algo que no se considerase objeto de las ciencias de la salud.

Es a partir de la segunda mitad del siglo XX cuando se produce el auge de las leches artificiales. Coincide históricamente con un momento en el que lo artificial adquiere mayor prestigio. Así, la leche artificial aparece como "lo moderno" y lo natural pasa a considerarse "antiguo". Las mujeres, que quisieran parecer "modernas", debían decantarse por la lactancia con leche de fórmula; además hacer frente al gasto que representaba el adquirir leche de fórmula, era una muestra de status social elevado, lo que reforzaba seguir alimentando al hijo/a con leche artificial. En este momento,los/las profesionales sanitarios/as solían recomendarlas, confiaban en ellas, conocían su composición, y las consideraban avaladas por la industria farmacéutica y la ciencia del momento. Además, para el/la sanitario/a, en cierto modo aparecía como un "medicamento" susceptible de ser recetado y pautado: un biberón cada tres horas. La lactancia materna también se empezó a pautar: diez minutos de cada pecho cada tres horas, con lo cual la mayoría de las lactancias naturales fracasaban y terminaban siendo lactancias artificiales.

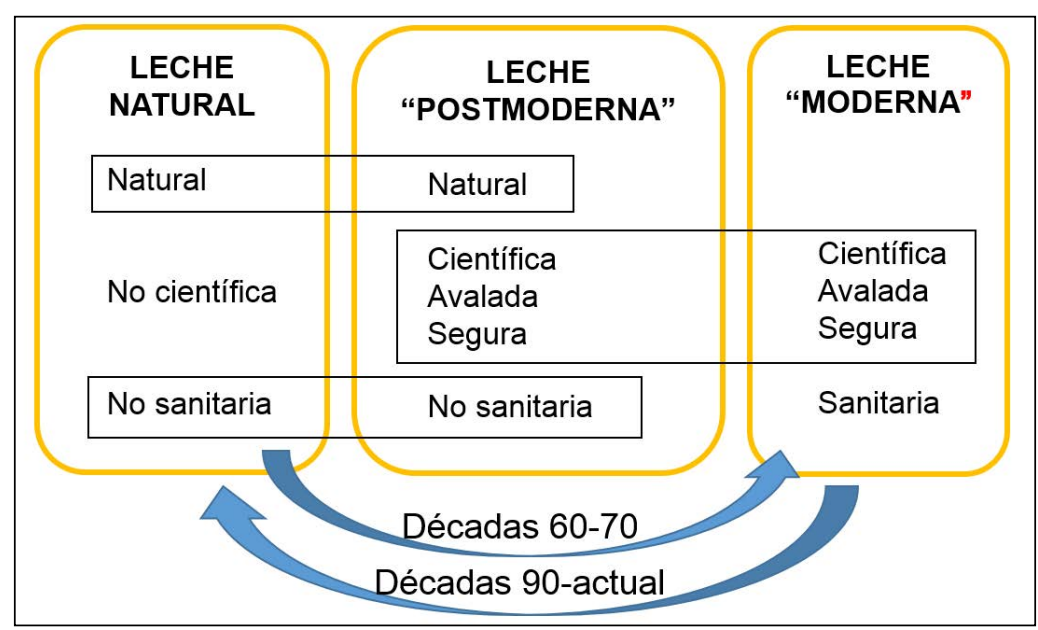

Ilustración 5. Cambios en la Visión de la lactancia. 
Sin embargo, en las últimas décadas surge un movimiento social que reivindica con carácter general "la vuelta a lo natural". En esta etapa se va configurando una representación social de la leche materna más compleja que discute lo artificial y científico de la leche de fórmula, entendiendo que puede ser perjudicial para la salud, ser incompleta, fuente de alergias, enfermedades y contaminación, dañina para el medio ambiente, etc. Esta visión crítica, lo que se podría denominar "posmoderna", favorece la lactancia materna.

Estas tres perspectivas, como hemos visto en las mujeres de nuestro estudio, siguen estando presentes en los discursos junto a ideas falsas o míticas.

Aplicando estas reflexiones, los/las sanitarios/as deberían ayudar a la madre lactante no sólo porque es "lo que se lleva" sino basándose en la evidencia científica. El hecho de que los/las profesionales recomienden la lactancia materna ahora, dota a la leche materna de un aval del que carecía en décadas anteriores, lo que la hace aparecer prestigiada frente a la artificial (en sentido contrario a lo que ocurrió con la artificial y la natural en su momento). Así, desde los talleres y aprovechando el prestigio de los/las profesionales responsables de los mismos, ${ }^{17}$ conviene avalar esta creencia en la leche materna, apoyándose en la evidencia científica que es abundante y demuestra las ventajas frente a la leche de fórmula.

\section{Técnica de lactancia materna y el lactante: "Si no te ayuda nadie, tú no sabes"}

Aunque la lactancia materna es algo natural, para la madre no es una conducta instintiva o refleja, a veces requiere de un aprendizaje, que también podría ser necesario para el/la bebé si el parto no ha sido natural o presenta alguna patología. Sin duda, la experiencia mejora la lactancia, pero también ayuda a la práctica del amamantamiento, lo que podríamos denominar "la cultura de la lactancia materna"18: el hecho de haber visto amamantar a otras mujeres o la experiencia de haber vivido durante su infancia o juventud la lactancia de los/as hermanos/as u otros niños/as. Es decir, una representación social sobre la lactancia materna como lo más natural y adecuado para la crianza de los/as hijos/as.

En una sociedad como la nuestra donde se ha perdido bastante esta "cultura de la lactancia”, parece que la formación de las mujeres durante el embarazo y los primeros días después del parto, lo que ya se ha denominado "socialización secundaria" sería imprescindible.

17 Estudiado en el capítulo 1 La experiencia del taller.

18 http://elpais.com/diario/2005/05/17/salud/1116280803_850215.html. Recuperar la cultura de la lactancia. consultado en google 29-02-2016 
"Creo que a todas nos preparan para el parto, para el embarazo, pero para la lactancia nadie te prepara; todo el mundo te dice que es una cosa natural y si no sucede de forma natural es que tu lo estás haciendo mal, que el error es tuyo." GDPi 4-7

El neonato nace con una predisposición innata para mamar, si no se le separa de la madre, ni se han usado anestésicos que puedan haber pasado al torrente sanguíneo del/la recién nacido/a, este/a mamará en las dos primeras horas de vida en las que está más reactivo/a, se agarrará al pezón con buena postura y se iniciará una lactancia natural sin grandes dificultades. Después de esas primeras horas el/la bebé entra en una etapa de menor actividad y puede estar varias horas dormido/a sin mostrar interés en mamar, por lo que es muy importante durante esos primeros momentos, interferir lo menos posible, dejando a la madre y al hijo/a tranquilos, para favorecer así el inicio de la lactancia natural.

"Él [Señala al niño] se enganchó muy bien, desde que nació.Y su hermana igual." GDP2 $23-5$

"Ese momento justo es el más importante [se refiere al nacimiento], porque es que es cuando los niños más desesperados están y se cogen al pecho". GDP2, 9-9

Si antes de este primer contacto con el pecho de la madre, el/la bebé es separado/a de ella, por cualquier motivo: por estar bajo los efectos de algún anestésico, presencia de alguna patología que requiera cuidados inmediatos tanto de la criatura como de la madre, porque así lo establezcan los protocolos de actuación en el paritorio, etc.; muchos niños y niñas tendrán dificultades para establecer la lactancia natural, como demuestran estudios al respecto (Righard \& Alade, I990).

Por todo lo comentado anteriormente y teniendo en cuenta los protocolos de actuación en los paritorios de nuestro país, que hasta hace relativamente poco tiempo separaban a la madre y al hijo/a nada más nacer, lo más habitual era encontrar dificultades para iniciar el amamantamiento. Sólo la experiencia, implicación y tenacidad de la madre podría hacer que un/a recién nacido/a mamara correctamente desde el primer momento. En las mismas circunstancias, las madres primerizas tendrían más dificultades.

"Yo al principio lo que pasaba es que no sabía. No sabía engancharse y me...es que me dolía, me daba coraje." GDY 2 3-9

Todos estos problemas se pueden solventar a través de profesionales sanitarios/as expertos/as en lactancia o familiares con experiencia en la materia que 
ayuden a la madre a colocarse bien, para que el niño/a se agarre correctamente al pecho, no provoque grietas en el pezón y así no sienta dolor en las primeras tomas.

"Al final quien me enseño en realidad fue una prima mía." GDPr 6-4

"A mí sí me ayudaron y me ponían al niño. Me le enganchaban ellas, si no, no." GDY2 7-3

"Me ayudaron mucho a coger las posturas, las posiciones porque ella no...no chupaba directamente, chupa con pezonera. Y para que no cogiese aire [...], la forma de expulsar los gases [...]. Y ellos me ayudaron en eso." GDYI 4-I

Pasado un tiempo, las madres descubren posturas, prácticas como el "colecho $^{\text {I9", }}$ encuentran utensilios (cojín de lactancia, sacaleches, etc.) y adquieren experiencia, lo que les facilitará dar el pecho y a la vez descansar por las noches.

"Yo le que hice... un cojín de lactancia [...] lo metía entre medias, [...] le cambiaba antes de comer porque si le cambiaba después entonces se desvela [...], le enganchaba al pecho y me quedaba dormida por el agotamiento, como estaba metido en un nidito, aunque me quedara dormida nunca se me caía, entonces aprendí así" GDPI 8-I

"Le acostaba con nosotros, ponía el cojín de lactancia entre mi marido y el niño $[\ldots]$ descansamos muchísimo." GDPi 7-4

"Yo le duermo, le pongo en la cuna y cuando se despierta a la hora que sea, ya conmigo a la cama y esto me lo critica hasta la pediatra, pero me da lo mismo, voy a hacer lo que me dé la gana." GDPi 8-5

En el taller de lactancia como se analizó en el capítulo anterior, la madre es asesorada por los/las profesionales responsables y por las otras madres participantes.

"Porque las enfermeras te ayudan mucho, pero algunas no han dado el pecho porque no han sido madres y otras son más mayores" GDPI I4-5

"Tiene que haber madres por allí que te digan: Mira, pues sí que es así,y ten paciencia y no sé qué" GDY2 5-3

Algunas madres confieren al lactante una cierta sabiduría, expresan que el/ la bebé sabe lo que quiere y se lo comunica a la madre a través de un lenguaje no verbal.

19 Compartir el lecho durante la noche y dar el pecho en él. 
"Es una sensación que si no la ves no lo puedes explicar y la gente: mírale, que a gusto se ha quedado, y diciendo él: esto es lo que yo quiero" GDPI I3-2

También le atribuyen el conocimiento suficiente para saber cuándo el pecho es más beneficioso para su salud, ya que lo busca como remedio cuando está enfermo/a, eludiendo otros alimentos que no tienen poder curativo.

"Durante el virus no quería nada más que el pecho. Nada. [...] Fíjate cómo él sabe que esto le está ayudando a curarse [...]. Digo: dentro de su intuición cómo sabe que es lo mejor para él, para curarse" GDY 2 8-3

Además, le creen capaz de manifestar su enfado al sentirse abandonado/a por la madre si esta se ausenta durante unos días, rechazando el pecho cuando la madre se lo ofrece de nuevo.

"Quédate con el niño este fin de semana, y no voy a verle ni nada. Y desde ese fin de semana se acabó ya [se refiere a la lactancia]. Cuando volví yo luego a recogerle él ya no me volvió a pedir el pecho más..." GDPI 4-II

Para algunas mujeres es el niño/a quién decide la persona que quiere que lo alimente, no sólo la lactancia materna sino también los biberones u otros alimentos cuando es más mayor; aunque el padre quiera implicarse en la alimentación de su hijo/a, éste puede no aceptarlo.

"Yo, mi hijo se acostumbró a que yo le daba el pecho y no quería que mi marido le diera ni el biberón, ni quiere aún que le dé de comer. $\mathrm{O}$ sea que eso de que el padre se implique más... si el niño quiere." GDY 20-8

Las mujeres que han vivido la lactancia natural en su proceso de socialización primaria y además tienen un parto natural no deberían tener problemas en el inicio de la misma, sólo habría que dejar a la madre y a la criatura juntas y tranquilas, sin interferir.

"Unas me decían: A demanda. Otras me decían: No, no,le tienes que poner veinte minutos en cada pecho. No, no, no, cinco minutos porque es muy chiquitito. Digo: bueno, a ver, ¿en qué quedamos?” GDY I 7-4

Por el contrario, para aquellas mujeres que puedan tener dificultades el apoyo del personal sanitario o algún familiar con experiencia será fundamental y deberá proporcionarse en los primeros momentos, si no la lactancia puede verse bastante comprometida. 
"todo el tiempo que yo necesité estuvo conmigo, a ver si el niño se enganchaba y tal, y al final se enganchó" GDY i 2-I

"Para darle el pecho y darle desde el principio tienes que tener mucho apoyo" GDF 29'12"

\section{Condicionantes para el inicio y el mantenimiento de la lactancia materna:} "Mucha paciencia y tenerlo muy claro"

En la introducción ya se comentó que el inicio de la lactancia materna, así como su mantenimiento en el tiempo, no solo dependen de la decisión de la madre, si no que hay muchos factores que condicionan tanto el inicio como la duración de la misma.

Durante mucho tiempo se pensó que, a través de la educación perinatal, incidiendo en las ventajas de la lactancia materna, se conseguirían altas tasas de inicio y una prolongada duración de la misma. A pesar de ello, muchas mujeres que querían amamantar a sus hijos/as no lo han conseguido.

Existen muchos estudios que analizan los factores condicionantes de la lactancia materna (Righard \& Alade, I990).

Aun así, se han recogido las opiniones de las madres y de las profesionales participantes en el estudio, sobre las circunstancias que a ellas les parece que condicionan tanto el inicio como el abandono de la lactancia natural. En primer lugar, se repasan los factores que influyen en el inicio de la lactancia y a continuación se determinan los que influyen en el mantenimiento de la misma.

\section{Condicionantes para el inicio de la lactancia materna}

Muchas mujeres consideran motivador para iniciar la lactancia el hecho de conocer sus beneficios. Incluso según ellas, los/as profesionales de la salud deberían insistir en esos beneficios para convencer a las madres que no se hayan planteado lactar a sus hijos/as.

"Muchas madres no le dan [lactancia materna] porque no piensan en el beneficio [de lactar] [...]Y creo que los profesionales, los ATS, son los que tienen que inculcárselo a esas madres" GDY2 2-4

Ellas mismas reconocen que no se han preparado lo suficiente para la lactancia materna, les faltan conocimientos, no tienen experiencia y como se analizó con anterioridad muchas mujeres carecen de "cultura en la lactancia materna”. En la actualidad, muchas mujeres no han visto dar de mamar nunca a nadie; el hecho de haber vivido de niñas la lactancia materna y la relación 
tan especial que se establece entre la madre y su hijo/a influye favorablemente en el inicio de la lactancia natural cuando estas niñas se convierten en madres. Es decir, si la lactancia natural formó parte de su proceso de socialización primaria, sobre todo en su infancia, estas mujeres reproducen en su papel de madres la lactancia materna sin grandes dificultades. $Y$ al revés, si la representación social sobre la crianza de los/as hijos/as es la lactancia artificial, dar el pecho será un gran reto. (Sordini, 2oro)

"Yo ya sabía que a mí me habían criado a pecho, a mi otro hermano igual, pero claro, el verla a ella dar de mamar no es lo mismo que, que diga: Yo a ti te he dado de mamar y eso. Pero, el vínculo que yo vi, pues eso me hizo mucho decir: Yo, yo, yo [quiero] dar de mamar." GDYI 29-І2

Para amamantar al hijo/a, además de la decisión y el deseo de dar el pecho por parte de la madre, es necesario y casi imprescindible que la mujer sea paciente y tranquila, además de estar muy concienciada en la lactancia materna.

"Mucha paciencia y tenerlo muy claro. Yo he tenido muy claro que no le iba a dar nunca de eso de farmacia." GDP2 I3-г3 $\mathrm{Y} \mathrm{I4}_{4}$-I

"Fíjate: Ahí [...] quince meses. Yo, muchas veces pienso que a lo mejor no fui lo suficientemente paciente y no... Es que hay que tener mucha paciencia." GDP 2 I3-I2

"Son muchos los factores que te influyen para perder la paciencia." GDY2 3-10

"Para darle el pecho y darle desde el principio tienes que estar [...] muy concienciada" GDF 29'12"

Como reconocen otros/as autores/as, el tipo de parto, el cansancio de la madre, el dolor ocasionado por los puntos, las grietas, etc., influyen negativamente en el inicio de la lactancia materna.

"El cansancio del hospital y tal. Los cambios hormonales...que no descansas, no duermes, los puntos te duelen, yo estuve con los puntos fatal. $Y$ eso pues, es un estado de ánimo que tampoco ayuda." GDY2 4-Io

"Es un inconveniente [para iniciar la lactancia] me duele [...] me sangra" $\mathrm{GDY}_{2} 2-9$

"Fue horroroso. Yo los tres primeros meses estuve a punto de dejarlo, porque mamaba y mamaba sangre. Era una herida abierta que se te abría cada tres horas" $\mathrm{GDP}_{2} 3^{-6}$ 
A todas esas circunstancias hay que añadir los mensajes negativos y desafortunados que recibe la madre a través de personas de su entorno o de algunos/as profesionales sanitarios/as. Estos mensajes en vez de animar a la madre para que inicie o intente la lactancia parece que surten el efecto contrario.

"A mí cuando me venía me dijeron ellas, ya puedes rezar a la patrona de tu pueblo, que no vas a tener leche." GDY 2 7-ro

"Se dice mucho: es que no pudo darle el pecho porque no tenía leche. La pobre no sabe que sí tenía leche pero que alguien le dijo que no tenía" GDPI I8-6

"Que la introdujera el biberón. Claro, para mí era más fácil” GDY2 II-3

Además, el inicio de la lactancia puede estar condicionado por el estado emocional de la madre, la existencia de alguna patología en el neonato o en la madre; en estas circunstancias, si no se cuenta con ayuda necesaria será muy difícil iniciar la lactancia materna.

"Cuando mi hija María me pilló primero que era madre primeriza [...] cuando salí de neonatos [...]fui a Carmen la enfermera del taller de lactancia y me animó a ir al taller de lactancia, lo que pasa que como había tenido una experiencia tan dura fue cuando a mí me dio el bajón de depresión y lloraba por todo[...] mi marido tampoco me animó en ese momento, que yo me da rabia no haber ido al taller de lactancia porque yo le hubiera dado a María el pecho, porque yo creo que sí hubiera tenido subida de leche"GDPI i8-7 y r9-I

"Cuando nació mi hijo [...] enseguida se lo tuvieron que llevar y no dejé que nadie viniera a verme, me dio un bajón increible, eché a mi madre, eché a mi tía, me quedé sólo con mi marido, llorando porque [...]mi hijo no estaba conmigo [...]por lo cual te sientes culpable, te sientes sola" GDPI I7-2

Según las mujeres de las entrevistas grupales, otro factor que influye en el inicio de la lactancia es el apoyo recibido durante su estancia en el hospital.

"Si no te ayudan, [...] tú te desesperas [...] y no [comienza a amamantar]." GDY 2 5-3

"Si no te ayuda nadie, tú no sabes" GDP2 1o-6

El apoyo familiar es otro condicionante para el inicio de la lactancia materna. Aunque por diversas circunstancias no todas las mujeres cuentan con esa ayuda ${ }^{20}$.

20 Será tratado en profundidad en el punto referido a la Familia. 
"Ella decía que el biberón ni pensarlo, y mi padre también, [...] Por mis padres yo les di la leche" GDY2 I2-II

Los grupos de apoyo a la lactancia materna, tanto los coordinados por profesionales denominados "para madres" como los denominados "de madre a madre" son otro condicionante que favorece el inicio y el mantenimiento de la lactancia natural como ya se estudió en el capítulo anterior.

"solamente duró dos meses con el pecho, y gracias al taller de la lactancia, porque si no, no hubiese tomado ni un día, porque lo que es en el hospital...no me ayudaron en nada" GDY I I-II

Además de la influencia de la familia en el inicio y mantenimiento de la lactancia, el entorno en el que vive la mujer también es muy importante. En entornos hostiles, la madre que quiere amamantar tiene que estar muy implicada y ser muy tenaz para poder superar todos los obstáculos que se van a presentar durante esta etapa de su vida.

"Tienes que saber lo mejor para ti y para tu hijo, si tu quieres hacer el sacrificio de incluso noches de no poder acostarte, eres tú con tu hijo... [La interrumpen]"

- Exactamente."

__ “[Continúa] [...], pero todo el alrededor así [Hace algún gesto], me ha hecho sentir la peor madre del mundo."

— "Parece que ibas contra corriente de todo el mundo."

- "[Habla la anterior] O sea, me han llegado a decir que qué trataba de darle yo, si no engordaba el niño.” GDYI 5-I2,I3 Y I4

"Si no estás concienciada se te hace un trabajo muy cuesta arriba, solo vas tirando tu y parece que estás remando contracorriente" GDF 29'32"

Si la mujer tiene baja autoestima y no dispone de la suficiente confianza y seguridad en lo que está haciendo, es muy fácil que se deje influenciar por los mensajes negativos que le llegan y abandone la lactancia materna.

"Ya, pero tu afán de querer hacer lo mejor, te dejas llevar" GDY2 I4-6

"Salí del hospital sin poder decir que había dado de mamar al niño [...], no salía ni calostro, ni leche, ni nada, me tocaban del pezón, me hicieron un daño terrible y pensé no voy a poder [se refiere a amamantar], [...] los primeros días fue horrible, venía al taller de lactancia, pero el niño no chupaba y no cogía peso; todo el mundo me decía: le metes un biberón" GDPi 5-I

"Es mejor biberón, que se lo enchufas y ya" GDY2 I5-Io 
Las madres primerizas tienen más dificultades para llevar a cabo la lactancia que las mujeres que ya han amamantado. Una experiencia positiva con el/la primogénito/a parece que favorece el inicio de la lactancia, sin embargo, algunas mujeres opinan que el hecho de no haber podido amamantar al primer hijo/a puede hacer que la madre se implique más en la lactancia con su segundo/a, al tener más claros los conocimientos, evita cometer errores que le lleven a abandonar la lactancia.

“Tengo una amiga que con el primero fue incapaz [...], porque lloraba mucho. Y, sin embargo, con el segundo, lo ha tenido como un reto y al final lo ha hecho. Y el niño ha llorado, le ha dado el biberón alguna vez, muy pocas, y al final ha conseguido sólo darle el pecho. Y es la misma madre para los dos." GDP2 I4-4

\section{Condicionantes para el mantenimiento de la lactancia: "yo cuando lo quite mi hija"}

Aunque lo ideal sería que el momento de abandonar la lactancia lo decidieran la madre y/o el/la niño/a, la realidad es que hay muchos condicionantes internos y externos que influyen a la hora de tomar esa decisión. Estos condicionantes pueden ser los mismos que influyen en el inicio de la misma, pero en muchos casos son diferentes.

Según las opiniones de las mujeres y de los/as profesionales participantes en el estudio uno de los condicionantes para mantener la lactancia materna sería el vínculo generado. Para alguna de estas mujeres, el amamantamiento es una satisfacción tanto para la madre como para su hijo/a y no quieren abandonar la lactancia porque al dejarla, romperían ese vínculo que tanto les hace disfrutar a los dos.

"tanto me insiste la gente, me paro a plantearlo y me digo: Pero bueno, ¿tengo yo por qué romper un vínculo tan especial?, que ahora mismo, para él que ya va a tener un poco más de entendimiento, para él es tan... tan satisfactorio, que le ves una sonrisa, que te acaricia, no veo yo que me tenga que poner un límite." GDYI i8-I

"yo no quiero romper ese vínculo, ahora que para él es tan...no sé, tan bonito. Pienso, ¿no? Que él lo está disfrutando ahora mismo igual que уо." GDYI I7-Iо

"elegían [la L.M.] por sentimientos: estoy muy a gusto me hace estar más cerca de mi hijo" $\mathrm{EP}_{2}$ I2'38" 
Sin embargo, en algunos casos, el hecho de sentir que el lactante depende totalmente para alimentarse de la madre puede generar ansiedad e influir en la decisión de abandonar la lactancia materna. ${ }^{2 \mathrm{~T}}$

"Del pecho pasé a la cuchara [...], me creaba un poco de ansiedad el pensar que si yo me tenía que ir o faltaba....No podía...no podía comer" $\mathrm{GDP}_{2} 4-4$

En otros casos parece que la introducción de la alimentación complementaria hace que el/la niño/a pierda el interés por la lactancia materna y poco a poco la rechace; o bien una separación temporal de la madre, aunque solo dure unos días, puede hacer que el/la bebé ya no pida mamar.

"Estuve dando a mi hija ocho meses, y la verdad es que lo dejé porque lo dejó ella. No quiso...le daba arcadas. Ya empezó con la fruta, con los cereales y ya, si le metía el pecho le daban arcadas. Entonces, se lo quitó ella" GDP2 $3^{-2}$

"podía haber seguido si yo hubiera querido, porque él quería...pero, ya te digo, fue dejárselo a mi madre un viernes y recogerle el domingo y ya está. No me lo volvió a pedir más." GDP2 $23^{-9} 9$

En ocasiones la lactancia se deja por recomendación del personal sanitario debido a algún problema de salud de la madre.

"lo tuve que dejar porque tuve un aborto, y me lo aconsejó la ginecóloga, pero me costó mucho [...] si lo hubiera dejado él no me hubiera costado tanto que el habérselo quitado yo" GDPI I-2

La familia, los vecinos/as y en general cualquier persona suelen opinar sobre el estado de salud del neonato. A la gente, en general, le gustan los/as bebés rollizos/as, cuando el/la niño/a es delgado/a suelen pensar que es debido a la lactancia materna, alimentación en la que no confían, es entonces cuando presionan a la madre para que suplemente a la criatura con algún biberón o incluso que abandone el amamantamiento. Estos comentarios influyen más en la madre si es insegura y tiene dudas sobre su capacidad para criar a su hijo/a.

"por eso yo la quité el pecho porque como me decían que perdía peso... aunque en los papeles, todas las semanas hacía peso." GDY2 II-3

"Que alguna vez le han visto llorando... (Cambia la voz) Ese niño llora porque tiene hambre y digo: Pues ese niño no puede tener hambre porque por la noche aguanta ocho horas." GDYI I4-I4

21 Se analizará en el subcapítulo 4.2.2.2 Dependencia 
"Nuestras madres tenían una mentalidad de biberón, [...]. Entonces en el momento en que el niño, eso, se queda un poquito más delgadito ya le echan la culpa al pecho. Y es una tontería porque mi hijo dejó el pecho y se ha seguido quedando igual de delgado." GDY I I4-Io

'Ni te preguntan si come bien, si duerme bien, si es tranquilo, ellos simplemente se asoman al carro con experiencia propia y te dicen (cambia la voz): Uy! qué poco come, pero este niño...pero ¿̇igues dándole de mamar? Este niño lo que necesita es un biberón, una buena papilla. Métele más cacitos de cereales, no hagas caso al pediatra. Entonces, cuando estás un poco desesperada, sobre todo al principio, porque tu hijo no hace peso, te hacen sentir como que eres la peor madre del mundo, que no quieres alimentar a tu hijo. Entonces influye mucho [...] estás rodeada de padres, suegros, hermanos, cuñados $[\ldots]$ creo que nos cuesta más trabajo.” G GPY 4-Io

Tanto el "qué dirán" los demás, sobre todo en poblaciones pequeñas donde se conoce todo el mundo, como el hecho de tener que dar de mamar en público y sentirse observada, pueden condicionar a la madre y decidir abandonar la lactancia ${ }^{22}$.

"Pero llegó el buen tiempo, y eso de exponer mi pecho [...] a mí no me gustaba, pero si no sí que hubiera seguido dándole el pecho.” GDY2 I-5.

"El problema es la sociedad que desalienta la lactancia" GDF r8"

Por otro lado, parece que la sociedad no ve bien que la madre disfrute de la lactancia materna. Resulta paradójico que cuando la madre ha superado la etapa más dura del inicio de la lactancia con sus múltiples obstáculos, ha pasado el puerperio inmediato, cuando ya no tiene dolor, ni grietas, ha superado la depresión postparto (en el caso de que se haya dado), cuando ha aprendido a dar el pecho y todo va bien, la gente de su entorno comienza a recomendarle que deje ya de amamantar a su hijo/a.

"Nosotras damos el pecho por el bien de ellos y porque nos gusta" GDF 5 '30"

"Quítale el pecho, digo cuando ella quiera,yo si estoy ahora a gusto, ahora que ya sé, $[\ldots]$ ya que va todo bien, $[. .$.$] yo cuando lo quite ella" GDPI$ IO-I7

“creo que en definitiva cuando él no quiera más se ha acabado" GDPi I2-3

22 Será tratado en profundidad en el punto 4.2.4 La esfera sociocultural. 
Sin embargo, algunas mujeres expresan tener capacidad para tomar sus propias decisiones en relación con la finalización de la lactancia y no dejarse influenciar por su entorno.

"Si me equivoco, me equivoco yo. Que es mi hijo y yo lo hago con toda la buena intención del mundo. A lo mejor lo estoy haciendo mal, yo no digo que no." GDY2 I4-7 $^{-1}$

"A lo mejor como a mí me comía bien y siempre me ha hecho peso, es verdad que no me he dejado, [manipular] ya te digo que somos los padres los que tenemos que estar pendientes de ellos, no los abuelos." GDYI I4-9

Sin duda se puede asegurar, a partir de las entrevistas, que un condicionante muy frecuente para el abandono de la lactancia, en las mujeres del estudio, es el atribuido a la reincorporación al trabajo. Mientras la OMS recomienda la lactancia natural exclusiva durante los seis primeros meses, en España el permiso maternal es de dieciséis semanas, lo que dificulta poder seguir esta recomendación. Por otro lado, las mujeres empresarias o con cargos públicos suelen reincorporarse antes de las dieciséis semanas, lo que parece que no ayuda a reivindicar un cambio en la legislación que aumente el permiso.

"Soraya Sáenz de Santamaría, estuvo dos semanas y ni siquiera (murmullo). Nos hacen un flaco favor porque son personas públicas y en lugar de como mujeres favorecer los derechos que tenemos que tener..." GDPi $20-8$

"Yo era empresaria y dejé la empresa para dedicarme exclusivamente al niño y ahora tengo un trabajo normal, cinco horas que me permite seguir criando al niño por las tardes, pero no todo el mundo puede" GDPI 20-8 "Si te aconsejan seis meses de lactancia, sólo de leche materna, pues dame seis meses, [se refiere al descanso maternal]. Si no, no le puedo dar, le tendría que meter biberones y eso ya no, ya lo estropeas." GDY2 23-3

En otros países de Europa el permiso maternal es más amplio, por esta razón las mujeres opinan que la legislación española no ayuda a mantener la lactancia exclusiva el tiempo que recomienda la OMS.

"En España [...] estar dieciséis semanas [...] es poquísimo. Cuando en otros países tienen dos años." GDY2 22-16

"Hay muchas madres, que hablo con ellas: Es que yo no puedo, trabajo ocho horas. Y no pueden y lo dejan." GDY2 22-I2 
"por tema de trabajo y tal, sí que quisiera dejar de darle la lactancia, pero también veo que no, porque aparte que es una vitamina fundamental y una comida esencial que necesita el bebé, pues la sigo dando por las noches."GDPI I-3

Hay mujeres que buscan soluciones para seguir amamantando a su hijo o hija cuando se reincorporan al trabajo, aunque eso les suponga reducir sus ingresos o sentirse perjudicadas respecto a los hombres y a las mujeres que no lactan; la reducción de jornada laboral y la excedencia por crianza de los/as hijos/as, puede impedir la progresión de la vida laboral de la madre tanto en su carrera profesional, como en sus ascensos. Sin embargo, para estas madres la lactancia es prioritaria.

"Depende. Yo he reducido la jornada y muy bien. De hecho, he podido avanzar el trabajo y seguir dando el pecho." GDY2 22-10

"Pedí una excedencia para estar con él [Se refiere al niño]. Por lo menos hasta que él tenga un año, son seis meses de excedencia. Nos apretamos el cinturón" GDY2 22-I4

Otras mujeres encuentran otras alternativas para seguir con la lactancia mientras trabajan: amamantan al hijo/a durante su jornada laboral, si un familiar se lo lleva, algunas se sacan leche en su puesto de trabajo y después la persona que cuida al hijo/a da en biberón la leche de la madre; con estas estrategias consiguen mantener la lactancia materna exclusiva hasta los seis meses. En estos casos, las madres refieren que no solo no cuentan con el apoyo legislativo necesario, sino que además no existe un lugar adecuado e higiénico para la extracción de leche en sus puestos de trabajo.

"En la plantilla de mi trabajo si somos el $95 \%$ mujeres y no tienes una sala o un lugar determinado para poderte sacar el pecho [...] yo me iba al servicio y había compañeras que me decían yo en el servicio no lo haría, yo por mi niño lo hago en un servicio "GDPI 2I-I

"Cuando me incorporé [al trabajo] a los 6 meses venía mi madre a traérmelo para que mamara." GDPI II-I

Además de las condiciones tan adversas para mantener la lactancia, antes explicadas, en ocasiones las madres se encuentran con la incomprensión e incluso las burlas de sus compañeros/as de trabajo.

"Yo que trabajo, [...] me sacaba la leche, pedí permiso para que los descansos me coincidieran más o menos en la mañana, la gente [comentaba] 
para qué te la sacas, ya déjalo, total le has dado 4 meses [...], mira decían: ahí llega la de la bolsa [...], lo veían como algo extraño.” GDPi II-I

"Decían mis compañeros así jactándose [...], ya viene Gonzalo a tomarse el chupito, mira la madre tetona [...] yo les decía: janda ya! que os gusta opinar de todo, ocuparos de vuestra vida y siguió mamando" GDPI II-3

Sobre este asunto parece que las mujeres lactantes no esperan ni apoyo, ni solidaridad en su medio laboral, por lo que el silencio de los/as jefes/as y compañeros/as en este tema es valorado por la madre de forma positiva.

"No me llamaron nunca la atención [...] supongo que todos se darían cuenta, pero nadie me dijo nunca nada. Se darían cuenta de que yo traía mis frasquitos todos los días y que me iba con frasquitos y venía [...]. Y estuve [...] cuatro o cinco meses haciéndolo todos los días." GDP 2 I5-1o

En general, la sociedad y el entorno social o familiar de la madre no ve bien lactancias más largas de un año. Según los discursos de las madres de nuestras entrevistas se sienten juzgadas y recriminadas por mantener la lactancia materna a partir de cierta edad del niño/a.

"No está muy aceptada a partir del año [se refiere a la lactancia]; la OMS recomienda hasta los dos años, pero socialmente no está, tengo una amiga que es psicóloga y me decía que a partir del año la dependencia es de la madre no del niño" GDPI II-2

“¿Y si ya es grande? ¿Y si ya es grande como este [Señala a un niño]? [La interrumpen]. Ya te miran como diciendo: ya es grande ¿¿dónde vas?” $\mathrm{GDY}_{2}$ 15-8

"La sociedad no está preparada para una lactancia prolongada" GDF o6’ $49 "$

Las mujeres participantes en el estudio, probablemente, tienen la representación social de lactancia materna corta, que no llega a los seis meses, esto se correspondería con las bajas tasas de lactancia de los años 70 y 80. Esto podría explicar en parte, el rechazo social hacia la lactancia natural cuando el niño o la niña es mayor de un año. Pero otras causas también pueden influir: en la sociedad actual la idea de "mujer moderna" se correspondería con la imagen de una mujer independiente, la sensación de dependencia del niño/a hacia la madre que expresan muchas mujeres puede hacer que se rechacen las lactancias más largas, tanto por parte de algunas madres como de la sociedad. La idea de "mujer moderna" también chocaría con la imagen de "madre vaca" con la que se asocia a las mujeres que dan lactancia natural, sobre todo si esta 
lactancia supera cierta edad del niño/a, parecería que la madre renunciaría a ciertas ventajas de la "mujer moderna" para quedarse relegada a productora de alimento para su hijo/a. Estas causas serán analizadas con detenimiento en el apartado 4.2.2.2 Dependencia.

Por otro lado, parece que nuestra sociedad quiere "niños modernos" es decir independientes como sus madres. En la actualidad la sociedad considera que el desarrollo y la maduración del/la bebé se puede forzar y acelerar, por ejemplo: llevar a los hijos/as a la guardería con sólo semanas de vida, separarlos de la madre tempranamente, por tanto, la lactancia materna exclusiva entorpecería esta maduración precoz del niño/a. Se culpabiliza a la madre si no quiere abandonar la lactancia natural para separarse del niño/a y se le dice que es ella quien tiene dependencia emocional del su hijo/a, como si fuera algo negativo que retrasa la independencia de la criatura. Aunque como defiende la Teoría del Apego (Becerril Rodríguez, 20I2), la separación del niño/a de la madre antes de los tres años no representa ninguna ventaja para él, sino al revés, a la hora de adquirir seguridad e independencia.

Tampoco podemos olvidar el carácter erótico del pecho femenino, por lo que una lactancia prolongada, no así con un/a bebé de pocos meses, puede tener connotaciones sexuales para mucha gente, la lactancia sería como una relación sexual entre madre e hijo/a (Massó Guijarro, 2013), de ahí la sensación de pecado que señalan algunas mujeres del estudio.

"Y que luego en la sociedad que vivimos, que hay ciertas personas mayores que también es como si estuvieras haciendo un pecado." GDY2 $15^{-6}$

Los talleres de apoyo a la lactancia materna, tanto los denominados "de madre a madre" como los denominados "para madres", objeto del estudio, favorecen el inicio y el mantenimiento de la lactancia materna, llegando en algunos casos a conseguir que la lactancia se prolongue gracias al apoyo que reciben las mujeres en ellos. Como se estudió en el capítulo anterior son lugares donde las mujeres encuentran personas y opiniones a favor de la lactancia natural que les servirán para hacer frente a las presiones de su entorno más cercano.

"Iba haciendo el mínimo peso, y entonces me desanimé y quise dejar la lactancia. Como con el primer niño se me retiró a los dos meses [...], yo veía que no hacía nada...pues me desanimé En el Taller me apoyaron, me dijeron que no pasaba nada, que era cuestión de tiempo, de la adaptación, que no tenía por qué salir como con el otro niño, que cada bebé es un mundo [...]. Y entonces lo seguí intentando" GDY I 3-3

"Yo hubiera dejado de dar el pecho si no es por Lola" GDY2 9-2 
"Sobre todo el apoyo es muy importante, pero si no te apoya la familia para eso están las reuniones.” GDY2 I3-4

Las opiniones de las mujeres recogidas en las entrevistas grupales coinciden con los condicionantes que otros/as autores/as reconocen que influyen, tanto en el inicio como en el mantenimiento, de la lactancia materna. Sobre todo, coinciden en los factores socioculturales: la incorporación al trabajo y la presión que ejercen en contra de la lactancia la familia, vecinos/as, conocidos/ as, compañeros/as de trabajo. Probablemente varios de estos factores inciden a la vez, como ellas reconocen, para que tomen la decisión de abandonar la lactancia materna.

"Parece que ibas contra corriente de todo el mundo." GDYI 5-13

"Son muchos los factores que te influyen para perder la paciencia." GDY2 3-ro

"Al incorporarte a trabajar, todo el mundo: $\mathrm{j}$ le sigues dando pecho?...vaya una tontería de estar sacrificada con la teta fuera" GDF i 758 "

Pero también apuntan ideas como que una lactancia natural frustrada con el/la primogénito/a favorece el inicio de la lactancia materna con el/la segundo/a, en esta circunstancia la madre se esforzaría más y no cometería los mismos errores. O bien que la introducción de la alimentación complementaria favorece la supresión de la lactancia materna. En cuanto al vínculo afectivo, para algunas mujeres favorecería el mantenimiento, pero para otras ese sentimiento de dependencia influiría más en el abandono.

Estas ideas podrían abrir nuevas líneas de estudio para trabajos científicos futuros.

Beneficios e inconvenientes de la lactancia materna: "muy enriquecedora para los dos, pero... muy dura"

Los beneficios de la lactancia materna se siguen estudiando aún hoy en día, como se comentó en el apartado de la leche materna. En la actualidad se desconoce su composición exacta y por tanto no se conocen todos los beneficios que aporta. En este apartado se pretenden desgranar las opiniones de las madres a cerca de las ventajas y los posibles inconvenientes.

En general, como toda actividad humana, tiene efectos positivos y negativos, las mujeres son conscientes de esta dualidad y así lo expresan: 
"A mí me ha gustado mucho, ha sido muy sacrificado, pero...no lo hubiera cambiado. A mí me parece muy enriquecedora para los dos y....y eso, muy duro" GDP2 2-I

"Y....yo, bueno, mi experiencia ha sido un poco dura pero (baja el tono de voz) merece la pena." GDP2 $\mathrm{I5}^{-} 7$

En primer lugar, se analizan los aspectos de la lactancia que a las madres les parecen beneficiosos y se finaliza con los inconvenientes, aunque como se estudiará lo que a una mujer puede parecerle una ventaja, para otra puede no serlo.

\section{Beneficios}

Una ventaja del amamantamiento es la comodidad, el pecho siempre está disponible, no necesita tiempo de preparación, la temperatura es óptima y si la madre sale fuera de casa no es necesario llevar ningún utensilio. En cambio, la lactancia artificial requiere llevar muchas cosas.

"Pienso que, de las dos cosas, [lactancia artificia o natural] es mucho más cómodo el pecho [...], allá donde vayas, se pone a llorar porque tiene hambre, y le das. Si no, tienes que estar pendiente del biberón, los polvos, el no sé qué...es más incómodo para la madre" GDY 2 I6-I4

"El pecho, bien entendido, es lo que menos te ata, porque no necesitas nada." GDYi I9-I

"un biberón...que si ahora llévate: que si el termo, que si los polvitos, que si el agua, que si...Yo salía con un maletón" GDYI I9-I

Otro de los beneficios que valoran de forma positiva las madres es la elaboración del vínculo materno filial, a través del amamantamiento.

"las madres que han dado de mamar a su hijo mucho tiempo, los niños se hacen más cariñosos." GDP $24-5$

"es una sensación pues algo no sé, inexplicable que se trasmite de madre a hija y no sé, te comunicas tanto tú con el afecto..." GDPI I-3

"es un contacto íntimo y no se puede expresar o sea el mirarte el niño y tu mirar al niño es o sea, aunque estés [...] en el sitio más concurrido de personas. Te aíslas, o sea, estás él y tú, no hay otra cosa" GDPi I-5

El vínculo afectivo de un niño de pecho, es mejor que el de un niño que no es de pecho" GDF 3'30" 
Según las madres del estudio, el vínculo materno filial establecido es más sólido gracias a la lactancia materna, incluso aprecian diferencia en el vínculo con otro hijo o hija, si éste/a no tuvo lactancia natural. Como ya se comentó en el capítulo 4.2.I.3. el vínculo influye de forma positiva en el mantenimiento de la lactancia materna.

"pero a mí me gustó muchísimo porque eso [...] es un momento que tenía con ella y la verdad es que, sí que lo veo que ella tiene un vínculo conmigo más estrecho, a lo mejor que María" GDPi I-4

Las madres refieren que lactando de forma natural el/la bebé se desarrolla mejor, obtiene una mayor protección y recupera de forma más rápida su salud en caso de enfermedad.

"lo he intentado pues eso, dar el máximo de tiempo posible, noto que se ha puesto malita, pero se recupera más rápida o sea que sí influye la leche materna." GDPi I-4

"pero yo persistí y le di los seis primeros meses lactancia exclusiva y mi hijo es súper majo [...] le veo un niño sano, fuerte, vital o sea es que además físicamente, mi hijo es como compacto y yo estoy segura que eso es la lactancia porque además cuanto más leo me doy cuenta que es beneficiosa por todo" GDPi $5^{-1}$

Algunas mujeres reconocen que el pecho sirve para todo, siendo muy útil en algunas circunstancias: si llora el niño o la niña porque está intranquilo/a, cuando tiene sueño, si presenta alguna molestia o le duele algo... mamar le alivia y no necesita chupete.

"Al final lo utilizas un poco también como chupete. ¿Llora? El pecho. ¿Se queja por algo? Le pones al pecho" GDP2 I7-ז3

"Con la teta lo solucionas todo" GDF 9' 37 "

Otra ventaja es la economía, las mujeres verbalizan que la lactancia materna es más barata que la lactancia artificial; además la lactancia con leche de fórmula puede ser un inconveniente para el/la bebé, la madre debe hacer un esfuerzo para que acepte el biberón y después cuando el niño/a tiene que abandonar su uso no lo acepta con facilidad.

"para mí fue positivo, el mero hecho de poder alimentar al bebé fue algo increíble, la gente me decía te has ahorrado dinero, no lo veía por el dinero, hombre el dinero también ayuda todo sea dicho, pero yo lo veía por darle el pecho, para mí fue positivo, aunque la mastitis y todo." GDPI 2-8 
"¡Anda que no se nota! (Se ríen) De dar el pecho a tener que comprar botes y biberones, y tetinas, y...de todo. Y [...] acostumbrarlos al biberón y luego desacostumbrarlos al biberón. Que es otro trauma que a los niños les pasa." GDYI 27-I4

En la introducción se relató que la lactancia natural también es beneficiosa para la madre, sin embargo, cuando las mujeres participantes en el estudio se refieren a esas ventajas les parece egoísta, como si una buena madre sólo debiera pensar en los beneficios para el bebé.

"egoístamente también, lo bueno que es dar el pecho para la recuperación de la madre. Es buenísimo" GDY i i-2

Por el contrario, abandonar la lactancia materna parece que tiene efectos negativos en la salud de la madre.

"Fue dejar de darle el pecho y faltar algo, [...] la verdad es que lo pasé mucho mejor el tiempo que estuve dando el pecho. Yo me notaba mucho mejor, no sé, parece como un alivio" GDYI I7-4

"Me dieron las pastillas estas para retirarme el pecho, y muy mal. O sea, lo pasé...psicológicamente y físicamente, las dos cosas muy mal." GDYI I7-6

"Me generó ansiedad separarme de mi hija" GDF 26"oo"

En general la etapa de la lactancia ha sido muy feliz y satisfactoria, en algunos casos la experiencia ha sido tan gratificante que consideran necesario compartirla con otras madres para que sean conscientes de lo positiva que es $\mathrm{y}$ de los sentimientos que genera.

"El tiempo que él estuvo tomando nada más que pecho fue el más feliz. Porque yo me iba, en cualquier sitio le daba a mi niño y no había problema" GDYI I9-7

"Porque todo es sufrir. Y por lo menos eso es el único, cosa...privilegio que nos dan, de poder sentir eso" GDYI 2I-2

"acaba de ser madre y está practicando la lactancia en tándem ${ }^{23} \mathrm{o}$ sea que fijate que bien los dos, esto es tan gratificante y creo yo, [...] pero es tan bonito que te dan ganas de contar a los demás lo beneficioso y lo bonito que es" GDPi ro-8

23 Por lactancia en tándem se entiende la lactancia materna que se mantiene con el hijo o hija anterior y que se inicia con el recién nacido, los dos hermanos/as reciben leche materna cada uno/a según sus necesidades. 
"Es tan beneficiosa la Leche Materna, en las circunstancias en las que está tu hijo, y ver luego después, los beneficios que vas a obtener" EPi 47 '59"

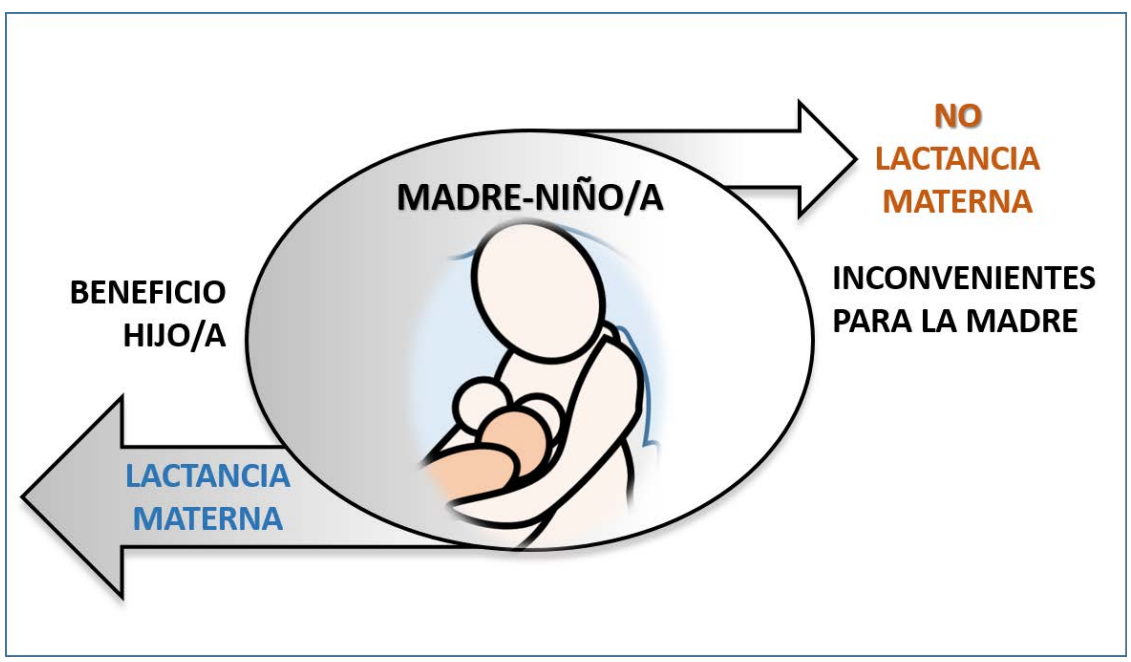

Ilustración 6. Tensiones Madre-hijo/a.

\section{Inconvenientes}

Algunas mujeres reconocen que la lactancia natural supone cambiar algunos hábitos, entre ellos la alimentación, sin embargo, también reconocen que algunos hábitos no saludables para el/la bebé los adaptan a los horarios de las tomas para perjudicar lo menos posible al niño/a, debido a que no quieren renunciar a dichos hábitos.

"Yo no bebía ni coca-cola. Yo sólo bebía agua." GDY2 2I-7

"muchas amistades de saber que yo le daba el pecho: (Cambia la voz) ¿Ah, le das el pecho? Pues ya no puedes fumar. Yo que soy la típica... que todos los domingos me iba al bar a tomarme una cañita... También, no podía tomarme una cañita porque si no..." GDY2 2I-I

"Soy fumadora. Pues yo me buscaba los horarios para yo poder fumar" $\mathrm{GDY}_{2}$ 20-16

"Después de darle el pecho yo me fumaba mi cigarro. Siempre después de darle a ella”. GDY2 2I-I

Incluso, otras madres manifiestan estar esperando el fin de la lactancia para poder retomar los hábitos abandonados durante el amamantamiento. 
"cuando deje de dar el pecho voy a abrir una coca-cola con un bocadillo chorizo picante" GDY2 2I-I3

Otro inconveniente puede ser la pérdida de libertad de la madre; ella siente reducida su libertad de movimientos porque el/la bebé depende las veinticuatro horas del día de ella. En los primeros meses tiene que alimentarle frecuentemente y no puede separarse del niño/a durante mucho tiempo.

"Los tres primeros meses $[\ldots]$ estás con él $[. .$.$] todo el día a cuestas"$ GDY2 2-5

"Muchas madres lo que no quieren es tener una dependencia, porque ahora mismo él depende". GDY I I8-3

Este sentimiento de dependencia pude influir en la decisión de la madre para abandonar la lactancia materna, al no amamantar la mujer se siente más libre y puede dejar a su hijo/a al cuidado de otras personas. Este aspecto se analiza en profundidad en el punto 4.2.2.2. Dependencia.

"si le das el biberón, le puedes decir a tu madre: Toma el niño, que me voy a comprar que..." GDY2 I6-I5

Por otro lado, muchas mujeres no se sienten cómodas dando el pecho en espacios públicos, prefieren, por ejemplo, que haya salas de lactancia en los centros comerciales y no exponer su pecho delante de la gente. Tema que se aborda en el punto 4.2.4 La esfera socio cultural.

"No hay mucho sitio, la verdad, para dar el pecho En los parques... No hay sitios. No ayuda mucho para darle el pecho al niño." GDY2 I5-4

"mi hija y mi marido se bajan a la calle, están disfrutando con todos los vecinos, y yo estoy en casa. Hombre, no me bajo a la calle porque a lo mejor me van a decir: ¡Mira esta! [...]. No le voy a dar el pecho aquí.” GDYi I8-3

"Exponer mi pecho $[\ldots]$ a mí no me gustaba" GDY2 I-5

"yo me lo he sacado en un servicio porque no tenía una sala, aunque fuera un cuarto pequeñito para poderme sacar el pecho [...] pero yo me lo he sacado en los servicios, cuando entraba otra persona después que yo para hacer sus necesidades porque no tenía una sala determinada" GDPI 2I-I

Por el contrario, otras madres disfrutan plenamente de su lactancia sin condicionarles el hecho de estar amamantando en un sitio público.

"pero si estaba en verano en una terraza, yo la ponía a comer en la terraza y no había ningún problema. No me iba a mi casa ni me suponía ningún problema." GDP 2 I6-II 
"El tiempo que él estuvo tomando nada más que pecho fue el más feliz. Porque yo me iba, en cualquier sitio le daba a mi niño y no había problema. A lo mejor, pues sí, hay sitios donde te cortas un poco más, [...] pero es porque tú te cortes, no porque los demás digan. Los demás que digan lo que quieran." GDY I I9-7

Sin embargo, algunas mujeres opinan que la lactancia natural es poco frecuente porque necesita mucho tiempo y resulta incómoda, consideran que dar un biberón es más rápido y sencillo.

"[la gente piensa que] es raro que una mujer dé el pecho. Que suena como incómodo con lo cómodo que es el biberón, que haces así [Hace un gesto] pas, pas y ya está." GDY2 I6-I3

Otro inconveniente del amamantamiento son las posibles complicaciones tales como: mastitis, ingurgitación, dolor, grietas, etc. que pueden presentarse a lo largo del periodo de lactancia.

"Y eso sin contar que te duele, que te sangra, que... te molesta." GDY2 2-7 "lo extraño mío fue que cuando el niño tenía Ir meses me dio mastitis, antes nunca me había dado [...], pero en general para mí fue positivo" GDPi 2-9

Algunas madres no creen que la lactancia les haya ayudado a recuperar su figura ni el peso de antes del embarazo, para ellas supone un inconveniente, al contrario de lo que se analizó en la introducción.

"y engordé 24 kilos con la lactancia, con lo cual no lo veo positivo (risas) pero es lo único, por el físico" GDPr 3-3

Parece que el discurso sobre las ventajas e inconvenientes de la lactancia materna en el estudio es ambivalente. Las mujeres participantes no se posicionan claramente en si la lactancia natural es beneficiosa o no. Hay experiencias encontradas entre las mujeres e incluso en la misma mujer. Sí parece haber unanimidad en reconocer que la lactancia materna favorece la creación del vínculo materno filial y en general es beneficiosa para el/la bebé. En cambio, en lo que se refiere a la madre, la familia o la sociedad, las mujeres ven tanto elementos positivos como negativos al mismo tiempo: lo que para algunas mujeres son ventajas para otras son inconvenientes. Por tanto, podemos decir que el niño/a tiene las ventajas de la lactancia natural y la madre sufre los inconvenientes, hecho que justifica que algunas madres abandonen la lactancia materna y como consecuencia, en algunas mujeres aparecen sentimientos de culpabilidad debido a que al abandonar la lactancia natural, estarían pri- 
vando a sus hijos/as de los beneficios de la misma. También se privarían de las ventajas que tiene la lactancia para ellas mismas, sin embargo, estas tienen poco peso y no les crea sentimientos de culpa.

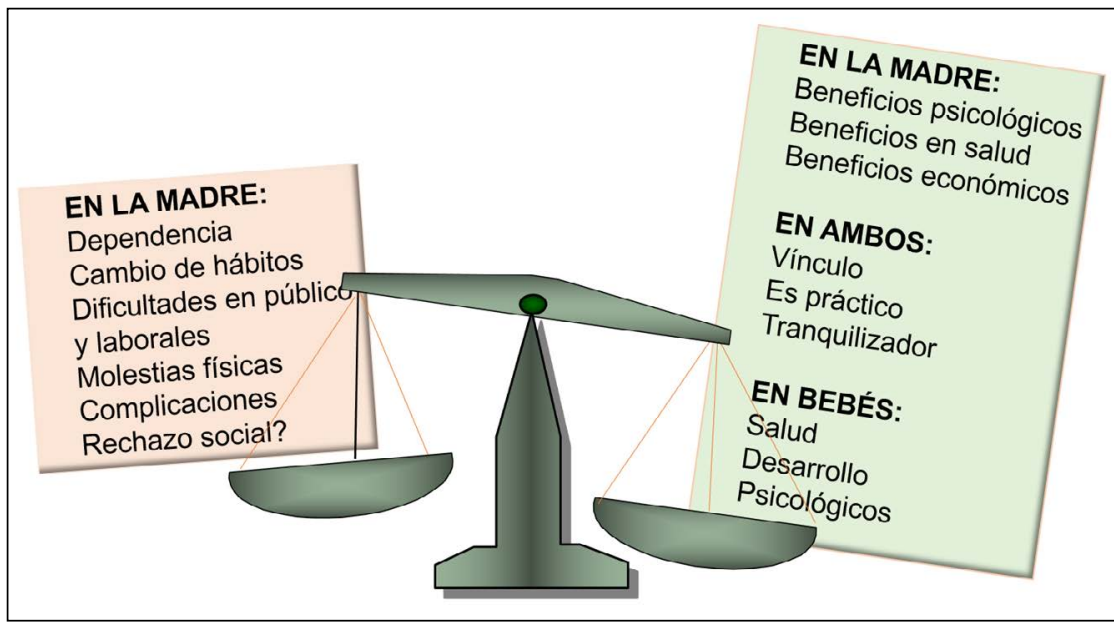

Ilustración 7. Beneficios e inconvenientes de la L.M.

Quizá desde los talleres, los/las responsables de los mismos, podrían enfatizar más sobre los beneficios del amamantamiento en la madre sin subrayar tanto los beneficios para el bebé, de este modo no se generarían sentimientos de culpa en la madre al abandonar la lactancia natural.

\subsubsection{LA ESFERA PRIVADA O PSICO Y RELACIONAL}

La lactancia parece una etapa muy fácil en la vida de la mujer, sin embargo, el análisis de las verbalizaciones de las diferentes entrevistas grupales pone de relieve que la mujer en esta etapa se siente vulnerable, frágil y lábil. Las emociones negativas son las que se han recogido con mayor frecuencia.

"Sí que lo recuerdo muy doloroso y sobre todo de decir: A mí me han engañado. Porque a mí nadie me ha dicho que esto dolía" GDP2 I2-9

El nacimiento de cada hijo/a supone en la madre una experiencia única y gratificante, pero el estado emocional de la mujer, en el puerperio inmediato, está condicionado por factores biológicos, psicológicos y socioeconómicos. El inicio y mantenimiento de la lactancia estarán fuertemente influenciados por el estado emocional en el que se encuentre la madre durante esos momentos. 
"El cansancio del hospital [...] los cambios hormonales [...] no descansas, no duermes, los puntos te duelen [...] un estado de ánimo que tampoco ayuda [a iniciar la lactancia]." GDY2 4-ıо

El periodo de lactancia es muy duro para la mujer, debido a los cambios físicos y psíquicos que experimenta; además la crianza del hijo/a supone abandonar un estilo de vida instaurado. Este cambio algunas madres lo viven como una pérdida de su libertad e independencia.

"Entonces, me pareció una esclavitud tan grande y algo tan...tanto tenía que dar yo en ese momento" GDY2 I-8

A la hora de iniciar, instaurar o mantener la lactancia, la opinión de la familia ejerce mucha influencia sobre la madre, en algunos casos la facilita y favorece, pero en otras ocasiones, impide su desarrollo.

"Pues a mí es que no me dieron ni el sacaleches ni nada. Yo por mi madre y por mi suegra, que me dijeron así [técnica o posición de amamantamiento]" GDPI I3-7

"No seguí por la influencia de mi madre, de: Ya está bien, que te vas a quitar mucho la vista. Porque tengo muchas dioptrías y ella me decía que me iba a afectar a la vista" GDP2 $2-6$

El nuevo miembro de la familia introduce una serie de cambios que afectarán a todos los componentes de la unidad familiar, en esta nueva situación, la pareja tiene un papel muy destacado.

"Mi marido me ha apoyado en todo, incluso me hacía fotos: se enfadó conmigo cuando me dio por llorar a los 15 meses, que me dijeron que tenía que dejar de dar el pecho" GDPi 7-4

"Mi marido sí que me decía pues no pases mala noche dale un biberón y yo le decía no, si yo tengo leche yo le doy leche materna" GDPI 6-3

En definitiva, la lactancia está relacionada con un conjunto de circunstancias sociales de la esfera privada, íntima o afectiva. En el estudio se han estructurado de la siguiente manera: 4.2.2.I Afectividad, 4.2.2.2 Dependencia, 4.2.2.3 Familia y 4.2.2.3.I Pareja.

\section{Afectividad: ¿'Ternura o Esclavitud?}

El periodo de lactancia evoca situaciones de bienestar, agrado y comprensión, parece que sea una etapa fácil en la vida de la mujer y que las emociones que tengan que surgir sean de ternura, felicidad y alegría. Sin embargo, ana- 
lizando los discursos de las entrevistas grupales, las madres verbalizan que es una etapa donde la mujer es muy vulnerable. Las emociones que con más frecuencia se han recogido son las emociones negativas y sorprende, además, que las citas en relación con las emociones negativas son más del doble que las citas de emociones positivas.

"Entonces, me pareció una esclavitud tan grande y algo tan...tanto tenía que dar yo en ese momento" GDY2 I-8

"También da mucha ternura verle la carita y ahí, tan chiquitita, y chupando. Yo estaba encantada de darle el pecho, yo miraba la hora para ver cuándo le tocaba para darle. Porque era una sensación...Yo, a mí me encantaba darle el pecho" GDY2 2-3

En las entrevistas grupales aparecen los siguientes términos: estado de ánimo, afectividad, emoción y sentimiento. Los términos se intercalan de forma imprecisa e indiscriminada, esto produce que, en algunos momentos de la conversación, no se comprenda bien qué quiere transmitir la mujer. Para estudiar el capítulo con rigor es imprescindible definir los términos, antes de comenzar el análisis.

Según el diccionario de la Real Academia Española se entiende por estado de ánimo términos como eufórico, depresivo, irritable. Por afectividad, comprensión y aceptación de la otra persona. Afecto equivale a cariño y emoción, se podría entender como la sensación que tiene una persona en una determinada situación. ${ }^{24}$

Una emoción podría definirse como "una experiencia afectiva en cierta medida agradable o desagradable, que supone una cualidad fenomenológica característica y que compromete tres sistemas de respuesta: cognitivo-subjetivo, conductual-expresivo y fisiológico-adaptativo" (Chóliz, 2005)

24 Diccionario de la Real Academia Española. En concreto para este trabajo se utilizan las siguientes definiciones de los términos:

Estado de ánimo: Disposición en que se encuentra alguien, causada por la alegría, la tristeza, el abatimiento, etc. Estado emocional basal de la persona (eufórico, depresivo, irritable).

Afecto. (Del lat. affectus).1. m. Cada una de las pasiones del ánimo, como la ira, el amor, el odio, etc., y especialmente el amor o el cariño. Comportamiento que constituye la expresión de los sentimientos experimentados subjetivamente. (Simpatía, cariño, Rechazo)

Afectividad. (De afectivo).3. f. Psicol. Conjunto de sentimientos, emociones y pasiones de una persona. 4. f. Psicol. Tendencia a la reacción emotiva o sentimental.

Emoción: (Del lat. emotǐo, -ōnis) 1. f. Alteración del ánimo intensa y pasajera, agradable o penosa, que va acompañada de cierta conmoción somática. 
Es interesante entender que la palabra emoción evoca alguna de las seis emociones primarias antagónicas: alegría, tristeza, miedo, ira, asombro o repulsión, sin embargo, también hay que tener presente las llamadas emociones secundarias o sociales como la vergüenza, los celos, la culpa o el orgullo y a las que Damasio denomina emociones de fondo: bienestar o malestar, calma o tensión. Además, este autor sugiere que la emoción también puede referirse a presiones y motivaciones, y a estados de dolor y placer. (A. R. Damasio, 2000, p. I2).

Además, varios autores diferencian entre emociones positivas, emociones negativas y emociones ambiguas (Jiménez, 2006; Lazarus, 1993) ${ }^{25}$.

Damasio afirma que, cuando las emociones se viven de forma progresiva y duradera, entonces se está ante sentimientos (A. Damasio, 2005). Para él, sentimiento es en lo que se transforma la emoción cuando se decide voluntariamente alargarla; además, refiere otro aspecto que diferencia a las emociones de los sentimientos: las emociones son públicas y dirigidas hacia el exterior, se convierten en sentimientos a través de la conciencia, empiezan a tener impacto en la mente y se hacen íntimos.

La afectividad es entendida como la manera en que el ser humano se siente afectado por los múltiples acontecimientos de su vida, son "las experiencias que definen y delimitan la vida emocional del sujeto y el conjunto de estados que el ser humano vive y que influyen en su personalidad y conducta", habitualmente se distribuyen en términos duales: alegría y tristeza, agrado y desagrado, etc. ${ }^{26}$

Por lo tanto, en este capítulo se analizan las vivencias de las mujeres centradas en la afectividad, es decir el conjunto de emociones y sentimientos experimentados por la mujer en el periodo de lactancia.

Las citas son muy abundantes en todas las entrevistas grupales, lo que aporta mucha información al respecto. No existen diferencias aparentes entre los talleres rurales y el taller urbano en cuanto a cantidad de citas se refiere,

25 Emociones positivas: Son agradables y se experimentan cuando se logra una meta. El afrontamiento consiste en el disfrute y bienestar que proporciona la emoción. (Alegría, amor, felicidad, etc.) Emociones negativas: Son desagradables y se experimentan cuando se bloquea una meta, ante una amenaza o una pérdida. Suponen un retraso que impiden al individuo progresar. (Ira, miedo, tristeza, vergüenza, ansiedad, aversión, etc.) Emociones ambiguas: Aquellas emociones que no son ni positivas ni negativas; o bien pueden ser consideradas las dos cosas en función de las circunstancias en las que tengan lugar, (Sorpresa, compasión, esperanza, etc.) (Chóliz, 2005; Jiménez, 2006).

26 "Afectos, sentimientos y emociones. Definiciones, situaciones especiales: Ansiedad, fobia dental". En www.unioviedo.es/psiquiatria/.../5pc-afectos-sentimientos.pdf. Consultado en google 19-01-.2015 
pero sí existen diferencias significativas en cuanto al modo de realizar la lactancia materna. Las madres verbalizan que en el mundo rural la lactancia es más difícil y desarrollar una lactancia prolongada cuesta más esfuerzo.

"Si no te ayuda nadie, tú no sabes. Porque además es que te ponen la cabeza...La madre de él, tu suegra, [...].Y tú no sabes.Y como nadie dice nada pues...Es un poco traumático. Yo, la primera vez, traumática total." $\mathrm{GDP}_{2}$ Iо-2

"Y gente aquí del pueblo, pues que claro, generalmente estás rodeada de padres, suegros, hermanos, cuñados...Todavía hay más...creo que nos cuesta más trabajo." GDYi 4-ı

En la vida de la mujer, el nacimiento de un hijo/a es una experiencia bonita, intensa y gratificante; sin embargo, el puerperio inmediato es un estado emocional diferente: la mujer se siente aturdida, agobiada y en ocasiones bloqueada debido a los cambios que experimenta. El puerperio está condicionado por factores biológicos, psicológicos y socioeconómicos, tales como: tipo de parto, complicaciones en el parto, historia afectiva, ausencia o presencia de apoyo familiar, economía familiar, etc.(Embarazo, padres, \& Andalucía.)

"El cansancio del hospital [...] los cambios hormonales [...] no descansas, no duermes, los puntos te duelen [...] un estado de ánimo que tampoco ayuda [a iniciar la lactancia]." GDY 2 4-10

"Es una sensación [se refiere amamantar] inexplicable que se trasmite de madre a hija y no sé, te comunicas tanto tu con el afecto... aparte que la he tenido en mi cuerpo, la doy de comer de mi" GDPI I-3

"Yo el tiempo que él estuvo tomando nada más que pecho fue el más feliz." GDYI I9-7

Las mujeres en el postparto experimentan una serie de cambios emocionales tales como labilidad emocional, irritabilidad, hipersensibilidad a la crítica, angustia, etc. teniendo su máximo apogeo entre el tercer y quinto día, pudiendo llegar hasta los quince días, además estos cambios coinciden con la instauración de la lactancia, haciendo que este periodo de tiempo sea el de mayor vulnerabilidad para la madre (Uriarte, 2006).

"Al dar a luz simplemente dicen toma mamá y te dan al niño, te dan una cosa chiquitita y dices tú ( murmullo) porque por mucho que te han enseñado es tu niño y no es el niño de la de al lado, que lo coges y dices que mono, es tuyo, tú lo tienes que bañar, tú lo tienes que vestir, tú lo tienes que cambiar, tú le tienes que coger y muchas veces dices es que se 
me va a romper de lo chiquitito que es, le tienes que poner ropa dices a ver si le rompo un dedito, no sé cómo meterle... y en el taller parece que te sentías al lado de otras mamás, no te sentías sola, y todas teníamos los mismos miedos." GDPI I4-5

Las madres durante el embarazo se preparan para el parto y la lactancia, sin embargo, algunas mujeres subestiman lo mucho que les cambiará la vida con el nacimiento de su hijo/a. Algunas madres tienen idealizada la maternidad y la lactancia a través de los clichés de las películas y la publicidad. Desean quedarse embarazadas, sueñan con acariciar su abdomen y sentir los movimientos de su feto, sueñan con decorar el cuarto del/la bebé, piensan en el parto aunque les asuste y aterre, quieren ver a su hijo/a, piensan en el día que lo amamanten y se duerma en su regazo mientras le canta... Todas las mujeres al final del embarazo están preparadas para los dolores, el parto y la lactancia, pero algunas no están informadas de la impotencia que sentirán cuando su bebé no pare de llorar, lo desesperadas que se sentirán ante la falta de sueño, lo frágil que se volverá su autoestima, lo culpables que se sentirán a veces por cosas que están fuera de su control...; no se han informado o no han querido ver la realidad de ser madre. Sea cual sea la causa, algunas madres no están preparadas para la llegada del nuevo miembro a la familia. Estas madres pueden ser más proclives a la tristeza, melancolía o ansiedad debido al desfase entre lo esperado y lo real. ${ }^{27}$

"Cuando estás tan agobiada el niño no se te engancha, ves que llora, que no coge peso...Llega un momento que dices: [...] ¡Pero bueno! [...] ¿Dónde está lo bonito, lo maravilloso?” GDP 2 I2-I

"Sí que lo recuerdo muy doloroso y sobre todo de decir: A mí me han engañado. Porque a mí nadie me ha dicho que esto dolía" GDP2 I2-9

"A mí me han engañado. Porque a mí nadie me ha dicho que esto dolía. [Ríen varias] Era esa sensación de: Esto es un timo." GDP2 I3-I

Algunas mujeres durante el embarazo tienen unas expectativas equivocadas del rol de madre durante la lactancia, piensan que se van a recuperar muy rápido del parto, que la lactancia será algo muy fácil, que van a reincorporarse a su vida social rápidamente, estando dispuestas a recibir gran cantidad de visitas todas las horas del día. Sin embargo, esta idealización del rol de madre choca con el gran esfuerzo físico y psíquico que requiere el trabajo del parto, la

27 "De madre a madre. De mare a mare. Amen arteko langutza. De nai a nai: Realismo ante la maternidad". Liga de la leche. Edición especial "20 años”. Septiembre 2007. 
adaptación y satisfacción de las necesidades del/la recién nacido/a y el cambio tan importante que supone en la familia la llegada de un nuevo miembro.

"Piensas que te van a dar el niño y según te lo dan se va a enganchar al pecho y se va a poner de leche por todos los lados." GDPi 15-4

"No creo que sea nuestra culpa (murmullo) es como que nos engañan he leído libros sobre la lactancia [...], pero da igual, hasta que tu no lo vives, pero es porque nos engañamos, es porque la gente no te cuenta la verdad y todo el mundo te dice que le ha ido superbién" GDPI I5-6

"No sabía que dolía [...],yo iba...pero engañada total. A mí nadie me dijo, [...] qué son los puntos, que cuando te viene la subida parece que bueno, que te pones malísima." $\mathrm{GDP}_{2}$ I2-9

"Me frustró un poco eso: Lo de la subida. Que todo el mundo decía: ¿No te notas más volumen? No notaba absolutamente nada y decía yo: Tengo que tener porque... (Chasquea la lengua) la niña mamaba y al final ya sí que yo notaba como así, algo." GDP2 I3-2

"yo salí diciendo soy mala madre, no voy a conseguirlo esto es horrible, además yo tenía problemas de salud añadidos, con lo cual a mí tampoco me daban un duro porque pudiera dar la lactancia y menos con un pecho eso fue ya el acabose y..." GDPr $3^{-12}$

En las primeras horas después del parto, la madre debe estar dispuesta a vincularse con la criatura, esto le supondrá un enorme trabajo de adaptación a su nueva realidad.

"Es estar con la teta todo el día fuera porque mi hija tenia cólico del lactante, entonces era terminar una toma y enlazar con otra, cuando llegué a mi casa yo pensaba jay Dios mío!" GDPi 6-3

La madre, dependiendo de su equilibrio hormonal, de la aceptación de su nueva imagen corporal, de la adaptación a su rol de madre, de los apoyos familiares y sociales con los que cuente, sufrirá o disfrutará de la crianza de su hijo/a.

"Depende de cómo vengas del parto, [...] cuando vienes con los cambios hormonales, muchísimos puntos, dolor [...]tú ya estás agotada, porque no duermes..." GDY2 3 -Io

"Es tan gratificante [se refiere al amamantamiento] [...] es tan bonito que te dan ganas de contar a los demás lo beneficioso y lo bonito que es y si tuviera otro hijo [...], desde luego repetiría" GDPi ı-8

"Porque todo es sufrir. Y por lo menos eso es el único, cosa...privilegio que nos dan, de poder sentir eso, que ellos no lo pueden sentir, claro "GDY $2 \mathrm{II}^{-2}$ 
"Me sentía súper feliz [...] es un contacto íntimo y no se puede expresar, mirarte el niño y tu mirar al niño [...] aunque estés en un centro comercial rodeado de gente, aunque estés en el sitio más concurrido de personas, te aíslas estás él y tú, no hay otra cosa." GDPI I-5

En todas las épocas y culturas, el ser humano ha experimentado las emociones propias y percibido las ajenas, procurando la dicha y evitando los desagrados, pero lo peculiar del ser humano es que las emociones se conectan con ideas complejas, valores, principios y juicios exclusivos. En la madre esta forma de pensamiento puede producirle sentimientos de culpa, tristeza, miedo, angustia, etc. llegando a ocasionarle un sufrimiento psíquico dependiendo de su vulnerabilidad individual, adaptación a la nueva realidad y apoyo familiar.

"Entonces, me pareció una esclavitud tan grande y algo tan...tanto tenía que dar yo en ese momento" GDY2 I-8

"Hay muchas más mujeres que en el fondo están frustradas por no haber dado el pecho." GDPI I9-7

"Fue horroroso. Yo los tres primeros meses estuve a punto de dejarlo, porque mamaba y mamaba sangre. Era una herida abierta que se te abría cada tres horas" GDP2 2 -6

"Pero eso de la culpa es malísimo. ¿Este niño se queda con hambre? Es verdad, que a lo mejor lo estoy haciendo [...] mal ¿no?” GDY2 I4-8

Asesorar a la mujer y su pareja de los cambios que se producirán en los primeros días, proporcionar un ambiente relajado donde la madre pueda tomarse su tiempo y descansar todo lo posible, limitar las visitas, promover y favorecer la red de apoyo doméstico, hace que la mujer desarrolle habilidades en lactancia, establezca el vínculo con su hijo/a y disfrute del periodo de lactancia. ${ }^{28}$

\begin{abstract}
"También da mucha ternura verle la carita y ahí, tan chiquitita, y chupando. Yo estaba encantada de darle el pecho, yo miraba la hora para ver cuándo le tocaba para darle. Porque era una sensación...Yo, a mí me encantaba darle el pecho" GDY2 2-3

"El mero hecho de poder alimentar al bebe fue algo increíble, la gente me decía te has ahorrado dinero, no lo veía por el dinero; [...] yo lo veía por darle el pecho, para mí fue positivo." GDPi 2-8
\end{abstract}

28 Bibliografía consultada para este capítulo:(Canóniga Pizarro, 2005; Álvarez, Becerra, \& Meneses, 2004). 
"He persistido y me considero súper valiente y estoy súper orgullosa de haber intentado una y otra vez, hasta que mi hijo al final empezó a mamar" GDPi 4-7

"es una cosa tan... muy bonita y un orgullo muy grande para mí el poder alimentar a mi hijo con lo mejor del mundo" GDY2 I-8

"Es tan gratificante [se refiere al amamantamiento] [...] es tan bonito que te dan ganas de contar a los demás lo beneficioso y lo bonito que es y si tuviera otro hijo [...], desde luego repetiría" GDPi ro-8

\section{Dependencia: el apego}

Como se acaba de analizar la lactancia, en la vida de la mujer, puede vivirse como una etapa dura, la madre se siente vulnerable por los cambios físicos y psíquicos que experimenta en el puerperio. Además, los ritmos de la familia giran en torno a las necesidades del/la recién nacido/a, quien depende de ella las veinticuatro horas del día. La crianza del hijo/a supone para la madre abandonar un estilo de vida instaurado y establecer un vínculo emocional con el hijo/a. Estas circunstancias pueden llevar a la madre a vivir el amamantamiento como un trabajo arduo y duro, llegando a verbalizar, en algunos casos, sufrimiento y pérdida de su independencia.

"Claro es un sufrimiento el primer y segundo mes de vida que no duermes, porque mama cada hora y tardan 40 minutos en mamar[...] y se vuelve a despertar y no lloran porque encima como les has enseñado a que cuando se mueven les pones en la teta, al final quien está hecha polvo es la madre." GDPi 7-3

"Que yo he llegado a comer, vamos, de tener que dármelo mi marido. Porque es que ella no paraba de llorar. Y yo sentarme, agarrarla y decirle a mi marido: Dámelo, porque es que yo no puedo" GDY ${ }_{2} 3^{-1}$

La investigación descubre que el inicio del amamantamiento es una etapa de múltiples cambios en la madre, la mujer tiene que adaptarse a su nuevo rol de madre y está emocionalmente vinculada al/la recién nacido/a las veinticuatro horas del día; en los primeros meses de vida, la criatura depende totalmente de los cuidados de su madre y de su padre.

"De estar atada de pies y manos" GDY2 I-8

"O sea, es que todo el día con ellos a cuestas. Y el pecho es lo que tiene “ GDY2 2-6 
"Y es como dices tú [señala a alguien]: es que esto no es vida, es que los primeros meses es así." GDY2 2-4

"por mucho que te ayuden depende de ti cien por cien" GDPI 7-3

El vínculo emocional que desarrolla el niño/a con sus padres (o cuidadores) y que le proporciona la seguridad emocional indispensable para un buen desarrollo de la personalidad fue estudiado por el psicólogo John Bowlby (I907-I990) en su Teoría del apego. La necesidad de la criatura de estar próxima a su madre, de establecer un vínculo emocional, de ser acunada y protegida es la tesis fundamental de la Teoría del Apego. (Becerril Rodríguez, 20I2)

La crianza con apego hace que el/la recién nacido/a busque la cercanía de la madre, ella le proporciona seguridad y además está dispuesta a cubrir sus necesidades físicas y emocionales durante todo el día.

"yo lo que veo del pecho es que solamente es para ti. Yo veo las madres que dicen: Anda, yo el biberón porque así implico al padre." GDY I I7-9

Para la madre el estar dispuesta a proporcionar cuidados al/la bebé las veinticuatro horas del día, le supone un cambio en su rol, abandonar su estilo de vida y un esfuerzo enorme para adaptarse a su nueva realidad, esto lleva a las madres del estudio a manifestar que el amamantamiento es una actividad muy dura y que genera gran dependencia.

"la lactancia es súper dura, es una cosa maravillosa, lo mejor que te puede ocurrir y la comunicación con tu hijo es maravillosa, pero que es durísimo" GDPi 4-7

"Para mí ha sido muy duro. Sobre todo, por las noches." GDY $23^{-6}$

En el puerperio la mujer experimenta cambios anatómicos y fisiológicos, cambios en la relación con la pareja y con la familia, pero sobre todo en el desarrollo de su estilo de la vida diaria. Se puede sentir más vulnerable, ya que los cambios están asociados a nuevas emociones, sentimientos y responsabilidades. En las primeras semanas la madre tiene su atención centrada en el/la recién nacido/a, difícilmente cambia su foco de atención a otros temas, sus prioridades e intereses han cambiado definitivamente. (Alba Romero et al., 20II)

"También yo, como tenía muchas ganas a lo mejor... Yo todo el tiempo era para él. [...] Que yo ha sido todo para él. Que a lo mejor por eso tampoco me ha costado tanto." GDY 2 3-9

La cultura influye en el desempeño del rol de madre, así como en las expectativas que tienen la mujer y quienes la rodean. En general, las mujeres 
tienen muchas expectativas con respecto a lo que significa ser una buena madre: abnegada, tierna, sacrificada, dando lo mejor de sí para sus hijos e hijas. La transición a ser madre, que ocurre en el período del postparto, es de importancia vital para ella, para su autoestima, su satisfacción personal y la construcción de una identidad positiva de sí misma.

Es oportuno recordar que la lactancia demanda a la mujer tiempo y esfuerzo, reduce de forma transitoria las oportunidades laborales y otras actividades de la madre e implica una postergación transitoria del cuidado de otros miembros de la familia y de sí misma. En la vida diaria de la mujer estos hechos pueden suponer un conflicto entre la lactancia y el deseo de ser buena madre para el/la recién nacido/a y otros hijos/as si los hay, realizar otras funciones de cuidadora, atender a la pareja, realizar el trabajo fuera de la casa, llevar a cabo actividades de desarrollo personal o de su autocuidado, dormir, etc. No es raro por tanto el conflicto emocional que genera el postergar estos intereses y/o actividades por la demanda de tiempo y energía que supone la lactancia. Durante los primeros meses de vida del/la recién nacido/a, en la madre casi siempre está presente el cansancio físico y la falta de sueño por las demandas del/la lactante durante la noche. Las mujeres no deben sentirse culpables por estos conflictos de intereses en el período postparto, sino que deben sentirse apoyadas por su pareja o su familia.

"me creaba un poco de ansiedad el pensar que si yo me tenía que ir o faltaba... No podía... no podía comer. Porque es que no lo quería." GDP2 4-4

"Fue una tortura, una batalla, es que sociológicamente nos hemos convertido en mujeres vaca, $[\ldots . .$.$] "GDPI 5-I$

La dificultad que entraña la adaptación al nuevo rol de madre, en ocasiones, hace aflorar en la madre su desconocimiento de muchas de las necesidades que requiere su hijo/a en los primeros días del nacimiento. Sin embargo, el trabajo diario de la lactancia materna permitirá a la mujer establecer la comunicación adecuada con su hijo/a, aumentará su capacidad y conocimientos para cuidar, educar y amar a su hijo/a. No hay buenas o malas madres amamantadoras, no hay una fórmula magistral, simplemente es saberse adaptar al nuevo rol de madre y vivir plenamente sus sentimientos, emociones y relaciones.

\section{Familia: Mi madre, mi marido, mi suegra}

Las mujeres cuando hablan de la familia, por lo general, se refieren a su madre, su suegra y/o su marido. El papel que desarrolla la pareja es estudiado en un subcapítulo dentro de este capítulo. 
A la hora de iniciar, instaurar o mantener la lactancia, la familia ejerce mucha influencia sobre la madre y esta influencia se mantendrá en el tiempo. En algunos casos es positiva porque facilita y favorece la lactancia materna, pero en otras ocasiones, ejerce una influencia negativa porque impide el desarrollo de la lactancia y además puede ser la familia el agente que no permite realizar ésta con total naturalidad.

"Ella [se refiere a su madre] decía que el biberón ni pensarlo, y mi padre también, me decía: No lo pienses, ¿eh? Que no lo pienses [...] Por mis padres yo le di la leche." GDY 2 I2-II

"Como te dejes llevar por las madres y las suegras, vas perdida. Vas perdida." GDY2 I3-4

"Las abuelas [...] entorpecen" EPI r 3 '35"

"Al final quien me enseño en realidad fue una prima mía." GDPr 6-4

En el ámbito rural la cercanía de la familia y los vecinos y vecinas puede influir negativamente para el desarrollo del periodo de lactancia, esto sucede porque las personas con las cuales se relaciona la madre, en base a sus experiencias, creen estar en posesión de la verdad con relación a sus conocimientos de lactancia y sus comentarios pueden influir negativamente sobre la madre, llegando incluso al abandono de la lactancia natural, cuando la madre se siente insegura, "desesperada" o "en un mar de dudas".

"Te hacen sentir como que eres la peor madre del mundo, que no quieres alimentar a tu hijo. Entonces influye mucho. Y gente aquí del pueblo, pues que claro, generalmente estás rodeada de padres, suegros, hermanos, cuñados...Todavía hay más...creo que nos cuesta más trabajo." GDY 4 4-Io

"El primer mes estuve en casa de mi madre y entonces ella me atendía junto con mi padre y mi marido, bueno mi marido estaba un poquito más centrado en mi otra hija" GDPI 6-3

"Ni te preguntan si come bien, si duerme bien, si es tranquilo, ellos simplemente se asoman al carro con experiencia propia y te dicen (cambia la voz): Uy, qué poco come, pero este niño... pero, ¿sigues dándole de mamar? Este niño lo que necesita es un biberón, una buena papilla. Métele más cacitos de cereales, no hagas caso al pediatra. Entonces, cuando estás un poco desesperada, sobre todo al principio, porque tu hijo no hace peso, te hacen sentir como que eres la peor madre del mundo, que no quieres alimentar a tu hijo. Entonces influye mucho [...] estás rodeada de padres, suegros, hermanos, cuñados $[\ldots]$ creo que nos cuesta más trabajo." GDY i 4-Io 
Existen diferencias muy importantes entre el entorno rural y el entorno urbano. En el pueblo el desarrollo infantil dentro del percentil recomendado por la OMS es ser delgado y la delgadez es sinónimo de desnutrición. En esos momentos, es cuando la familia intenta influir negativamente en la madre para que abandone la lactancia y evitar la delgadez del menor.

"No lo ven natural [...], lo que he dicho al principio, que se vive aquí totalmente diferente que en Madrid [se refiere a la lactancia materna]" GDYI I6-2

"Soy de Madrid y paso la mitad del tiempo allí, y yo creo que aquí en el pueblo es totalmente diferente. $\mathrm{O}$ sea, en el pueblo tienes que criar a un niño que se le vea gordo en el carro, y si no, es un niño que está pasando hambre." GDYi 4-8

"Nuestras madres tenían una mentalidad de biberón, [...] Entonces, en el momento en que el niño, eso, se queda un poquito más delgadito ya le echan la culpa al pecho. Y es una tontería porque mi hijo dejó el pecho y se ha seguido quedando igual de delgado." GDYI I4-Io

Si las abuelas no han lactado es más probable que ejerzan una influencia negativa sobre la madre lactante.

"Mi madre tuvo cuatro hijos y a ninguno de los cuatro les dio el pecho, pero porque entonces tampoco había una promoción de la lactancia como la de ahora [...] los primeros días y porque el niño lloraba: Ah, pues dale biberón [...] por una parte sí que me animaban, porque ellos ven y lo entienden ahora, que es lo mejor para los bebés, pero por otra parte... también veían que a lo mejor no tenía yo lo suficiente como para alimentarle" GDP2 10-6

La influencia negativa que algunas familias ejercen sobre la madre, hace que la mujer sucumba a la presión del grupo y abandone la lactancia, este hecho puede ser debido a la inseguridad e incertidumbre que siente la madre en esos momentos de su vida, llegando incluso a negar lo evidente y retirar la lactancia natural, aunque el desarrollo infantil sea el adecuado. Algunas familias incluso pueden llegar a realizar comentarios hirientes hacia la madre para que esta abandone la lactancia.

"No seguí por la influencia de mi madre, de: Ya está bien, que te vas a quitar mucho la vista. Porque tengo muchas dioptrías y ella me decía que me iba a afectar a la vista" GDP 2 2-6

"Mi hermana me decía: Bah, pero darle el pecho [...], ¿qué te va a tener aquí, muerta de sueño? Anda ya, métele un biberón y punto". GDP2 I7-I 
"Yo la quite el pecho porque como me decían que perdía peso... aunque en los papeles, todas las semanas hacía peso, pero como decían "las familias" [Se refiere a los familiares] que no hacía peso, que la introdujera el biberón. Claro, para mí era más fácil” GDY2 II-3

"Cuando me ven dando el pecho: estás loca, no se va a criar el niño, estás loca" GDPi I6-I

Esto se refleja también en las afirmaciones de las profesionales entrevistadas.

"a la mínima dificultad [...] tienen a toda la familia [...] tú no tienes leche, tu leche no vale, esto tiene algún problema y ya está" $\mathrm{EP}_{2} 66^{\prime} 53^{\prime \prime}$

Sin embargo, cuando la familia se implica, apoya y cree en la lactancia natural, trasmite a la madre seguridad, ella se siente cobijada y arropada por los suyos y esto influye positivamente tanto en el inicio como en el mantenimiento de la lactancia. Puede suceder que en un entorno familiar que apueste por la lactancia materna, la abuela sea la primera consejera en lactancia para la madre.

"Yo estuve con mi madre, mi madre es la que me puso a la niña, mi madre se levantaba por las noches para ponérmela, mi madre...Porque tenía más experiencia después de tener ocho." GDY2 I2-9

"Pues a mí es que no me dieron ni el sacaleches ni nada. Yo por mi madre y por mi suegra, que me dijeron así [técnica o posición de amamantamiento]" GDPi I3-7 $^{-7}$

"Mi madre [...] me decía [...] si te la pones al pecho, así desnudita y tú con ella pues te va a subir antes [...] en los dos primeros meses [...] estuvo nada más que con el pecho y estaba yo encantada." $\mathrm{GDP}_{2} \mathrm{I}_{4}^{-} 7$

En ocasiones, puede ocurrir que de tanto insistir a la madre para que realice una lactancia natural, la madre se sienta agobiada e intimidada; en ese caso la defensa a ultranza de la lactancia natural, puede llevar al abandono del amamantamiento.

"Mi madre es defensora de la teta. Me he sentido un poquito agobiada por ella, porque era: Dale la teta, teta, teta. Las leches [...] no valen para nada, dice, y tienes que darle el pecho. Y yo creo, que cuando estás tan agobiada el niño no se te engancha [...] Que ella lo hace con todo...con toda su buena intención" GDP 2 II-I

Los comentarios que la familia realiza con toda su buena intención, pueden ocasionar más inseguridad en la madre y generarle muchas dudas. Los 
mensajes contradictorios en el entorno familiar llegan a confundir a la madre y aunque los familiares quieren lo mejor para ella y el/la bebé, lo único que consiguen al final es que surja la culpa en la madre.

"Si no te ayuda nadie, tú no sabes. Porque además es que te ponen la cabeza...La madre de él, tu suegra, te dice de una manera, tu madre de otra [...]" GDP 2 9-II

"Pero eso de la culpa es malísimo. ¿Este niño se queda con hambre?" "Es verdad, que a lo mejor lo estoy haciendo nada mal ¿no?, tengo que mejorar." GDY2 I3-4

"Pero con la buena intención, a lo mejor estropean más. Cosa que lo que quieren es arreglar." GDY2 2 I3-II

Cuando la madre se ha criado en un entorno familiar donde la lactancia materna era habitual, la mujer copia y reproduce en su hijo o hija el modelo de lactancia aprendido en el seno de su familia, pone en práctica la experiencia, las habilidades y las enseñanzas que observó y aprendió durante su infancia. Este tipo de mujer apuesta por una lactancia materna desde su embarazo y llegado el momento de lactar, la abuela materna será el primer consejero en lactancia para la madre. La mujer, entonces, contará con el apoyo familiar necesario para vencer los avatares que surjan a lo largo del periodo de lactancia.

Es interesante observar que en realidad lo determinante no es el apoyo que pueda dar la abuela en ese momento, sino la realidad que vivió la madre en su infancia, es decir, la representación social que tenga la mujer sobre la lactancia materna.

"Yo soy la primera, luego tengo un hermano, le saco dos años, pero luego al siguiente le saco doce años. Entonces, yo vi de dar de mamar a mi hermano. Yo ya sabía que a mí me habían criado a pecho, a mi otro hermano igual, pero claro, el verla a ella dar de mamar no es lo mismo que te diga: Yo a ti te he dado de mamar y eso. El vínculo que yo vi, pues eso me hizo mucho decir: Yo, yo, yo [quiero] dar de mamar." GDYI 29-I2

Sin embargo, cuando las abuelas no han amamantado, la madre no contará con el suficiente apoyo familiar para vencer todos los avatares del periodo de lactancia. En estos casos la mujer será más proclive a abandonar el amamantamiento de su hijo o hija.

"Cuando fui al Taller de la Lactancia ya estaba desesperada. Yo me ponía nerviosa, los que estaban a mi alrededor también porque la niña lloraba 
mucho, y me decían: (cambia la voz) Esta niña se queda con hambre, esta niña se queda con hambre, tienes que ayudarla con biberón." GDYI 3-II

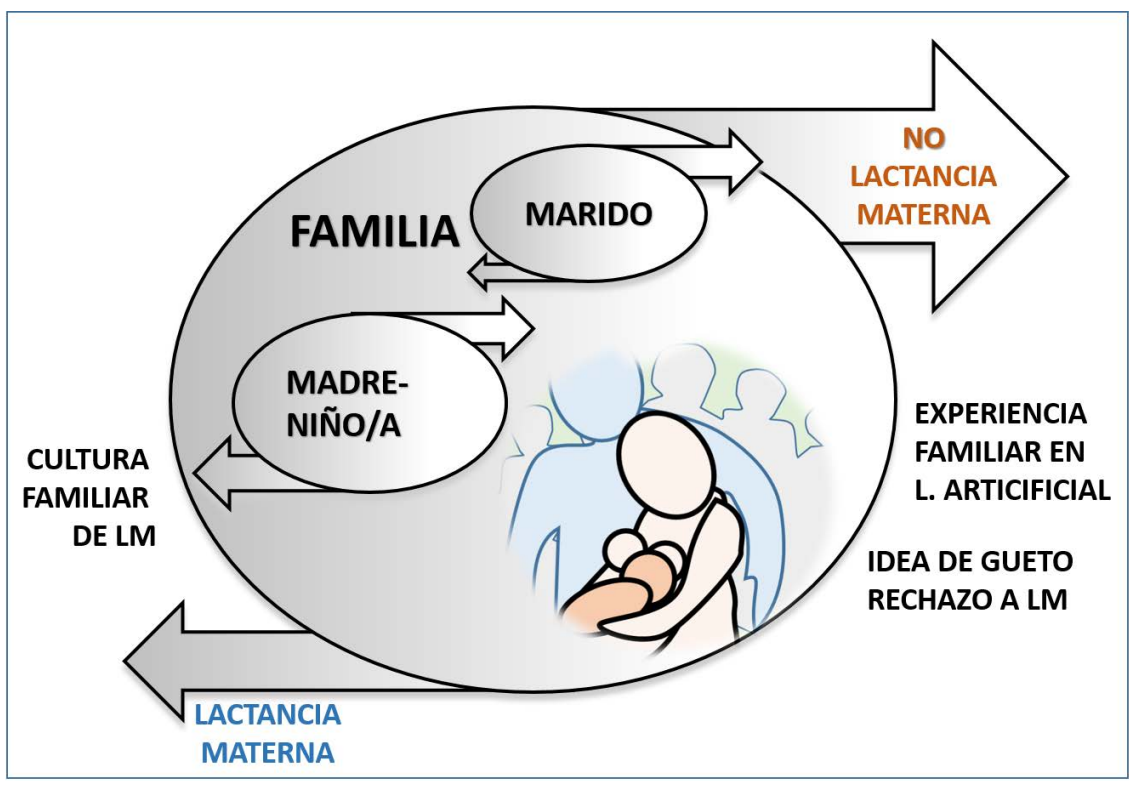

Ilustración 8. Tensiones familiares.

En este caso lo que se observa es la expresión de un proceso de socialización primaria de la madre que no incluía la lactancia materna, por lo que ésta se ve como un añadido en el rol de madre que se debe asumir.

Respecto al objeto de estudio, puede sernos útil analizar las ideas y prácticas de las mujeres, entendiendo que la maternidad, así como la lactancia descansan en representaciones sociales asumidas y compartidas en gran medida en nuestras sociedades, que se asumen como naturales en la socialización primaria y se ponen en práctica en el desempeño concreto del rol de madre.

Una visión de cambio social lleva a reflexionar sobre el papel que los grupos de apoyo juegan en los procesos de socialización secundaria, más o menos estructurados, y que modifican amplían o cuestionan las representaciones sociales asumidas en la socialización primaria. Entender que los talleres funcionan no sólo como grupos de autoayuda sino como grupos en los que se asumen determinadas subculturas es interesante para hacer de este proceso algo consciente tanto para quienes los organizan como para sus participantes. 


\section{Pareja: "Mi marido"}

La llegada del nuevo miembro a la familia entraña una serie de cambios que afectan a todos sus componentes. Debido a los cambios que se producen, el estudio de la pareja tiene que ser abordado como un subcapítulo dentro del capítulo de familia. Todos los miembros de la familia tienen que adaptarse a la nueva realidad y es aquí donde la pareja tiene un papel destacado.

"El padre cuenta como yo" GDY2 I4-II

Ser padres conlleva muchos cambios en la vida de las personas y dependiendo de la representación social que se tenga de estos conceptos, se vivirá la maternidad, la lactancia y la paternidad de forma igualitaria o surgirán situaciones de desigualdad en la pareja. Se puede entrever por tanto que la maternidad, lactancia y pareja están íntimamente ligadas al concepto género.

Cuando la madre cuida a su hijo/a sin la ayuda del padre, aunque este tenga régimen de visitas, no sólo siente que el vínculo afectivo es más fuerte con ella, sino que piensa que el padre se está perdiendo toda una serie de emociones y sentimientos al no vivir el crecimiento y el desarrollo de su bebé día a día.

"Yo soy madre soltera [...] el padre la ve tal y cual, pero no es lo mismo el sentirme yo minuto a minuto estar con ella. Sinceramente ellos se lo pierden" GDPi $7-8$

Desde el inicio de la lactancia la pareja puede ser proactiva, colaborar en los cuidados diarios e involucrarse en la crianza del nuevo ser; pero también puede ocurrir que la pareja sienta que la lactancia materna cambia la relación con la madre, relegándolo a un segundo plano y sienta que el tiempo y la atención que la madre invierte en la pareja ha disminuido.

"A mi marido le encantaba. Hasta [...] ver a la niña cómo se agarraba... y a toda la familia. Que yo era un espectáculo." GDP 2 I8-II

"Mi marido me ha apoyado en todo, incluso me hacía fotos: se enfadó conmigo cuando me dio por llorar a los I5 meses, que me dijeron que tenía que dejar de dar el pecho" GDPi 7-4

"ya no hacemos lo de antes, o ya no tenemos tiempo para nosotros" GDPi6-3

El pediatra Carlos González"29 en una entrevista decía "El papel del padre durante la lactancia no es biológico y por tanto podemos definirlo y moldearlo

29 http://depaapa.blogspot.com.es/2007/02/el-papel-del-padre-durante-la-lactancia_05. html. El papel del padre durante la lactancia podemos definirlo y moldearlo. Consultado en google el 20-01-2015. 
a nuestro gusto. Cada familia se organiza según sus tradiciones, preferencias, expectativas y posibilidades"

La pareja puede haberse criado en un entorno familiar donde la lactancia materna era habitual, recordar cómo fue criado el hombre facilita la lactancia y repetir ese modelo hace que la madre se sienta respaldada, apoyada y comprendida por su pareja. Es vivir la maternidad, la lactancia y la paternidad desde la igualdad.

"Mi marido es el noveno de nueve hermanos, mi suegra ha estado dando el pecho, cada 2 años iba teniendo hijos y dando el pecho a todos, trabajaba y todo, mi marido ve perfecto el pecho." GDPI I9-ıо

Algunas de las verbalizaciones ponen de relieve que la mujer no desea compartir o manifestar sus sentimientos al hombre, no permite a su pareja participar de la lactancia, aunque él quiera ayudar, colaborar y compartir el desgaste físico y emocional que entraña la crianza. Algún discurso informa que observar cómo la mujer amamanta provoca en la pareja cierta intriga, pues no puede sentir y conocer por sí mismo las sensaciones que en esos momentos experimenta la mujer.

"Yo era demasiado quizá...acaparadora [...]. Era como que no quería que nadie me...me ocupara ese momento, $[. .$.$] cuando él me ve que está$ mamando, él siempre dice: Le he visto nacer, [...] y en parte, en algún momento de mi vida sí que me gustaría haber sido mujer para ver lo que sientes tú. [...]Me dice que qué siento yo cuando, cuando él mama." GDYI 2I-I

En otros discursos las madres manifiestan que sus parejas pueden sentir celos de que el hijo/a sea amamantado. Otras veces, les sugieren que abandonen la lactancia, aun a pesar de estar perfectamente instaurada, pues consideran el amamantamiento un obstáculo para realizar sus actividades como pareja:

"Hay veces que mi marido dice: jolín ahora con la teta quítasela ya! Que es muy grande. No podemos salir." GDF30' 56 "

"El mío es por un poquito de celos [...] sí, contigo se calla y conmigo no [...] $\mathrm{GFD}_{3 \mathrm{I}^{\prime} 25 "}$

En otras ocasiones, la mujer durante el periodo de lactancia puede manifestar duda o miedo; la madre se pone nerviosa y trasmite al hombre agobio e inseguridad, en esta situación la pareja se deja imbuir por la incertidumbre y es incapaz de manifestar su apoyo a la lactancia, invitando a la mujer a abandonar el pecho. 
"Los primeros días como él me veía tan agobiada sí que...Me veía muy agobiada a mí porque yo me ponía muy nerviosa porque no se enganchaba. Éste me decía: Mira, pues déjalo y ya...En ese aspecto yo le decía: No, no, si yo quiero darle el pecho. Y le voy a dar el pecho. Pero él se agobió mucho, y claro,él también me decía: Pues mira, déjalo, no le des el pecho." GDPI I9-то.

"Yo podía hablar con mi marido como me sentía, pero mi marido no entendía que a lo mejor a mí me entraban ganas de llorar, en cambio hablabas con otras y te decían a mí me pasa igual" GDYI 22-II

"Mi marido tampoco me animó en ese momento" GDPI 8-6

"[El marido] Si ve que a su mujer le angustia: ¿lo podría dejar? El marido lo que más cómodo le resulte [a la madre]" EPI I3'15"

Para facilitar la incorporación del hombre al cuidado de los hijos e hijas, instituciones como Unicef, asociaciones como la World Alliance for Breastfeeding Action (WABA) o la Asociación hombres por la igualdad de género (AHIGE), han elaborado guías que eviten la discriminación que una sociedad machista pueda generar. Muestran el papel principal y no secundario que debe ocupar el padre junto a la madre y el/la lactante, evitando roles estereotipados que puedan generar discriminación..$^{30}$

En otras circunstancias las madres se sienten relegadas, llegando a manifestar soledad y enfado con la pareja. Las mujeres no solo se sienten incomprendidas por su familia y pareja en ocasiones se sienten maltratadas por la sociedad. El artículo de opinión "Madre o vaca" publicado en el periódico el Mundo $^{3 \mathrm{t}}$ es un claro ejemplo.

"Enfadarme más con su padre que con él. Yo con él, yo no." GDY2 $4^{-1}$

"Yo muy sola, me sentí muy sola, porque mi marido estaba siempre trabajando y me decía pues dale un biberón y ya está (murmullo) y yo luchando sola y llorando porque no dormía nada, que pena, yo que sé." GDPI 7-8

"Una filosofa francesa [...] los hombres buscan mujeres más disponibles porque nos convertimos en mujeres vaca, eso hasta una propia mujer entonces claro más daño nos hacemos nosotras." ellos a lo que están acostumbrados en su casa" GDPI I9-8

30 http://www.llli.org/docs/fathers_support07.pdf. Rol del padre en la lactancia. Consultado en google 20-01-2015.

31 MAGAZINE DEL MUNDO. n 57717 de octubre 2010. Artículo "Madre o Vaca". 
"Leo que hay un montón de mujeres que leen e incluso escriben que nos hemos convertido en mujeres vaca y que los hombres buscan mujeres que estén más disponibles" GDPI 5-I

El artículo de opinión "Madre o vaca", el cual no ha dejado indiferentes a las mujeres que han participado en las entrevistas grupales, está en sintonía con la corriente de pensamiento que defiende la filósofa francesa Elisabeth Badinter comentada en la introducción de este trabajo.

En las entrevistas grupales las mujeres también verbalizan que una vez instaurada la lactancia la madre tiene la sensación de no descansar, de sentirse desbordada, de no tener tiempo para ella, de no dar abasto y parecer que continuamente está amamantando al/la recién nacido/a, es entonces cuando la pareja invita a la mujer a introducir el biberón.

"Mi marido sí que me decía pues no pases mala noche dale un biberón y yo le decía no, si yo tengo leche yo le doy leche materna" GDPi 6-3

"Que yo he llegado a comer, vamos, de tener que dármelo mi marido. Porque es que ella no paraba de llorar. Y yo sentarme, agarrarla y decirle a mi marido: Dámelo, porque es que yo no puedo" GDY2 I5³ $^{-3}$

"Pues le tendrás que dar un biberón, pues le tendrás que ayudar porque... la niña está llorando porque tiene hambre. Y así todo el rato [...]. Te agobiaba." GDY $23-8$

Cuando la mujer está cansada, desbordada y abatida por el esfuerzo y el trabajo que conlleva la lactancia, las palabras que el pediatra Carlos González manifestó, en una entrevista para definir el papel de los padres, tienen un gran acierto:

"Los padres pueden apoyar a su esposa, asegurarle que lo está haciendo muy bien, que están orgullosos de ver qué buena madre es; que, aunque no tenga tiempo de arreglarse está más guapa que nunca. Pueden hacerla reír. Pueden protegerla frente a las críticas de familiares y otras personas que no estén de acuerdo con la lactancia. Pueden sacar al bebé a pasear un par de horitas para que la madre pueda dormir la siesta." ${ }^{2}$

En alguna unidad familiar de las estudiadas en las entrevistas grupales, puede surgir una ambivalencia de sentimientos en torno a la lactancia materna: la pareja se sacrifica y renuncia al vínculo generado con su hijo o

32 http://depaapa.blogspot.com.es/2007/02/el-papel-del-padre-durante-la-lactancia_05. html. El papel del padre durante la lactancia podemos definirlo y moldearlo. Consultado en google el 20-01-2015. 
hija a través de la lactancia artificial y apuesta por el amamantamiento, pero en la mujer surge una imagen negativa con relación a la lactancia materna, aunque siga amamantando.

"Se sacrificó entre comillas, porque para él darle el biberón era como sentirse más cerca del niño [...] prefirió que quitáramos ese biberón que antes dábamos por la noche [...] con el pecho era suficiente y él prefirió decir lo quito para convertirme en mujer vaca, pues vale soy mujer vaca." GDPi 20-5

$\mathrm{Al}$ analizar las citas se observa que algunas mujeres trasmiten los comentarios que sus parejas hacían cuando amamantaban en público. Manifiestan pudor ante la lactancia en público, pero amamantar en la calle no es un impedimento para seguir mamando. Todas estas citas relacionadas con el pecho y la exhibición en público para amamantar, están relacionadas con la imagen corporal de la mujer y el amamantamiento, pero además ligadas al pudor de no poder exponer el pecho por tener un componente sexual. Todo ello se analiza en el capítulo 4.2.4.I La imagen de la mujer lactante.

"Porque mi marido no es la típica persona de: Bah, saca aquí el pecho." GDY2 I4-IO

"Mi marido le importaba 3 narices que me vieran dando el pecho [...] tan orgulloso, al principio me decía " no se te ocurrirá darlo en público, aquí cuando venga alguien te vas a la habitación "y luego decía "vamos dale de comer " porque él sentía que estaba bien el niño." GDPI i6-4

"A mi marido no le gusta que lo saque en la calle, pero me dice que le dé el pecho. (Sube el tono de voz) Que me tape, eso sí. Pero que le dé el pecho. (Se ríe). Y sobre todo que vigile donde le dé el pecho." GDY 2 I5-4

Tradicionalmente la identidad masculina se construyó a través de la identidad laboral, siendo el trabajo fuera de casa el centro y motor de la vida del hombre, se les educaba para alcanzar el éxito en el ámbito laboral; las demandas del trabajo en la esfera pública tenían prioridad, estas ideas explican por qué se excluía de la identidad masculina el cuidado hacia los demás. Esta forma de entender la vida tiene sus valores y también sus prejuicios: así, el varón se convertía en el que hacía "todo por la familia, pero sin la familia”. Así, los hombres generalmente dentro de las tareas del hogar, actúan de manera diferente entre el cuidado a los hijos y las hijas y las tareas domésticas.

Por otro lado, muchos varones que participan activamente en el trabajo de la esfera privada, sin embargo, delegan en la mujer la gestión, planificación, la 
organización y la responsabilidad de este espacio. Para vivir la paternidad con alegría y responsabilidad sería necesario compartir la vida, desde la ayuda mutua entre iguales y aprender a estar con la criatura en los primeros meses de vida. Esto es algo más que traer el dinero a casa, es participar en el cuidado del hijo/a.

"Piensan que no participan, es como... ellos dos están en su burbuja, en su momento ideal, qué felices son los dos, cuánto se quieren... y yo aquí fuera, [...] y me ha propuesto sacarme un biberón y él darle el biberón" $\mathrm{GDF} 32^{\prime} \mathrm{O} 2$

Para evitar que la relación de pareja se resienta con la llegada de un nuevo ser es imprescindible que la pareja coopere en los cuidados y en la educación del nuevo miembro, así los nuevos sentimientos y responsabilidades serán un espacio de encuentro entre los miembros de la unidad familia. La AHIGE ${ }^{33}$ anima a los hombres a seguir ese modelo de actuación:

"Cuidando cuidas la relación: Inicias un camino de comunicación y confianza que podréis recorrer y vivir como un gran regalo que os da la vida. Es cierto que también habrá problemas y situaciones dolorosas: así son las relaciones de amor en realidad. Aun así, este amor es una experiencia única." (AHIGE, 2008)

Este modo de entender la paternidad facilita la adaptación de todos los componentes de la unidad familiar a la nueva realidad. La paternidad vinculará al hombre en la responsabilidad de la crianza y educación de sus hijos/as y en este contexto, el padre y la madre asumen al nuevo miembro como un proyecto de vida en común, así el hombre será un gran apoyo para la madre, ayudándola en los momentos de cansancio y en las horas difíciles, al comprenderla facilitará la lactancia, y ella se sentirá segura, pero incluso él llegará a luchar por la continuidad de la lactancia, aunque la madre quiera dejarla.

"Llegué del hospital y cuando llegaron las tres de la mañana y tuve que sentarme en la cama y darle la teta, tenía yo más sueño que el muchacho, y yo daba más cabezazos que él, mi marido vio el riesgo y me dijo métetelo en la cama y dáselo tumbada que yo me voy a dormir a la otra habitación" $\mathrm{GDF}_{43}{ }^{\prime} 39$

"A los nueve meses dije: Le voy a quitar el pecho. Y mi marido: No, no, no. Y yo: que sí, que sí, que sí. Y seguí hasta el año." GDY2 I5-2

Sin embargo, en las unidades familiares donde la llegada del nuevo ser ha sido desestabilizadora de la relación y la carga de trabajo, incrementada

33 Asociación hombres por la igualdad de género (AHIGE). 
por la crianza del nuevo miembro, no es bien aceptada; todo esto genera un desequilibrio en la pareja, que puede en algún caso, suponer tensiones que abocan a la ruptura de la relación y esta "salta por los aires". El amamantamiento genera la ruptura de la familia.

"yo tenía que esconderme[...] en mi casa, me tenía que esconder, el que era mi marido le daba asco verme al niño enganchado a la teta, fíjate y entonces me decía que vaya mierda que volver a casa y encontrarse a la mujer gorda con la teta al aire" GDPI $5^{-1}$

"Mi hijo tiene 18 meses y sigue siendo lactante, pero a mí la lactancia me ha costado incluso el matrimonio" GDPr $4^{-7}$

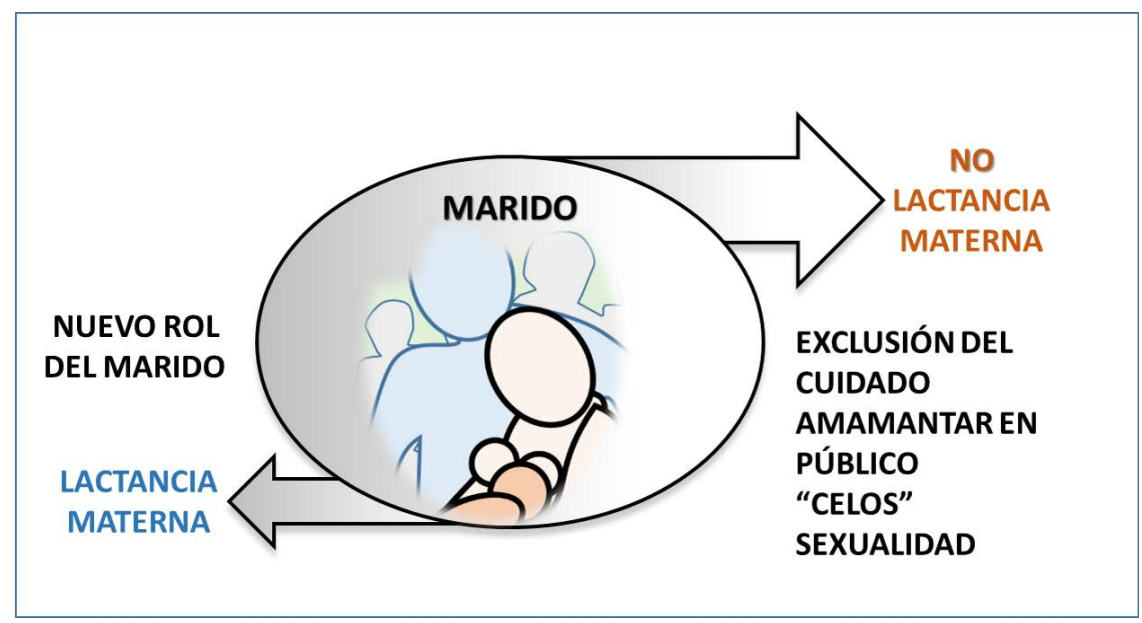

Ilustración 9. Tensiones con la pareja.

En resumen los comentarios de las mujeres oscilan entre diversas posiciones discursivas, desde la crítica o el reflejo de situaciones de desigualdad que podríamos considerar de origen patriarcal, pasando por críticas o reflejos de visiones feministas clásicas tipo igualitario (donde la lactancia materna aparece como amenaza a la igualdad), hasta llegar a visiones más afines al ecofeminismo o lactivismo (donde amamantar es un derecho de la madre y ser amamantado un derecho del niño/a, en cualquier lugar, sin miradas ni comentarios de desaprobación y hasta que el niño/a desee).

Esta visión puede estar muy presente en las mujeres que acuden a los talleres y puede incluso que sea buscada por la mujer que acude a ellos, quizá porque: aparece como antagónica al machismo; y sigue la tendencia pro-lactancia y anti-biberón. 
Sin embargo, esta visión por esencialista puede inducir a la idea de que ser mujer lleva implícito lactar como valor irrenunciable por encima de otras opciones personales o profesionales, abocando en la práctica a la mujer a un rol muy tradicional, aunque revestido de feminismo. Algunos autores han criticado esta visión dual (naturaleza-cultura y mujer-hombre) por determinista y esencialista, al entender la naturaleza como algo biológico, sin dimensión cultural y a la mujer como portadora de unos valores inherentes al hecho de procrear, cuidar y nutrir. (Jackson \& Pearson, 1998)

Esta visión también puede ser criticable por el riesgo de caer en el "fundamentalismo excluyente" hacia las madres que practican otras formas de lactancia, llegando a ser denominados por ello grupos sectarios.

Después del análisis de los resultados en este subcapítulo podemos extraer algunas recomendaciones para el desarrollo de los talleres como que se favorezca que los talleres sean "inclusivos", para evitar posiciones "esencialistas", centrándose en el hecho de la promoción de la lactancia materna; y que en los talleres se analice la lactancia materna en relación a las posiciones feministas, y observando las relaciones de género que la lactancia materna puede hacer aflorar en las mujeres que participan en ellos.

\subsubsection{PAPEL DE LOS Y LAS PROFESIONALES DE LA SALUD. "PERO NO SE DANCUENTA DE QUETÚ NO SABES"}

Los/las profesionales de la salud se encuentran en una posición única para llevar a cabo la promoción, protección y apoyo a la lactancia materna, teniendo el privilegio de ayudar tanto en el inicio como en su mantenimiento. Los requisitos y herramientas para lograr el asesoramiento en lactancia serán la capacitación y la actualización de los conocimientos de los/las profesionales, además de una actitud positiva para una buena promoción y desarrollo. La información que faciliten debe ser adecuada, correcta y siempre basada en la evidencia científica. De ahí que las habilidades de asesoramiento del/la profesional y su formación sean de vital importancia para lograr una lactancia exitosa. ${ }^{34}$

En este apartado se aborda la visión que tienen las mujeres que asistieron a los talleres sobre los/las profesionales de la salud, tanto de hospital como de atención primaria, y la atención que se les dispensó en relación con la lactancia materna. Además, analiza sus opiniones sobre las distintas categorías profesionales: enfermeras/os, matronas/es, auxiliares, pediatras o ginecólogos/as y las contradicciones entre ellos/as en relación con el apoyo o no a la lactancia natural.

34 Ampliamente estudiado en el apartado 4.1.2 Promoción de la lactancia materna. 
"Duró dos meses con el pecho, y gracias al taller de la lactancia, porque si no, no hubiese tomado ni un día, porque lo que es en el hospital...no me ayudaron en nada. Absolutamente en nada" GDYI I-II

En una primera aproximación se puede ver que hay abundantes citas y no existen diferencias entre las variables del estudio.

\section{En el hospital: "No saben guiarte”}

Cuando no se dan los requisitos mencionados con anterioridad y los/as profesionales de la salud no son expertos en lactancia materna, ciertas conductas o comentarios, tanto en el paritorio como en la planta de hospitalización, pueden suponer un obstáculo para iniciar la lactancia materna e incluso pueden crear dificultades para mantenerla. En ocasiones, un simple comentario realizado por un o una profesional en presencia de la madre, puede tener una influencia muy negativa sobre ella y su capacidad para amamantar.

"[Me dijo: ] ¿con esa teta quieres dar el pecho? Vas tú apañá" GDF I6 200"

"cuando has dado a luz y los profesionales de allí te han tocado y han dicho: no hay leche, toma biberón y se lo vas a dar cada tres horas y dale agua... entonces $[\ldots]$ ¿..qué está pasando?” $\mathrm{EP}_{2} 67^{\prime} 36^{\prime \prime}$

"A mí cuando me venía me dijeron ellas: [Se refiere al personal de la planta] ya puedes rezar a la patrona de tu pueblo, que no vas a tener leche. Que con "eso" no vas a poder darle [de mamar]" GDY2 7-10

Generalmente se considera que, si el parto es eutócico y en el paritorio no se separa a la madre del/la recién nacido/a, lo habitual es que el niño/a mame sin dificultad desde los primeros minutos de su vida. Sin embargo, algunas mujeres opinan que los/las profesionales de la salud sienten extrañeza al observar que una criatura lacta sin problemas desde el inicio de la vida cuando la madre es primípara.

"Me sacó el pecho, y enseguida se enganchó. Es que se quedó ella como diciendo...Parece mentira que sea la primera y lo bien que...". GDY2 $7^{-14}$ "Tú parece como que hubieras dado toda la vida de mamar a [...]. Como si hubieras...y era la primera. [...] Porque ya sabía." GDY 2 7-Ir yı2

Por el contrario, cuando la madre y el/la recién nacido/a fueron separados en el paritorio por diversas causas (patología en la madre relacionada con el puerperio inmediato, parto instrumentalizado que requirió vigilancia del recién nacido o cesárea), entonces la lactancia materna no se inició espon- 
táneamente y las madres necesitaron ayuda para la instauración, para evitar la aparición de complicaciones y dificultades en el hospital. Muchas mujeres participantes del estudio verbalizan que en esos momentos tan críticos, no obtuvieron el asesoramiento necesario para iniciar la lactancia y no recibieron por parte del personal sanitario, la ayuda necesaria para instaurar la lactancia materna, incluso comentan que llegado el caso un o una recién nacido/a puede recibir alimentación en biberón aunque la madre haya expresado su negativa.

"No saben guiarte. Y se supone que en un hospital que se dedica... a los bebés deberían...Yo no digo que sepan mucho, porque a lo mejor la lactancia es un...no sé cómo decir [...] pero bueno, que tengan algo de idea, porque el primer paso es en el hospital." GDYI 7-4

"Decían cuando le tengas en el pecho, él te va a buscar el pezón, mi hijo no buscaba el pezón, yo me decía es mi hijo que le acabo de dar a luz y no me busca el pezón, yo no tengo leche y yo le ponía y nada, entonces él intentaba chupar, pero no sacaba nada [...] al final acabaron dándole algún biberón en el hospital, a pesar de mi negativa." GDY2 $25^{-9}$

"los del hospital, lo primero que me dijeron, porque mi hijo el problema que tiene es que se le va mucho la lengua, entonces el pezón me lo metía para dentro, y entonces no se enganchaba. Luego ya [...] una pezonera, [...] No te preocupes que ahora te traemos un biberón" GDY I 5-15

En otras ocasiones las madres necesitan ayuda para conseguir una postura adecuada que: facilite la lactancia, no produzca grietas en el pezón y no sienta dolor al succionar el/la bebé. En resumen, la madre debe estar cómoda aún a pesar de su inexperiencia, la episiotomía o la cicatriz de la cesárea si existe, la vía periférica, etc., además, el niño/a no tiene que tragar aire y debe sentirse seguro; consiguiendo todas estas premisas la lactancia será eficaz.

"A mí me llegaba una enfermera que cogía, me cogía el pecho, me ponía al niño y sí, el niño se enganchaba, pero una vez que ya se soltaba luego yo ya no sabía cómo volverle a poner." GDY i 8-8

"Cuando me empezó a poner el niño [se refiere al personal del hospital] $[\ldots]$ a mí me lo puso de pie y se enganchó [...] el niño no tiene fuerza y le tienes que poner en pie; para mí cambió todo o sea fue de estar llorando en la habitación con mi marido: Dios que he hecho, que he hecho, que he hecho. A cada tres horas a ver que ha hecho el niño" GDPI I $17-2$

Las citas en las que las mujeres se encuentran insatisfechas por el trato que reciben en el hospital son numerosas. Estas mujeres manifiestan que les 
hubiera gustado que algún/a profesional les hubiese ayudado a ponerse el niño/a al pecho, les hubiera enseñado "la técnica de amamantar", las posturas más adecuadas...Pero también critican la falta de empatía, la falta de dedicación de algunos/as profesionales en esos momentos de labilidad emocional, además con algunos comentarios o ciertas actitudes por parte de los/las profesionales, las madres incluso se sienten "mal cuidadas".

"Me decían esta es la cosa rara que está aquí, le da el pecho para jugar un poco y ya está, pero a mí nadie me ayudó, ojalá me hubiesen ayudado allí, simplemente me dijeron que me pusiera pezoneras porque a lo mejor así el niño se enganchaba" GDPi i8-5

"No te dicen nada. Vamos, que no te explican, no sabes...A ver, cada persona es un mundo y ellos están cansados de ver a gente, está claro. Y pasan, pero tú eres única, entonces no sabes, es que no sabes." GDP2 IO-5

"Me atendieron fatal." GDY2 5-7

"En el hospital no me ayudaron nada, todo lo contrario." GDFıo'o3"

En opinión de algunas madres, al menos en ciertos hospitales, la lactancia materna no es considerada una prioridad y por lo tanto no se apoya y no se favorece que las madres que lo desean amamanten a su hijo o hija.

"si quieren en el hospital, hacen que tu hijo no tome el pecho, nadie te ayuda."GDPi 5-I

"Cuando das a luz en el hospital. Que nadie te enseña nada." GDP2 9-3

"No hay nadie que te diga: Te pongo a la niña en el pecho" GDP2 9-7

No sólo ven como negativo la falta de ayuda a la hora de iniciar el amamantamiento, sino también ciertos comentarios que pueden desanimar a la mujer a la hora de lactar a su hijo/a.

"En el hospital había enfermeras [...] que decían, incluso siendo compañeras, hay niños que no pueden mamar y no pasa nada, hay madres que no tienen leche y se acabó; eso de que hay madres que no tienen leche es mentira, pero como te lo digan 2 o 3 veces y te pille baja te crees que no tienes leche" GDPi i8-6

Algunas madres se sienten abandonadas después del parto, en su opinión, a la mujer durante los nueve meses del embarazo, se le realizan numerosas pruebas: analíticas de sangre, de orina, frotis, ecografías, etc., mientras que después del parto el personal sanitario se centra en el/la recién nacido/a, se explora y vigila a la criatura para descartar patologías 
en las primeras horas de vida y sin embargo la madre y la lactancia materna se ve relegada a un segundo plano.

"Es como que se olvidan de la madre y se quedan con el bebé." GDY2 23-I2 "Yo es una sugerencia que quería hacer, pues bueno poned algún control para la madre después que ha dado a luz porque simplemente es como que te esfumas"GDY2 25-IIYI2

El embarazo y el parto hace muchos años que se ha medicalizado, es decir, que un proceso natural y no patológico se controla por el sistema sanitario como si lo fuera, en cambio la lactancia materna todavía no se ha medicalizado, por tanto, la madre se siente abandonada, pues en ciertos hospitales como se ha comentado, la lactancia materna se considera algo natural que debería establecerse por sí sola entre la madre y el hijo/a sin ayuda de un/a profesional.

"Porque yo tuve un embarazo de alto riesgo. Entonces, bueno, me tenían controladísima, me hacían ecografías, análisis, tal, pruebas, esto, lo otro...Y de repente ya, doy a luz y ya no hay más." GDY 2 24-8

\section{En Atención Primaria: "Incluso es que te atienden a otros horarios"}

Desde las primeras horas de vida del hijo/a, hasta que aumenta la producción de leche y se instaura la lactancia materna, muchas madres necesitan de un/a profesional capaz de resolverles las dudas, asesorarlas en la técnica de la lactancia y apoyarlas emocionalmente. Como se trató en el apartado 4.I.4 del estudio, algunas mujeres reconocen que no recibieron esa ayuda hasta que no llegaron al taller de apoyo a la lactancia de su centro de salud.

"No nos enseñan mucho a saber dar el pecho que aquí donde nos enseñan es en el taller de lactancia" GDPr 6-4

"que fue un trabajo; tanto mío como del Taller, porque ya te digo que no...y me dedicaron mucho tiempo y mucho apoyo. Por eso pienso y he dicho al principio que la ayuda debería venir a lo mejor un poco antes, del hospital." GDYI 6-I

La relación con los/las enfermeros/as responsables del taller suele ser muy bien valorada, en ellos/as encuentran el asesoramiento profesional necesario para iniciar la lactancia, pero también, y no menos importante, el apoyo emocional y la empatía que tanto valoran las mujeres en esos momentos.

"Iba nada más que para desahogo porque para mí Lola y Javier han sido mis pañuelos de lágrimas.” GDY2 I3-6 
Si no se tienen en cuenta el estado emocional de la madre y su vulnerabilidad en los primeros momentos del puerperio, cualquier consejo o comentario que se haga por parte de los/las profesionales con poca sensibilidad pude hacer dudar a la madre sobre su capacidad para criar a su hijo/a.

"la enfermera que tenía en lactancia yo salía llorando, yo me decía soy mala madre, soy una torpe porque me dijo [...], que con las pezoneras existe el problema de que $[\ldots]$ se le puede cortar antes la leche a la madre" GDPi 3 -I2

La disponibilidad, la accesibilidad y la implicación en la lactancia materna de las enfermeras y enfermeros de atención primaria responsables de los talleres, son destacables para algunas mujeres.

"Incluso es que te atienden a otros horarios" GDYI I2-2

La habilidad para transmitir confianza a la madre sobre su propia capacidad para amamantar a su hijo/a y la dedicación del tiempo necesario para cada caso, es otro aspecto al que hacen referencia las madres al hablar de los/ as enfermeros/as de los grupos de apoyo.

"todo el tiempo que yo necesité estuvo conmigo, a ver si el niño se enganchaba y tal, y al final se enganchó." GDYI 2-I

"Estuvo conmigo, yo iba con mi hija [a la consulta]. Y ponía a la niña [a mamar] y me decía [la enfermera]: Tranquila, [...] no tienes que hacer nada [para amamantar] Y estuvo así, por lo menos...casi quince días conmigo" GDY 2 8-7

Las mujeres participantes en el estudio disponen de un taller de apoyo a la lactancia materna en sus centros de salud. En el caso del taller de Yepes la enfermera que les atiende durante el embarazo también es responsable del taller, junto con el "enfermero de pediatría”, por lo que es fácil que ya se conozcan. En el caso del taller urbano y el de Fuensalida las responsables son dos "enfermeras de pediatría", por tanto, cuando la madre tiene otro hijo/a más mayor también existe la posibilidad de que se conozcan. Al contrario que en el hospital donde no suelen conocer a los/las profesionales que las atienden durante su estancia.

Por otro lado, los/las profesionales responsables de los talleres son expertos/as en lactancia materna, se han formado específicamente, han asistido a cursos, disponen de conocimientos y habilidades que ayudan a que la relación con las madres sea mejor. 


\section{Otros profesionales}

Las referencias sobre otros y otras profesionales son escasas, tan solo algún comentario aislado. Durante la estancia de las mujeres en el hospital, los comentarios de las mujeres se pueden referir tanto a matrones y matronas como enfermeros/as, auxiliares de enfermería, ginecólogos/as... pero no parece que tengan, según ellas, un papel diferenciado en cuanto a su implicación en la defensa de la lactancia materna, como se comentará, parece que las actividades que desarrollan estos y estas profesionales dependen más de las preferencias personales o la voluntariedad que del tipo de profesional.

"Ese día [...] se les notaba a las matronas que me atendieron que estaban por la lactancia materna." GDY2 7-3

"Apáñate como puedas. Y claro, al final vino la ginecóloga y dijo: Sacadla algo, porque la va a explotar, la va a explotar. Pero la que había por allí la... matrona o quien fuera fatal, las auxiliares fatal." GDY2 4-I6

"Estuvo en neonatos porque el niño nació en Madrid y allí coincidí con una auxiliar experta en lactancia y a pesar de que estaba lleno de cables y de tubos, me lo empezó a poner y me subió la leche a las 72 horas" GDPI 2-I5

En cuanto a otros/as profesionales distintos a los/las responsables del taller en atención primaria, sólo hacen referencia a algún médico/a o pediatra, a quienes consideran no estar muy al día en cuanto a las recomendaciones que hace la OMS en materia de lactancia materna.

"Hablamos de médicos que se han quedado en el pasado [...] no entendía que le diera io minutitos ahora al niño y que después de esos io minutitos me volviera a enganchar al niño, que eso era vicio." GDPI I2-2

"Mi pediatra no sabe ni la mitad de lo que yo hago [...] mi hijo está creciendo sano y feliz, pues ya está, ¿por qué lo voy a hacer de otra manera? [...] estoy súper orgullosa, sabes y creo en el destete natural [...]. Por qué le voy a decir a mi hijo, si para él es un placer y para mí también es un placer, que deje de mamar" GDPi I2-3

\section{Contradicciones: "entre ellos no están coordinados"}

En el estudio las mujeres destacan la falta de coordinación entre los/las profesionales, la falta de políticas hospitalarias de apoyo a la lactancia materna, de protocolos de actuación en los hospitales donde parieron, etc. Así la ayuda que algunas madres reciben dependerá del o la profesional que esté en ese turno, de sus conocimientos, habilidades, de su predisposición o voluntariedad 
a la hora de defender la lactancia natural, es decir de la suerte que tenga la mujer de coincidir con ciertos/as profesionales.

"Vamos, yo con mi hijo tuve que preguntar que si podía beber agua, porque me dijeron en el primer momento que no, y a vosotras os han dicho que sí desde el primer día, que se podía beber agua." GDYI Io-4

"Sobre todo es tener suerte de la enfermera que te toque" GDP2 9-II

"Yo en mi caso tengo que hablar bien del hospital." [...] no sé, que a lo mejor que con la gente que me tocó... ese día, estaban muy por la labor" $\mathrm{GDY}_{2} 7$ - $\mathrm{Y}_{3}$

"Pues eso, pues eso es lo que digo, que entre ellos no están coordinados." GDYi Io-8

"Una auxiliar se dedicaba muchísimo [...] al lactario como sala [...] les daba unas charlas impresionantes, pero a la vez que les ayudaba a sacarse la leche, $[\ldots]$ les calmaba que es lo que necesitan muchísimo [...] lo hacía voluntariamente"EPr $39^{\prime} 27^{\prime \prime}$

Al no existir políticas de defensa de la lactancia materna ni protocolos de actuación orientados a promover la lactancia natural, los/las profesionales de la salud se contradicen a la hora de asesorar a las madres.

"Yo no me quejo del hospital de Toledo, yo me quejo de ciertas personas. Yo he tenido una experiencia buenísima [...] y fue cambiar de turno y liarla." GDF 15'30"

"Le preguntaba: Bueno, ¿y cuánto tiene que mamar? Unas me decían: A demanda. Otras me decían: No, no, le tienes que poner veinte minutos en cada pecho. No, no, no, cinco minutos porque es muy chiquitito. Digo: Bueno, a ver, ¿en qué quedamos? GDYi 7-4.

En el análisis de sus opiniones también parece que influye la edad de los/ las profesionales que asesoran a la madre; consideran que los/as más noveles parece que tienen mejor disposición a ayudar y son más amables que quienes tienen más experiencia; esto probablemente se debe a que en las universidades se ha incluido en los programas formativos la lactancia materna, por lo que los/las profesionales más jóvenes tendrían mejor formación. Además, habría que tener en cuenta que los/las profesionales con más experiencia, después de mucho tiempo de ejercicio pueden tener desencanto o decepción con su profesión llegando a sufrir el llamado "síndrome de burn-out".

"Debería tener todo el mundo la misma formación, el mismo trato" GDF $72^{\prime} 48^{\prime \prime}$ 
"los profesionales se tienen que ir reciclando, tienen que ir aprendiendo nuevas cosas, ir adaptándose a las nuevas necesidades" GDF $77^{\prime} 29^{\prime \prime}$

"En el hospital [...] un ATS muy amable, un chico, no tuve problema, me dijo: Venga, ponla a mamar, pero tú túmbate y te la pongo yo en el pecho. Llegó una enfermera ya mayor y me dijo que nada de nada, que tumbada que nada, que en una silla sentada. [...]Y dije, pero bueno, ¿qué es esto?" GDYi $7^{-1}$

"Mira, no vayáis a preguntarla porque es que me va a coger manía. Porque es que venía de malas maneras" GDYı 8-г2 y 9-I

Si como ya se ha comentado entre los/las profesionales del hospital no hay coordinación a la hora de asesorarlas, tampoco entre atención especializada y atención primaria existe tal coordinación; lo que recomiendan en el hospital lo desaconsejan en atención primaria y viceversa. Además, tampoco se ponen de acuerdo los/las profesionales de medicina y enfermería de atención primaria.

"En el hospital me recomendaron que me pusiera pezoneras [...] y cuando vine aquí la enfermera que tenía en lactancia [...] me dijo no se me ocurriera que los consejos que siempre se dan en los hospitales, de las pezoneras, que con las pezoneras existe el problema de que al bebé se le puede cortar antes la leche a la madre, porque no chupan igual" GDPI 3-I2

"Yo me fui a mi médico y me dijo que lo dejase y ya está. [...] Pero Lola me dijo que no. Que es normal, que a todas las madres nos pasa, que siguiera" GDY2 9-5

Las contradicciones también se dan entre lo que aconseja la OMS en cuanto a duración de la lactancia materna exclusiva y el permiso maternal vigente en nuestro país.

"Es incompatible porque te aconsejan seis meses de lactancia y luego te dan cuatro de baja." GDPi 3-I2

Existen estudios científicos que resaltan que las intervenciones de profesionales de la salud en el parto y en el puerperio inmediato pueden interferir en la lactancia: llevarse al niño/a para bañarlo enseguida, ponerle colirio en los ojos, administrarle vitamina $\mathrm{K}$, separar a la madre del hijo/a para que ella descanse, dar biberón con leche de fórmula, dar chupete, etc. Estos estudios aportan la evidencia científica de que cuanto más natural sea el parto, y menos se intervenga en el puerperio inmediato por parte de los/las profesionales, más fácil será establecer la lactancia materna. (Righard \& Alade, I990)

La Iniciativa para la Humanización de la Asistencia al Nacimiento y la lactancia (IHAN) fue lanzada por la OMS-UNICEF en I99I-I992, para 
animar a los hospitales y en particular a las salas de maternidad a adoptar las prácticas que protejan, promuevan y apoyen la lactancia materna exclusiva desde el nacimiento. Entre los diez pasos que proponen para una lactancia exitosa están: Disponer de una política sobre lactancia materna y capacitar a todo el personal. Son dos aspectos que las mujeres del estudio echan en falta en los hospitales donde fueron atendidas durante el parto. Pero no sólo los hospitales, también los centros de atención primaria deberían seguir estas recomendaciones evitándose así la sensación de descoordinación y los mensajes contradictorios de los/las distintos/as profesionales.

Cuando el parto no sea eutócico y haya que separar a la madre del/la recién nacido/a para vigilar su estado de salud, deberían existir protocolos de actuación que puedan facilitar la instauración y establecimiento de la lactancia materna.

"Estuvo en neonatos porque el niño nació en Madrid y allí coincidí con una auxiliar experta en lactancia y a pesar de que estaba lleno de cables y de tubos, me lo empezó a poner y me subió la leche a las 72 horas" GDPI 2-I5

En cuanto a las distintas categorías profesionales, las mujeres no hacen referencia a cuál de ellas correspondería el asesoramiento en lactancia materna y así esperan recibir y de hecho reciben ayuda de distintos profesionales: auxiliares de enfermería, enfermeras/os, matronas, ginecólogos/as, pediatras, etc. Pero lo perciben como si fuera algo voluntario, algo que no forma parte del ejercicio profesional diario. Quizá deberíamos tener en cuenta la propia experiencia de las mujeres sanitarias en lactancia materna: si tuvieron a sus hijos/as en pleno apogeo de la lactancia artificial, o no pudieron dar de mamar a sus hijos/as, si como madres trabajadoras no pudieron mantener la lactancia natural al terminar su permiso maternal, etc. Todo esto podría condicionar su actitud hacia la lactancia materna en el ejercicio de su profesión.

"Teníamos, ya no, una auxiliar que se dedicaba al lactario como sala ...] les daba charla y les ayudaba a sacarse la leche con la mano [...].esta auxiliar lo hacía voluntariamente todavía sigue trabajando [...], sigue haciéndolo, pero no como lo hacía antes[...] porque... llevamos unos años que el trabajo que tu pones no está agradecido, entonces la gente se cansa, de una colaboración sin una compensación no solo económica, sin un reconocimiento... pero las mamás la recuerdan y la buscan... porque efectivamente hacia una labor muy buena" EPr $39^{\prime} 24^{\prime \prime}$

Por otro lado, algunas mujeres no sólo se quejan de la falta de asesoramiento en lactancia materna, sino que se quejan del trato recibido, de la falta de empatía 
y comprensión de su estado emocional, esto es algo que el sistema sanitario debe corregir independientemente de su política sobre la lactancia materna.

"De todas maneras es que [...] a veces te da miedo hasta preguntarles." GDYI 8-9

Quienes defienden de la lactancia materna intentan conseguir que, ante cualquier enfermedad o tratamiento médico a la madre, no se recomiende su abandono. En medicina, y tal vez en menor medida en enfermería, suele existir un enfoque más biomédico y paternalista que considera que las recomendaciones hechas por estos profesionales deben ser seguidas por los/las usuarios/as como lo mejor, en el caso que nos ocupa para la madre y su hijo/a, obviando la autonomía de la mujer (sus deseos, sus creencias, sus metas). En muchas ocasiones, ante la duda de si un tratamiento pude perjudicar al/la bebé o no, en lugar de buscar información y, en su caso, tratamientos alternativos, el/la profesional opta por lo más sencillo y lo que le proporciona más seguridad: retirar la lactancia, sin tener en cuenta la autonomía de la mujer.

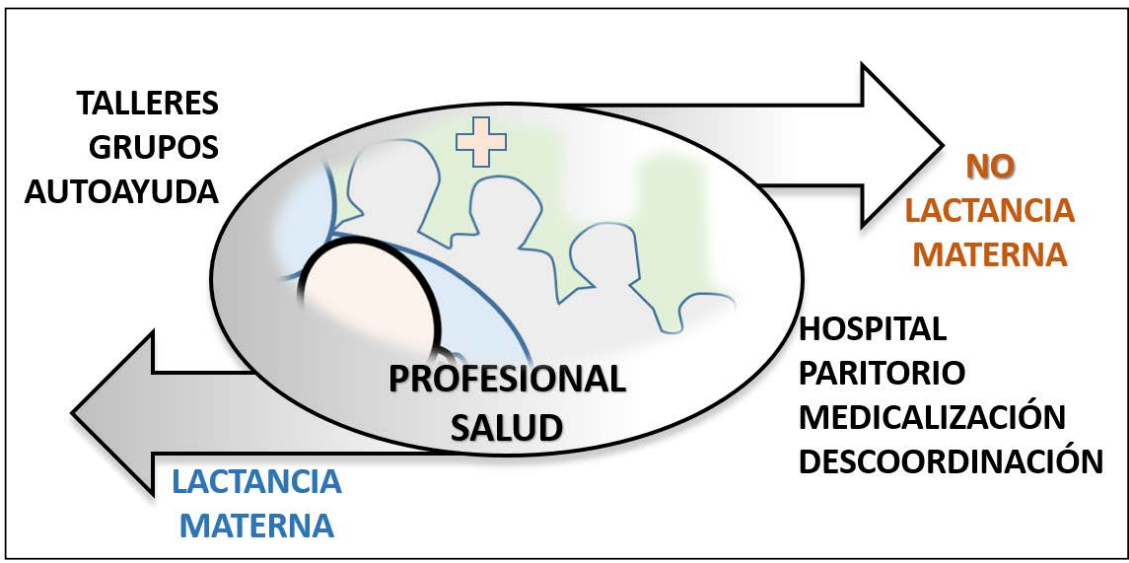

Ilustración ro. Tensiones en el ámbito sanitario.

Las complicaciones y los problemas resueltos por los/las responsables de los talleres de apoyo a la lactancia materna y la alta participación de mujeres en los mismos, están provocando cambios positivos en las actitudes de otros y otras profesionales de la salud, sobre todo de atención primaria. En algunos casos, los médicos/as, antes de recomendar retirar la lactancia materna, sugieren a la mujer acudir a estos talleres y consultar con los/las responsables de los mismos para encontrar solución a las dificultades que hayan podido surgir. 


\subsubsection{LA ESFERA SOCIO CULTURAL: "NO ESTÁ BIEN VISTO"}

En este capítulo se aborda otra línea del discurso que se desarrolla en las entrevistas grupales y a las profesionales que, en rigor, no podía encuadrarse en los capítulos anteriores. Se trata de aquellas ideas o reflexiones que de forma general describen la problemática social que vive la mujer amamantadora en su entorno y las posiciones discursivas que mantienen en lo que ellas consideran, en ocasiones, oposición social a la lactancia tal y como la conciben.

"[la L.M.] es un empeño, es una mujer que cuando se engancha el muchacho crea un vínculo y en ese momento le surgen todas las ganas de hacerlo, pero no tiene apoyo $[\ldots]$ los deseos son inmediatos [...] cuando te lo ponen encima $[. .$.$] pero lo que te van a decir es, rápidamente, que te$ separes porque lo estás malcriando" $\mathrm{EP}_{2} 7 \mathrm{O}^{\prime 1} 5^{\prime \prime}$

Es la esfera más pública o social de las mujeres lactantes y por lo tanto una esfera menos concreta, más abstracta y reflexiva. Esto hace que el desarrollo de este apartado tenga necesariamente un carácter más interpretativo.

Para analizar las ideas respecto a la oposición social a la lactancia materna que perciben las mujeres, subdividiremos el este capítulo en tres apartados:

4.2.4.I LA IMAGEN DE LA MUJER LACTANTE, donde se recogen las experiencias negativas que vive la mujer en el entorno social al dar el pecho (especialmente en público) o al defender la lactancia materna. Las reflexiones parten de la experiencia de sentir que la lactancia materna "no está bien vista" en los lugares del estudio, al menos para determinados colectivos.

4.2.4.2 EL RECHAZO SOCIAL A LA LACTANCIA MATERNA, se describe en qué consiste la oposición social a la lactancia materna y cómo la experimentan.

4.2.4.3 REIVINDICACIÓN DE LA LACTANCIA EN EL PLANO SOCIAL, análisis de las reivindicaciones que las participantes en las entrevistas grupales realizan sobre la lactancia materna, como son la defensa del espacio público para la lactancia y la necesidad de medidas para una conciliación de la lactancia materna y la vida social.

\section{La imagen de la mujer lactante: "Nadie te mira, nadie te ve"}

Las mujeres participantes verbalizan la sensación de pudor o vergüenza que experimentan al dar el pecho en determinados espacios públicos al contrario de lo que les sucede en el taller. Como se expuso en el capítulo donde 
se analizó el pudor, parece ser que el cuerpo de la mujer puede mostrarse en privado o en situaciones muy concretas, pero no exhibirse en público, ni siquiera para dar de mamar.

Efectivamente, se comenta que en determinados entornos dar el pecho supone "reparo" y "vergüenza", lo que obliga a un cierto recato y reserva a la hora de hacerlo en público.

"yo la primera vez que le di en público, entramos en una cafetería, me siento, le empiezo a dar el pecho, y empiezan a entrar los obreros, [...]y yo: Ay Dios mío todo el mundo me está mirando" GDY 2 I7-6

Por lo tanto, se trata de una vergüenza que hay que perder si se quiere practicar una lactancia natural. De forma inversa, se podría afirmar que las mujeres creen, al menos inicialmente, que dar el pecho en público es vergonzoso. No es difícil inferir de los discursos que la causa principal del sentimiento de vergüenza es el hecho de tener que mostrar el pecho.

En esta línea interpretativa se impone como motivo principal el contenido sexual del pecho de la mujer. La sensación de vergüenza y pudor que produce la exposición del pecho en espacios públicos está asociada, en la gran mayoría de las ocasiones, a concepciones histórico-religiosas del cuerpo de la mujer que permanecen vigentes en la actualidad y que lo relacionan con el pecado y la culpa. El mayor número de verbalizaciones de sensación de vergüenza relacionada con el pecado y la culpa se produjeron en el taller de Yepes. El origen de ese sentimiento en las mujeres, puede explicarse por un fuerte arraigo de las creencias religiosas en dicho municipio (que mencionamos anteriormente).

"mi hermano me lo ha dicho, porque he dicho, digo: No sé si me va a aguantar en el bautizo toda la misa, digo, a lo mejor me... (Cambia la voz) ¡Sí hombre! Ahí en la iglesia te vas a sacar... [el pecho]” GDYi 15-8 "Y que luego en la sociedad que vivimos, que hay ciertas personas mayores que también es como si estuvieras haciendo un pecado." GDY2 $25-6$

"No lo ven natural y...Y luego, pues eso, yo lo que he dicho al principio, que se vive aquí totalmente diferente que en... [Madrid][...] pues anda que no van en el metro con la teta fuera y...y no pasa ni media." GDYi i6-2 y 3

Así, superar la concepción del pecho de la mujer como símbolo sexual es un requisito imprescindible para poder practicar la lactancia natural en otros espacios más allá de los de la esfera íntima. En este cambio la percepción del pecho como objeto sexual se desplaza hacia una visión centrada en la alimen- 
tación, lo natural, la maternidad... se puede decir entonces que el pecho se convierte en algo asexual, para cuidar al hijo/a:

"Yo no le quería dar en ningún sitio, de vergüenza. Luego ya no, luego ya no lo vemos como pecho...le estás dando de comer" GDY 2 I7-3

"Yo a lo mejor en la cafetería me ponía [a darle el pecho] [...] Te tapabas, ya no me daba [vergüenza]. No lo veía como un pecho, lo veía cómo cuidar un niño." GDY2 I7-5

La autoimagen de la mujer en el momento de la lactancia se desplaza hacia visiones más relacionadas con la idea de madre. Evidentemente esto prolonga lo ya experimentado durante el embarazo, con los cambios físicos que éste impone, aunque presumiblemente ahonda el cambio de la autoimagen desde "mujer" a "madre".

"Pero que si estoy en un espacio abierto, no molesto a nadie, me pongo un pañuelo que no hiera la sensibilidad de nadie y le doy el pecho a mi hijo donde me parece" GDPI II-3

Este cambio de autopercepción sin embargo no se corresponde con las representaciones sociales de los pechos femeninos como objeto sexual, lo que se experimenta en la sensación desagradable de sentirse observada, ser el centro de atención, sentir pudor, o sentir que hace algo indebido al ofrecer el pecho en espacios públicos.

"Me pilla en la plaza sentada en una terraza y mi hijo mama. No me voy a mi casa corriendo a darle de mamar [...] porque no creo yo que vaya desnuda por la calle para que diga la gente." GDYI I5-7

"A veces cuando vas a darle el pecho en cualquier sitio, la gente te mira raro." GDYI I5-I

"la propia gente me dice que cómo se me ocurre en la plaza darle de mamar $[\ldots]$ gente que me ha llamado guarra, por dar el pecho en un bar, un señor." GDY I I5-7

El taller de lactancia propicia este cambio, al naturalizar el hecho de mostrar el pecho a personas desconocidas.

"Te pones en cualquier sitio a darle [de mamar]. Si da igual, ¿no? Sí una vez ya perdida la vergüenza... Al principio no." GDY2 I7-2

"Pero si estaba en verano en una terraza, yo la ponía a comer en la terraza y no había ningún problema" GDP2 I6-I8 
Sobre este asunto es interesante reseñar que la asistencia de hombres a las sesiones de los talleres es prácticamente nula, aunque no se impida la presencia de acompañantes. Cabe destacar que en el taller de Yepes uno de los enfermeros coordinadores es varón, pero esto no causa dificultades para la asistencia, el papel de "profesional sanitario" desempeñado minimiza la vergüenza que las mujeres podrían experimentar.

Otro aspecto a resaltar es la incidencia que la lactancia puede tener en la recuperación del aspecto físico de la mujer. Aunque en general este cambio de imagen aparece como negativo, en ocasiones se sostiene que el amamantamiento es un proceso natural que favorece la recuperación física de la madre tras el embarazo y el parto:

"Engordé 24 kilos con la lactancia, con lo cual no lo veo positivo (risas) pero es lo único, por el físico (risas) pero es lo único, por el físico." GDPr 3-3

"Yo creo que egoístamente también, lo bueno que es dar el pecho para la recuperación de la madre. Es buenísimo." GDY I i6-II

Según las verbalizaciones de las mujeres, en los entornos donde ellas se mueven son frecuentes los comentarios que minimizan los beneficios de amamantar al hijo o hija, enfrentándolos a los problemas que puede llevar asociada la lactancia natural.

"Cuando digo a la gente que he criado a mi hijo con un pecho me han llegado a decir: se te va a quedar mal el cuerpo." GDPi I6-I

Contra estos argumentos, las mujeres despliegan argumentos de sentirse orgullosas de amamantar a su hijo/a aunque haya pérdidas físicas derivadas de este hecho:

"Me han llegado a decir que al criar al niño con un pecho se me iba a quedar una teta muy grande y otra muy pequeña, mira perdona con mi edad puedo hacer topless" GDPI 6-I

En este punto, se interpreta que la lactancia materna aparece como una nueva entrega de la madre, esta sacrifica su imagen física, social y pública para alimentar al hijo/a con el mejor de los alimentos. Se trata de un añadido a una visión que se podría denominar "sacrificial" de la maternidad: Una representación social de la mujer que incluye "la entrega" "el sacrificio" como dimensiones necesarias de la maternidad.

"Tienes que saber lo mejor para ti y para tu hijo, si tú quieres hacer el sacrificio de incluso noches de no poder acostarte, eres tú con tu hijo... [La interrumpen]" GDYI5-IO 
"Porque todo es sufrir. Y por lo menos eso es el único, cosa...privilegio que nos dan, de poder sentir eso, que ellos no lo pueden sentir, claro"

GDYI 2I-2

Además, este sacrificio de la imagen, en el caso de la lactancia (como también lo pudo ser en el embarazo) tiene una de sus dimensiones más claras en la posible pérdida de la imagen como objeto de deseo sexual, la lactancia materna, en cierto modo, invisibiliza a la mujer.

"Al principio te crees que te mira todo el mundo y estas ahí incomoda y luego nadie te mira, nadie se [fija en la mujer] [...] nadie te ve." GDY 2 I7-6

"Una vez un compañero [me dijo]: :y no se te han quedado las tetas flojas?

Digo: ¿quieres ver las tetas?, yo te las enseño. Si las tengo fofas: el mejor servicio que han hecho en toda su vida ha sido dar de comer a mi hijo." GDPI I6-2

Incluso en ocasiones, se describe la disminución del deseo sexual por parte de la pareja como efecto de la lactancia, relacionándolo con los cambios de la imagen que el hombre percibe de la mujer:

“A mi marido le daba asco verme al niño enganchado a la teta, [...] me decía que vaya mierda que volver a casa y encontrarse a la mujer gorda con la teta al aire y el niño chupando... imagínate" GDPI 5-I $^{-1}$

Como ya se estudió en profundidad, en el punto 4.2.2.3, en las entrevistas grupales critican algunas opiniones vertidas en los medios de comunicación cuestionando la lactancia materna, desde visiones aparentemente feministas, en base al cambio en la imagen, en su rol social e incluso en la pérdida del atractivo sexual. Estas ideas se han difundido en algunos medios de comunicación refiriéndose a la mujer amamantadora como "mujer-vaca".

"Una filosofa francesa [decía que] los hombres buscan mujeres más disponibles porque nos convertimos en mujeres-vaca, eso [lo dice] hasta una propia mujer, entonces, claro, más daño nos hacemos nosotras..." GDPi I 9 -8

Estas teorías, a decir de las participantes, se refieren también a la pérdida de atractivo de la mujer en el momento de la lactancia materna, relacionándolo con las posibilidades de la pérdida de la pareja.

A decir verdad, las críticas a estas visiones radicales contra la lactancia materna, coexisten en las entrevistas grupales con expresiones o comentarios que parecen asumir algunos aspectos de esta forma degradante de ver a la mujer amamantadora. 
"En el hospital antes de entrar en neonatos una salita que tiene 3 o 4 sacaleches eléctricos; había allí gente que sí parecían vacas, la gente se sacaba tarros y tarros" GDPI I7-5

"cuando he tenido que sacarme en el trabajo la leche, me la he tenido que sacar con la mano [...] pues como cuando [...] ordeñas a una vaca" $\mathrm{GDP}_{2} \mathrm{I5}_{5} 6$ y 8

En resumen, a través de sus discursos las mujeres dejan entrever que experimentan como extraño el hecho de dar el pecho entre otras cosas porque sufren un cambio en la visión de la imagen que proyectan: sobre todo en relación a los hombres, pasan desde ser vistas (y verse a sí mismas) como "objeto sexual", a ser vistas y verse como "objeto maternal". Evidentemente esto tiene que ver con las representaciones sociales del pecho femenino. También en cierto modo, esto supone un nuevo sacrificio. Esta forma de experimentarlo está en línea con la idea, muy presente en nuestra cultura, del valor del sufrimiento, especialmente en lo que tiene que ver con la maternidad.

\section{El rechazo social a la lactancia materna: "todo el mundo en contra de la lactancia"}

$\mathrm{Al}$ interpretar las reflexiones de las mujeres y las profesionales conviene analizar la idea, muy frecuente en sus discursos, de cierta oposición a la lactancia materna en sus entornos sociales.

"Parece que ibas contra corriente de todo el mundo." GDYI 5-15

"Para empezar es raro que le des el pecho" GDY2 I6-г3

Así mismo, es posible apreciar en sus discursos que esa oposición es ejercida también por parte de alguna de las parejas u otros familiares.

"yo me sentí muy sola, porque mi marido estaba siempre trabajando, siempre, y me decía pues dale un biberón y ya está" GDPI 7-9

"las ayudas están entre los profesionales de los hospitales, los pediatras, [...] están en los familiares, están en los medios de comunicación, [...] no hay apoyo en las empresas [...] En [educación] primaria no hay nada ni cuando hablan de los mamíferos." $\mathrm{EP}_{2} 68^{\prime} 53^{\prime \prime}$

"no hay apoyo en la sociedad" $\mathrm{EP}_{2} 66$ '10"

Esta oposición parece exacerbarse y generalizarse cuando el pecho se da en determinados ámbitos o espacios públicos, se percibe una cierta crítica por parte de la sociedad en general por el simple hecho de dar el pecho apelando a consideraciones éticas o sociales. 
"A veces cuando vas a darle el pecho en cualquier sitio, la gente te mira raro. (Ríe ligeramente) Cuando es una cosa que es lo más normal del mundo." GDYI I5-I

"lo ven como una posesión de la madre hacia los hijos, lo ven como una falta de respeto" GDPI II-7

"Después de tantos años las creencias siguen igual y no van a cambiar. Fuera [del taller] las mujeres están solas" $\mathrm{EP}_{2} 6 \mathrm{r}^{\prime} 5 \mathrm{O}^{\prime \prime}$

No son muy numerosas las citas en lo referente a este aspecto, pero sí se descubre a lo largo de todo el discurso, la idea eje de que la lactancia materna a pesar de sus beneficios y ventajas es cuestionada por muchas personas e instancias sociales.

En las entrevistas, las mujeres dejan traslucir que el amamantamiento es beneficioso, pero que hoy en día tiene que ser apoyado si se apuesta por una lactancia materna eficaz, aunque este hecho se considere incompresible. Como se estudió en el primer capítulo, los talleres de lactancia se convierten en "grupos de apoyo" debido a que para conseguir una lactancia materna eficaz en la sociedad actual se necesita un apoyo institucional o grupal, ya que sin este apoyo no se daría de forma natural.

"Entonces, mi madre tuvo cuatro hijos y a ninguno de los cuatro les dio el pecho, pero porque entonces tampoco había una promoción de la lactancia como la de ahora, yo creo." GDP 2 II-2

Como se ha señalado esto es así no sólo porque haya dificultades prácticas y de pareja, sino porque existe un rechazo social; hecho que se analizará de forma más pormenorizada en los siguientes puntos:

El rechazo a que las mujeres participen en los grupos de apoyo a la lactancia materna, por considerar que sus métodos son negativos, lo que se expresa con la palabra "secta".

El rechazo a la lactancia en sí misma, lo que tendría que ver por un lado con las críticas a lactar en público, y por otro a que, al volcarse en la lactancia, la mujer se aboque a papeles sociales considerados regresivos.

\section{El rechazo a la participación en los grupos de apoyo a la lactancia}

Cabe destacar que este rechazo se muestra de forma clara y articulada en las entrevistas grupales. Efectivamente, las mujeres manifiestan que con frecuencia encuentran oposición de familiares, de la pareja y de otras personas a su participación en los talleres de lactancia materna. Esto parece deberse 
no tanto a sus fines (fomento de la lactancia materna) como a los métodos que se supone emplean. La idea de organizar los talleres como "grupos de autoayuda" para lograr el fin del fomento de la lactancia, parece ser vista con reticencia por muchas personas del entorno de las participantes del estudio.

"en el pueblo influye mucho la familia, y si la madre dice: ¿Para qué vas a ir a esa tontería?" GDYI $25^{-2}$

Como se examinó en el capítulo 4.I.3.3 Dificultades familiares, el rechazo a que la mujer participe en los talleres se expresa, en ocasiones, con la palabra "secta". Esto hace que en algunos casos las participantes eviten asistir al taller porque se sienten excluidas, "gente de la lactancia", las consideran un grupo social constituido como una secta.

"Mi ex fue una vez a ver a Carmen fue a la consulta para decirle que si éramos un tipo de secta o algo así" GDPi 19-6

"hubo un tiempo donde se decía en Fuensalida que aquí era una secta [...] ¿cómo es posible que puedan decir eso?" $\mathrm{EP}_{2} 59^{\circ}$ o6"

"nos llaman secta, nos dicen que somos una secta sí. A mí eso me repateó" GDF $38^{\prime} 20^{\prime \prime}$

Esta expresión resulta muy significativa si se toma en consideración que la Real Academia de la Lengua en su acepción tercera, entiende secta como un "conjunto de fieles a una religión que el hablante considera falsa". Pero, además, en la actualidad el concepto de secta remite al frecuentemente empleado en los medios de comunicación españoles de "secta destructiva", que se caracterizaría por la falta de libertad de elección de los participantes, adoctrinamiento, coacción y el "lavado de cerebro".

Sin duda la fuerte crítica que el uso de la palabra supone y el hecho de que no se emplee para otros grupos orientados hacia la promoción de la salud y la prevención de la enfermedad (como los grupos de enfermos/as crónicos/ as, o los de deshabituación tabáquica), denota que, efectivamente, existe un cierto rechazo a los grupos y asociaciones que defienden la lactancia materna y sus métodos. Pero también parece constituir una crítica al estilo de crianza que generalmente se defiende en los grupos de lactancia.

"Es la crítica a la crianza natural: solo teta, portear a los bebés, cogerlos cuando lloran, el colecho..." GDF 39' 17"

\section{El rechazo a la lactancia materna en sí misma}

Los discursos con respecto al rechazo a la lactancia son contradictorios. Por ejemplo, existen algunas citas en las que se asegura que la lactancia materna se valora mucho a nivel social. 
"Socialmente si eres madre y no le das el pecho, no eres completa." GDPr $15^{-6}$

Pero contrariamente, muchas veces las participantes se quejan de la visión anticuada que tiene la sociedad sobre la lactancia, sobre todo al considerarla poco práctica o antigua.

“-Dar el pecho se ve como algo... Como se veía antiguamente, ¿no? Que los pobres, como no podían comprar la leche, eran los que daban el pecho. [La interrumpen]"

—_Exactamente."

— “[Continúa] No se ve como que es la mejor manera de alimentar a un bebé."GDY I 25-9

En una sociedad de mercado como la actual, en la que el consumo es tan importante, la lactancia natural es una práctica que no requiere de productos manufacturados o industriales, la mujer no necesita comprar, no aumenta el consumo de las familias. Si además estas mujeres defienden la crianza natural, aún consumirán menos productos: ni chupetes, ni carritos...entonces parece que van contra corriente de la sociedad capitalista donde el consumo de las familias es una parcela muy importante de nuestra economía. Quizá este es un factor a tener en cuenta a la hora de analizar el rechazo a la lactancia materna en sí misma.

"Hay mucha tontá [...] entras en una tienda de niños, todo de chupetes, biberones... o en la farmacia y yo me quedo mirando... y el mío no usa de ná y me apetece comprar algo, pero no usa de ná" GDF 59 '30"

Sería interesante relacionar el papel de la lactancia natural en lo que tiene que ver con los procesos sociales desencadenados en la sociedad de consumo, tanto en lo referido a la mercantilización del cuerpo (especialmente en los aspectos estéticos, del cuidado y sanitarios) como a lo que tiene que ver con la alimentación. Evidentemente la lactancia natural en gran medida sitúa fuera de los circuitos comerciales la alimentación del niño y la niña y en menor medida otros aspectos del cuidado infantil.

Sobre todo, los discursos ponen de manifiesto que existe un claro rechazo a que la mujer amamante en público; la exposición del pecho en espacios públicos está mal vista, tal y como se analizó en el capítulo 4.2.4.I., La imagen de la mujer lactante, al considerar el pecho como objeto sexual, esto explica que parte de la sociedad vea la lactancia como una práctica indecorosa y la madre experimente vergüenza al amamantar a su hijo/a en 
público. Desde esta perspectiva resulta claro que, en ocasiones, la lactancia puede herir la sensibilidad de la gente.

"Aquí en la plaza, aunque me mira la gente como si fuese un bicho raro [alguien ríe], porque es que, además, la propia gente me dice que cómo se me ocurre en la plaza darle de mamar. Como si es que yo le estuviese haciendo un daño." GDYI

"A mí me ha pasado que me han llamado guarra [...], por dar el pecho en un bar, un señor." GDYI I5-3

"mi hija y mi marido se bajan a la calle, están disfrutando con todos los vecinos, y yo estoy en casa. Hombre, no me bajo a la calle porque a lo mejor me van a decir: ¡Mira esta! [...]. No le voy a dar el pecho aquí.” GDYI I8-3

Otro aspecto criticado es la prolongación de la lactancia más allá de unos pocos meses. Cuando esto ocurre, a decir de las participantes, las críticas son muy claras, e incluso a ellas mismas les parece extraño o inadecuado.

“Hay gente que les da hasta los dos años." GDY2 I5-I2

"La sociedad no está preparada para una lactancia prolongada." GDF $06^{\prime} 55^{\prime \prime}$

Las posibles causas de este rechazo social a la lactancia pueden ser:

El problema generacional: posiblemente la visión de la promoción de la lactancia y por lo tanto de los talleres por parte de las mujeres de la generación anterior (la correspondiente a las madres de las participantes) pueda deberse a que en su generación en España la lactancia materna fue mucho menos frecuente, menos duradera y más reservada a clases sociales bajas. Además del peso que estas ideas tienen en sí mismas, puede entenderse que la defensa a ultranza de la lactancia materna pone en cuestión la responsabilidad de las madres que no lactaron o lactaron poco en su momento (cosa bastante habitual entre los años 70 y 80 ).

"Mi madre, [...] era de la época en que estaban de moda los biberones.

Dice: Yo iba al pediatra y me sacaba la teta, la gente me miraba mal."

GDP2 II-IO, I2-I

Efectivamente, la insistencia en los beneficios para el/la lactante cuestiona a aquellas mujeres que, por diversos motivos sociales y culturales, no ofrecieron una lactancia natural a sus hijos/as, ahora ese hecho lo perciben como un déficit de cuidados maternales y por lo tanto su respuesta coherente 
es cuestionar las ideas defendidas por el movimiento de la lactancia materna como falsas, para disminuir el sentimiento de culpa que puede surgir.

"No lo entienden o dicen ¿Para qué se lo das? Es mejor biberón que se lo enchufas y ya" GDY2 I5-10

"Nuestras madres tenían una mentalidad de biberón. [...] Entonces, en el momento en que el niño, eso, se queda un poquito más delgadito ya le echan la culpa al pecho." GDY I I4-Io

Luego para que las mujeres que asisten a los talleres afronten la oposición que pueden encontrar en las generaciones anteriores, convendría tratar en los mismos talleres las causas sociales de la escasa práctica de la lactancia materna en épocas anteriores, lo que disminuiría la presión ejercida sobre las madres no lactantes de la generación anterior y disminuiría estas críticas.

La oposición de las mujeres que no dan el pecho. Lo mismo puede aplicarse a las mujeres que no dan el pecho en la actualidad: posiblemente el hecho de que la promoción de la lactancia materna emplee como argumento principal la salud del hijo/a, es visto como un cuestionamiento del rol de madre de aquellas mujeres que no lactan.

"Hay muchas más mujeres que en el fondo están frustradas por no haber dado el pecho." GDPi i9-7

"somos más juzgadas por mujeres que por hombres, yo creo que es envidia." GDF 64"09"

Por tanto, en los talleres no se debería basar la defensa de la lactancia materna en las críticas (ya sean directas o indirectas) hacia aquellas mujeres que por diversos motivos no pueden o no quieren lactar.

La oposición de la pareja. El rechazo a la lactancia que muestran algunos hombres, puede ser debido, tal y como estudiamos en el apartado 4.2.2.3 Pareja, a su modo de entender la paternidad.

"Yo creo que lo de [la lactancia materna] es el privilegio que tenemos las mujeres." GDYI 2I-2

"No sé si es envidia o son celos, como ellos solo tienen una función..." GDPi I6-3

"Yo, su padre le baña, le corta las uñas, le hace todo lo que puede, que no es darle el pecho, porque no puede" GDYI I9-זо

Cabría considerar que las representaciones sociales de lo femenino y lo maternal, al seguir fuertemente asociadas al embarazo y al parto, se reafir- 
man y prolongan en la lactancia natural. De esta forma, podría entenderse que la lactancia materna no permite que la maternidad biológica (femenina por naturaleza) dé paso a la maternidad entendida como el cuidado hacia el menor, en la que sí tiene cabida el varón.

"Yo era demasiado quizá...acaparadora [...]. Era como que no quería que nadie me...me ocupara ese momento, $[\ldots]$ cuando él me ve que está mamando, él siempre dice: Le he visto nacer, [...] y en parte, en algún momento de mi vida sí que me gustaría haber sido mujer para ver lo que sientes tú. [...] Me dice que qué siento yo cuando, cuando él mama." GDYI 2I-I

Ahondando en esta interpretación, cabe señalar que algunas investigaciones antropológicas han destacado que la leche artificial en sociedades empobrecidas puede considerarse más nutritiva que la leche materna, lo que unido a que suele ser adquirida por el padre ("la leche del padre") mediante su salario, contribuye a dar valor al hombre en su rol de padre (Scheper-Hughes, I997). Evidentemente este hecho resulta muy perjudicial para la supervivencia del/la lactante, pero además contribuye a perpetuar la desigualdad de la mujer frente al varón en estos contextos.

"Dar el pecho se ve como algo... Como se veía antiguamente, ¿no? Que los pobres, como no podían comprar la leche, eran los que daban el pecho." GDYI $25-9$

En cierto modo la defensa de la lactancia materna en nuestro entorno podría analizarse salvando las distancias, como el caso inverso.

La visión de la lactancia materna como algo que reduce las posibilidades de participación del varón en el cuidado del hijo/a, dificulta la corresponsabilidad en los cuidados al/la lactante y podría ser la causa de su rechazo por parte de los hombres.

"yo lo que veo del pecho es que solamente es para ti. Yo veo las madres que dicen: Anda, yo el biberón porque así implico al padre." GDYI I7-9

Lógicamente estas concepciones dependen de las experiencias que hayan tenido los progenitores en su infancia, es decir, del papel de la lactancia natural en sus familias de origen.

"Mi marido es el noveno de nueve hermanos, mi suegra ha estado dando el pecho, cada dos años iba teniendo hijos y dando el pecho a todos, trabajaba y todo... mi marido ve perfecto el pecho." GDPi I9-Io 
En la práctica, debería presentarse la lactancia materna como la corresponsabilidad de los cuidados impartidos al hijo/a por parte de la pareja o la familia, aunque sólo la madre pueda amamantar. Esto es evidente si se considera que las estrategias para favorecer la lactancia materna implican no sólo a la mujer, sino a la unidad familiar y a la sociedad en sus diversos campos. En la práctica en los talleres se debería intentar integrar a los padres en las sesiones donde se aborden las estrategias facilitadoras de una lactancia materna satisfactoria.

La oposición desde determinadas corrientes feministas. Otro aspecto que explicaría el rechazo social a la lactancia está en línea con la reivindicación de igualdad entre géneros que viene teniendo lugar en nuestras sociedades. Ciertas visiones tópicas del feminismo se apoyan en el hecho de que dar pecho supone una prolongación de la maternidad biológica que parece hacer descansar el cuidado del hijo/a de manera casi exclusiva en la madre. Estas simplificaciones en ocasiones, como hemos visto, permiten argumentar, desde algunas corrientes feministas, contra la lactancia materna haciendo ver que aboca a papeles tradicionales de la mujer centrándola en la maternidad, y que por tanto dificulta la igualdad entre géneros.

Aquí, desde la promoción de la lactancia materna se debería poner el énfasis en cuestionar la "visión esencialista" de la mujer, que asigna actitudes y capacidades, distribuye papeles en razón del género, dando por sentado que la mujer, por su propia naturaleza, es más apta para el cuidado de los hijos/as. Por tanto, el hecho de lactar debería separarse de las numerosas tareas que es necesario cubrir en el cuidado de los hijos/as de forma compartida.

Además, dado el escasísimo margen de conciliación de la vida laboral y del cuidado de los hijos/as en España, la lactancia materna podría verse y experimentarse como una dificultad para el desarrollo profesional de las mujeres, lo que, de ser así, es necesariamente rechazable.

"mira, decía, ahí llega la de la bolsa, porque cogía mi bolsa, me iba, lo veían como algo extraño; si estás aquí, para qué te vas a sacar leche, total..." GDPI II-I

"En la plantilla de mi trabajo si somos el $95 \%$ mujeres y no tienes una sala o un lugar determinado para poderte sacar el pecho [...] yo me iba al servicio y había compañeras que me decían yo en el servicio no lo haría, yo por mi niño lo hago en un servicio" GDPI II-2

En este punto, se hace imprescindible propiciar una reflexión sobre la lactancia materna como derecho de progenitoras e hijos/as, que no puede en 
ningún caso suponer el menoscabo de otros derechos de la mujer como los laborales y en general los relacionados con la participación en la vida social.

En este punto, los argumentos tratan de explicar la compatibilización de la lactancia con la actividad laboral como un signo de progreso social, hecho que debiera darse con más frecuencia, en vez de criticar la lactancia como regresiva.

"Estas periodistas que se creen progres, vale por la incorporación de la mujer al trabajo, yo creo que no está reñido el trabajo con la maternidad y la crianza de un hijo [...], no porque des el pecho estamos yendo hacia atrás, yo creo que eso es algo natural que va a seguir así siempre" GDPi 20-6

"En las democracias avanzadas [...] se apuesta por ello, cada vez se paga más a las madres para que se incorporen más tarde y los niños vayan mucho más tarde a la guardería [...] para que las madres estén más tiempo y puedan prolongar la lactancia" GDPI $20-8$

A la vista de estos resultados se hace necesario reflexionar sobre los discursos feministas en sus diferentes posicionamientos históricos: desde la visión de "lactancia natural como discriminatoria" para la mujer, hasta la "lactancia como reivindicación feminista" o incluso, como "forma de empoderamiento de la mujer".

"Después de cuatro años [celebrando la semana de la lactancia y exponiendo fotos de las madres amamantando] las mujeres se muestran con poderío: lo que estoy haciendo me gusta y quiero que lo sepas" $\mathrm{EP}_{2} 44^{\prime 2} 2 \mathrm{O}^{\prime \prime}$

En resumen, se debería integrar en el discurso sobre igualdad de género y lactancia, la idea del derecho a lactar, aunque rechazando el "esencialismo" que naturaliza el papel femenino de la mujer como madre y lo opone al papel activo de ésta en la sociedad. En tanto esta reflexión no alcance los diferentes estratos sociales, un discurso feminista no bien informado o poco riguroso se opondrá a la promoción de la lactancia materna considerando la lactancia artificial como más igualitaria. ${ }^{35}$. En la dimensión práctica, debería incluirse en los talleres, la discusión sobre estos asuntos y sus repercusiones en el hecho social de dar el pecho.

35 Para una discusión sobre las diferentes posturas feministas respecto a la lactancia materna véase: http://www.ecopolitica.org/index.php?option=com_content\&view=ar ticle\&id=108\%3Aies-la-lactancia-compatible-con-el-feminismo\&catid=25\%3Aecofe minismo\&Itemid $=1$ 


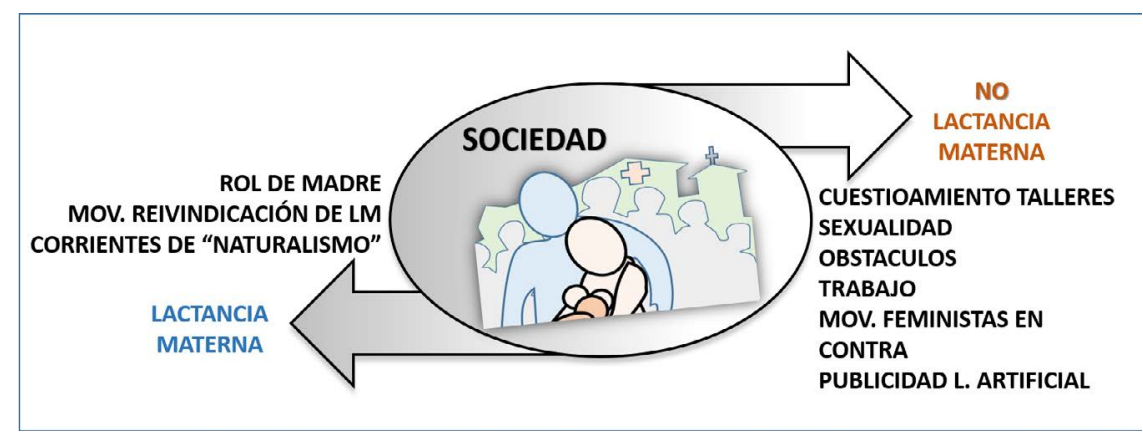

Ilustración Ir. Tensiones sociales.

Estas críticas y oposición social a la lactancia y sobre todo a su realización en espacios públicos que señalan las mujeres participantes en nuestro estudio, conducen a posiciones discursivas que sostienen que es necesario llevar a cabo una serie de estrategias para hacer que la lactancia materna sea aceptada o al menos socialmente tolerada.

\section{Reivindicación de la lactancia en el plano social:}

\section{"A contracorriente de todo el mundo"}

Una vez analizadas las representaciones sociales sobre la lactancia y las dificultades para lactar, prosigue el análisis de los conflictos sociales a los que se enfrenta la lactancia y las estrategias que se proponen. Por tanto, se investigan las opiniones de las participantes sobre la reivindicación de la lactancia materna en el plano social y se recogen las estrategias empleadas o sugeridas por ellas.

Conviene resaltar que las participantes del estudio opinan que amamantar en público es más fácil en las grandes ciudades.

"en Madrid, dice mi padre: pues anda que no van en el Metro con la teta fuera y...y no pasa ni media." GDYI

Del análisis pormenorizado de sus discursos se puede concluir que los objetivos que se plantean en relación a los conflictos sobre la lactancia materna son:

- Defender un espacio público para la lactancia o más bien hacer del espacio público un espacio adecuado para lactar.

- Conciliar la lactancia materna con la vida social y laboral.

- Naturalizar o "re-naturalizar" la lactancia materna en nuestra sociedad. 
Estos objetivos se sirven de un abanico de estrategias tales como: crear grupos de apoyo a la lactancia materna, visibilizarla, reivindicar espacios públicos para tal fin, recabar el apoyo de la autoridad sanitaria y articular un discurso social sobre la misma.

\section{La "estrategia" de los grupos de apoyo}

A pesar de la mejora de la opinión sobre la lactancia materna en estos últimos años, las mujeres participantes del estudio suelen verbalizar que la lactancia materna todavía necesita ser defendida y apoyada.

Si se trata, de "renaturalizar" la lactancia, los grupos de apoyo adquieren un papel relevante: primero porque descubren a las participantes que la lactancia, más allá de una técnica que necesita ser aprendida, precisa de un "grupo de autoayuda", debido a que en la sociedad actual la lactancia materna no se da de forma "natural", siendo necesario un apoyo grupal para llevarla a cabo de forma satisfactoria. Como ya se ha comentado, en el plano social, los talleres de lactancia son considerados grupos de autoayuda y pueden incluso cumplir funciones de grupos reivindicativos de la lactancia materna.

"que tienen que saber, para que también puedan tener una base y contestar a otras mujeres de porqué está funcionando [la L.M.] [...] y detrás, que ayudaran a otras mujeres y que dieran de mamar en cualquier parte." $\mathrm{EP}_{2}$ $22^{\prime} 28^{\prime \prime}$

Esta dimensión, en unos grupos más y en otros menos, dependiendo de los diversos actores y por lo tanto de los diversos momentos, puede ser más o menos activa, dando lugar a grupos más o menos reivindicativos. Esta idea explica también la reticencia a abandonar los grupos por parte de algunas mujeres, incluso cuando ya han dejado de dar el pecho. ${ }^{36}$

Esta cuestión, se refleja en determinados actos sociales, como la "Semana de lactancia materna” organizada por la gerencia de atención primaria. A estos actos, se desplazan desde los centros de salud tanto profesionales de la salud como las madres participantes en los talleres acompañadas de sus hijos/as; es una reunión de carácter festivo, que puede llegar a interpretarse por parte de la sociedad y de las propias participantes como un acto reivindicativo de la lactancia materna en los espacios públicos.

Por otro lado, no conviene olvidar que, en torno a los grupos de apoyo a la lactancia, se articulan grupos que se adscriben a movimientos sociales que

36 Asunto éste que fue tratado en el capítulo 4.1.6. 
entienden la lactancia materna como objeto de reivindicación social de la mujer, los grupos "lactoactivistas" o "lactofeministas". ${ }^{37}$

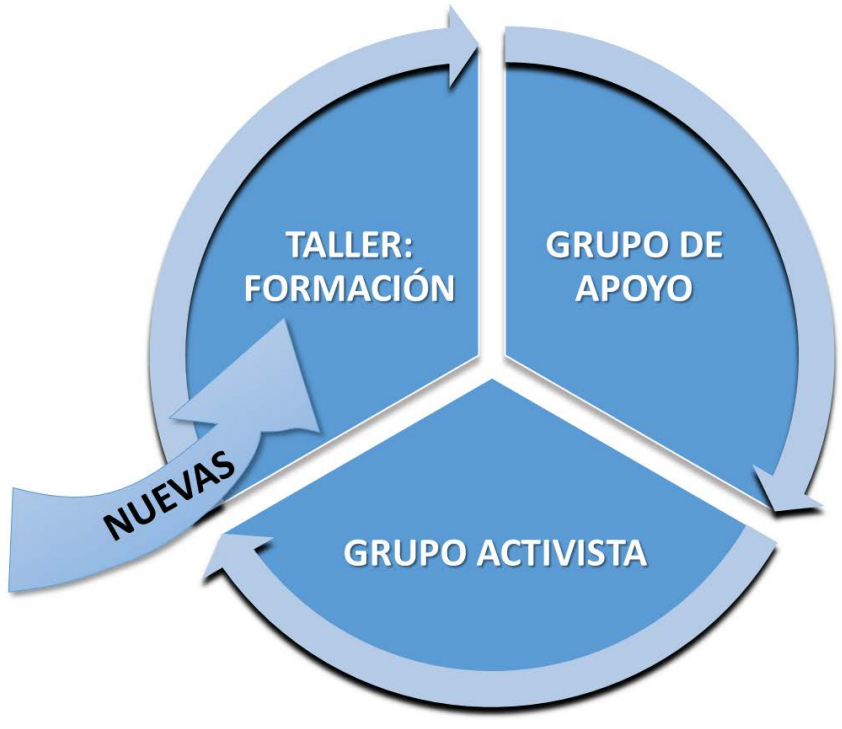

Ilustración I2. Evolución de los Grupos.

\section{La estrategia del apoyo de los y las profesionales de la salud}

En todo lo tratado hasta el momento, el personal sanitario tiene un importante papel, especialmente aquellos/as implicados/as en la lactancia materna que al menos en nuestra zona de estudio se concreta en las enfermeras/os de atención primaria, que suelen ser quienes organizan y dirigen los talleres de lactancia materna.

El y la profesional de la salud, sobre todo la enfermera/o, se convierte ahora en aval de la lactancia materna (como el médico/a o pediatra lo fue en décadas anteriores de la lactancia artificial). Sus ideas técnicas sobre la idoneidad de la lactancia natural son usadas como las razones más poderosas para reivindicar la lactancia materna, apoyándose en la salud del niño/a como motivo fundamental frente a otras causas que deben inexorablemente pasar a un segundo plano.

Si como ya se ha expuesto los talleres de apoyo a la lactancia pueden llegar a ser grupos de autoayuda y reivindicación de la lactancia natural, el y

37 A los que nos hemos referido en la introducción de este trabajo. 
la profesional de la salud, pasa del simple formado/a en la técnica de amamantamiento, a la persona que organiza los talleres como espacios de apoyo mutuo para el fomento de la lactancia y copartícipe en actividades colectivas de apoyo y fomento de la lactancia natural (como las mencionadas Jornadas de lactancia materna) que evidentemente pueden ser vistas como formas de movilización a favor del amamantamiento.

Centrándose en el personal de enfermería, en el momento actual, no existen otras actividades de promoción de salud similares a nivel comunitario (salvo quizá alguna intervención en salud escolar en algún centro educativo). Esta carencia se da en parcelas del estilo de vida sobre las que los/las profesionales sanitarios/as, especialmente la enfermera, trabajan cotidianamente (como la promoción de la actividad física, la alimentación saludable, el apoyo a los cuidadores, por poner tres ejemplos). Así, la lactancia materna aparece (al menos en la zona de estudio) como la única actividad de promoción de salud comunitaria. Con buen juicio, conviene que la enfermera sea consciente de esta coincidencia estratégica para definir su papel en el movimiento de la lactancia materna y sopesar el interés que puede tener el emplearse en el movimiento social de la lactancia materna en favor de la salud de la población. Esta podría ser una línea interesante para ampliar su papel hacia la esfera social, tomar relevancia como profesional en los aspectos relacionados con la salud y no con la enfermedad y pasar a ocupar un papel sanitario protagonista en salud, no tan subsidiario del de otros y otras profesionales.

\section{La estrategia de visibilizar la lactancia}

"Están diciendo que demos más el pecho las mujeres, pero no hay facilidades para darlo" GDPi 2I-8

Parece ser que, apoyándose en la falta de espacios para la lactancia, la primera de las estrategias que emplean las mujeres de los grupos para hacer de la lactancia materna algo socialmente aceptado, es la de darle visibilidad, hacer que no sea necesariamente algo de la esfera estrictamente íntima, sino un hecho social manifiesto ${ }^{38}$. Para algunos/as profesionales este sería "un objetivo a conseguir" desde los Talleres.

38 Hoy en día es frecuente asistir a incidentes relacionados con la dificultad de lactar en espacios públicos como locales comerciales o incluso en los parlamentos. Como ejemplo baste recordar el reciente "incidente" en el parlamento europeo: http://www. lavanguardia.com/vida/20090327/53668679224/una-diputada-danesa-da-el-pecho-a-su-bebe-en-el-parlamento-europeo.html 
Como se ha señalado, reservar la lactancia materna a la esfera íntima supondría recluir a la mujer en el ámbito privado, además de dificultarla.

“SSí, hombre! Pues te llevas un biberón. Digo: Si es que yo no quiero darle el biberón a mi hijo, porque él tiene su pecho directamente para que mame, ¿por qué me tengo que sacar un biberón...? [...]. ¿Por qué le tengo que acostumbrar a un biberón para un ratito nada más? Si yo me puedo sacar el pecho y darle de mamar perfectamente. [...] Se casa mi hermano en septiembre igual, y me dice que si también lo voy a hacer. Digo: Pues lo voy a hacer. Si lo tengo que hacer, lo voy a hacer. Y el que quiera que mire y el que no que no mire. [...] ¡Pero si es lo más normal del mundo!" GDY I I5-8,I6-I

Por lo tanto, es posible interpretar que la lactancia en espacios públicos se muestra como una estrategia de resistencia al confinamiento en la casa y se relaciona con la reivindicación del papel de la mujer en la sociedad.

"Digo: ¿Por qué me tengo que quedar yo en mi casa, pudiéndome bajar una silla perfectamente a la calle y darle de mamar a mi hijo, que no estoy haciendo ningún mal a nadie, y disfrutando también como están disfrutando ellos?” GDY I I8-7

Esto adquiere mayor relieve cuando se habla de espacios en los que las representaciones sociales de la lactancia que la asocian al pudor y el pecado se hacen más notorias, como puede ser la calle y sobre todo la iglesia:

"Le dije a mi hermano, digo: No sé si me va a aguantar en el bautizo toda la misa, digo, a lo mejor me... (Cambia la voz) ¡Sí hombre! Ahí en la iglesia te vas a sacar... Digo: ¿Y qué pasa por que me saque el pecho en la iglesia? Pero si es lo más natural del mundo. ¿Qué igual se tiene que esperar el cura un poquito...y seguir el bautizo diez minutos más tarde?" GDYI $15-8$

En las entrevistas grupales las madres inciden en la falta o escasez de lactarios en los lugares públicos que faciliten la lactancia. Efectivamente, disponer de ellos supondría una mejora, ya que persiste la idea de que lactar no se debe hacer en público y por otro lado, en general, no se dispone de sitios adecuados para dar el pecho.

"No hay mucho sitio, la verdad, para dar el pecho, en los parques... No hay sitios..." GDY2 $25-4$

"Incluso centros comerciales, restaurantes, museos que no tienen una sala de lactancia habilitada, que no tienen (murmullo) Hay más facilidades en Madrid que en Toledo, pero ni siquiera en Madrid." GDPI 2I-3 
"Tuve que ir los servicios, bajar la tapa del baño y sentarme para darle el pecho."

—"Es triste" GDPr 2I-7

Incluso en instalaciones sanitarias parece que no existen espacios adecuados para amamantar.

"Y fui a ver a un paciente y le dije: Mire, que le tengo que dar a mi hija el pecho, ¿Dónde puedo darle a mi hija el pecho? Y me contestaron que me

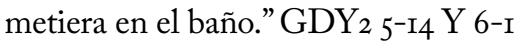

Por otro lado, las mujeres en las entrevistas reseñan la ambivalencia de la creación de los "lactarios" que, concebidos teóricamente como espacios apropiados para favorecer la lactancia, se convierten en espacios que impiden que las mujeres puedan lactar en los espacios públicos o compartidos. (Además suelen estar señalizados con la imagen de un biberón). Así en realidad pasan a ser usados como "espacios de confinamiento" para las mujeres que lactan, creados para evitar su presencia en el espacio público, algo así como "guetos para la lactancia" que evitan situaciones problemáticas. Podría darse la paradoja que en algún centro comercial a la mujer se le impida amamantar a su hijo/a fuera del espacio habilitado para tal fin.

"El centro comercial de La Abadía [...] el otro día mi bebe con I7 meses se hizo sus necesidades tuve que ir a cambiar, entró detrás de mí una mama y no cabíamos los dos carros [...] ni ventilación ni nada (murmullo) es que, no es ni sano." GDPi 2I-5

"La semana de la Lactancia Materna fue: ¡Vamos a salir a la sociedad!" $\mathrm{EP} 2.34^{\prime} 40^{\prime \prime}$

\section{La estrategia de elaborar el discurso}

A través de las dificultades sociales que sufren las mujeres para dar el pecho, recogidas a lo largo de este trabajo, podemos ver con claridad que existen poderosas fuerzas sociales que se oponen a la lactancia materna, luego para hacer frente a ese rechazo la postura al menos, para algunas de ellas, es constituirse en grupos reivindicativos de la lactancia, una vez que abandonan los talleres de apoyo.

Esto ocurre, en general, no de forma premeditada ni prevista por los/las organizadores/as de los talleres (en nuestro ámbito de estudio por el personal de enfermería), ni por las madres, sino más bien en base a las experiencias de las mujeres al lactar. Así se va articulando un discurso que da cuenta de las 
razones para la defensa de la lactancia materna como algo que debería favorecerse. Este discurso de defensa aflora de forma desorganizada y polémica en las entrevistas grupales, pero se podría hacer una posible interpretación en torno a las siguientes afirmaciones:

- La excelencia de la lactancia materna, frente a la artificial, avalada por el saber científico del campo de la salud, aunque no plenamente incluida en la agenda de las instituciones hospitalarias.

- El aspecto natural de la lactancia materna y la visión negativa de la leche artificial, concebida ésta como un sucedáneo que es defendido por los intereses comerciales y por las ideas antiguas favorables a lo técnico e industrial.

- La resolución de las polémicas suscitadas con las mujeres de la anterior generación, entendiendo que su práctica (de la lactancia artificial) no se debe entender como un déficit de cuidado, sino como el resultado de la promoción de la lactancia artificial en aquellos momentos.

- La creación de un discurso contra las posiciones del feminismo clásico evitando sostener posturas esencialistas que reducen a la mujer a papeles sociales limitados a lo maternal.

- La resolución de las paradojas frente a quienes no optan por la lactancia materna en la actualidad, discutiendo las ideas simples de la lactancia como un derecho del niño/a y un deber de la madre, y asumiendo posturas más conciliadoras con los diversos roles sociales de la mujer en nuestras sociedades.

- Cuestionando que el papel del varón no se minimiza al practicarse la lactancia materna, siempre y cuando se realice un reparto de papeles diferente en el cuidado de los hijos e hijas.

- Abogando por un aumento de la duración del descanso por maternidad, para que se incluya el periodo de lactancia exclusiva mínimo recomendado por la OMS.

- Defendiendo el uso del espacio público como espacio para la lactancia materna y cuestionando las representaciones sociales que relacionan la lactancia materna como una práctica ofensiva o impúdica, impropia del espacio público.

Estas líneas discursivas que se extraen de las opiniones de las mujeres participantes del estudio pueden ser útiles para elaborar un discurso en defensa de la lactancia materna en el plano social, que discuta las todavía vigentes 
representaciones sociales que la dificultan, y que pueda ser asumido tanto por los grupos sociales implicados en la defensa de la lactancia, como por los/las profesionales de la salud que se dedican a su fomento en nuestra sociedad.

\section{CONCLUSIONES}

Una vez finalizado el análisis pormenorizado de los resultados, quienes investigan, extraen las siguientes conclusiones con respecto a los talleres de lactancia materna:

- La mujer en el tercer trimestre de embarazo centra su atención, casi de forma exclusiva, en el momento del parto, este hecho puede causar en la madre desinterés por aspectos relativos a la maternidad, tales como la lactancia, que acontecerán a posteriori del parto, y por tanto no estará suficientemente receptiva a la información que se le facilita durante el curso de "educación maternal". Luego, sería muy recomendable programar las actividades formativas en lactancia natural al inicio del embarazo.

- Las madres (sobre todo en el taller de Yepes) esperan encontrar una formación de tipo teórico sobre la lactancia, por lo tanto, sería conveniente explicar a las mujeres durante la sesión formativa en lactancia que los talleres son grupos de apoyo y autoayuda, hecho que evitaría la falsa percepción con la que llegan las madres a los talleres de lactancia y mitigaría la posible frustración que conlleva no poder alcanzar las expectativas que anhelaban las madres.

- La sociedad en general y la familia en particular con mucha frecuencia plantean serios obstáculos para que la madre asista con asiduidad al taller de lactancia. El equipo investigador propone con relación a este aspecto invitar a las mujeres de las generaciones anteriores a la formación en lactancia, así como a la pareja de la madre amamantadora; hecho que se convertiría en una estrategia facilitadora de la lactancia materna y neutralizaría a posteriori el rechazo social a una práctica natural en la vida de la mujer.

- Llegado a este punto cabe insistir que los talleres de lactancia materna actúan como grupos de autoayuda, resultando muy útiles a la hora de conseguir una lactancia natural efectiva en las mujeres participantes; todo ello es posible porque en el taller la madre encuentra: el apoyo necesario, el asesoramiento oportuno y la comprensión adecuada para hacer que la lactancia sea vivida con tranquilidad, seguridad, confianza y serenidad. En definitiva, el taller proporciona a la madre las herramientas adecuadas para que la mujer se empodere en el hecho natural de lactar. 
- Las mujeres que acuden con asiduidad a los grupos de apoyo manifiestan de forma unánime, su cariño y respeto hacia los/las enfermeros/as responsables de los talleres, observan en ellos/as empatía, dedicación y profesionalidad a la hora de asesorarlas en lactancia, tanto es así que las madres suelen sentir un cierto duelo cuando llega el momento de abandonar el taller, hecho que además, en la mayoría de los casos coincide con la incorporación de la mujer a la actividad laboral que realizaba antes de quedarse embarazada.

Las conclusiones que el equipo investigador extrae del estudio de los resultados con respecto a la representación social sobre la lactancia materna son las siguientes:

- Cuando se pretende conseguir una lactancia materna duradera y feliz en la mujer es imprescindible: tener en cuenta el estado emocional de la madre, ayudarla a encontrar herramientas que le permitan sobrellevar la carga de trabajo que genera la dependencia del/la bebé en sus primeros días de vida, y sobre todo es vital asesorarla para crear, establecer y conseguir un vínculo materno filial fuerte y seguro que contribuya a vencer todos los obstáculos e impedimentos que se encontrarán madre e hija/o a lo largo del periodo de lactancia.

- La representación social sobre la lactancia y el cuidado de los hijos e hijas es determinante para la lactancia, el paradigma de la vuelta a lo natural como deseo de la población contribuye a que la lactancia materna sea considerada muy positiva. Todas las participantes consideran la leche materna fuente de salud para sus hijos/as siendo muy valorada y apreciada por ellas, sin embargo, aún a pesar de esos alicientes, en la actualidad todavía existen múltiples factores que dificultan el inicio de la lactancia materna, por ejemplo: decisiones de la pareja, familia, profesionales de la salud y entorno social de la madre.

- Las participantes en el estudio no reconocen inconvenientes de la lactancia materna relacionados con el niño o niña, mientras que sí reconocen inconvenientes relacionados con la mujer; en este sentido cabe destacar el rechazo social que perciben las participantes durante el amamantamiento en espacios públicos. Para conseguir una lactancia materna eficaz, en dichas circunstancias, se hace imprescindible un cambio en la autoimagen de la madre pasando de verse a sí misma como posible objeto sexual a simplemente una madre, pero no solo la mujer debe cambiar en este sentido, si no que la sociedad actual debe reivindicar 
y recabar el apoyo institucional necesario que otorgue a las madres el poder necesario para realizar dicha actividad en cualquier espacio $u$ entorno sin recelos de terceros. Por tanto, las estrategias para defender la lactancia materna serían: renaturalizar la lactancia con el apoyo de profesionales de la salud y los talleres. Hacer del espacio público un espacio adecuado para lactar y así visualizar la lactancia. En este sentido cabe incidir que en múltiples ocasiones la oposición social a la lactancia materna tiene que ver con algunos aspectos de la lucha por la igualdad de género, por lo que la reivindicación en defensa de la lactancia materna además puede llevar asociado un discurso por la igualdad de género.

Para terminar con relación a la intervención de profesionales de la salud en el fomento de la lactancia, los/las investigadores/as del estudio aprecian las siguientes conclusiones:

- El intervencionismo por parte de profesionales de la salud durante el puerperio inmediato compromete el inicio de la lactancia natural, siendo más complicada la instauración de la lactancia materna cuando el hijo/a ha sido separado de la madre en las primeras horas del inicio de la vida.

- Las mujeres con relación a la lactancia se sienten insatisfechas con la atención recibida durante su estancia en el hospital, aprecian que el apoyo a la lactancia materna depende exclusivamente de la voluntariedad del o de la profesional que les atiende y perciben, además, descoordinación entre ellos/as, así como diferencias entre los mensajes recibidos en el hospital y atención primaria, a veces contradictorios, con respecto a la lactancia materna.

- No se aprecian diferencias significativas entre los talleres analizados. Todas las participantes del estudio de forma unánime manifiestan que donde realmente recibieron apoyo, asesoramiento y comprensión, para llevar a cabo el amamantamiento de sus hijos e hijas de forma adecuada a sus circunstancias, vivido con tranquilidad y confianza fue en los grupos de apoyo a la lactancia, allí aseguran que consiguieron su objetivo, dar el pecho a sus hijos/as todo el tiempo que quisieron. 


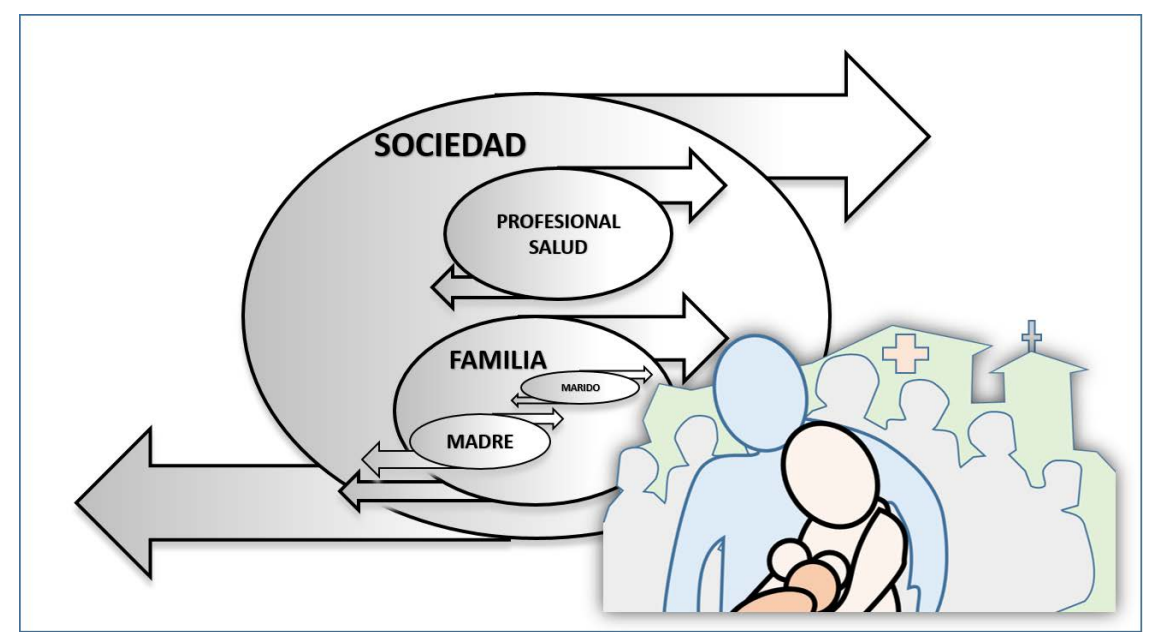

Ilustración I3. Tensiones en la Lactancia Materna.

\section{REFERENCIAS BIBLIOGRÁFICAS}

AHIGE, A. d. H. p. 1. I. d. G.-. (2008). Ser padre: Alegría y responsabilidad. Málaga.

Alba Romero, C., Aler Gay, I., \& Olza Fernández, I. (20II). Maternidad y Salud. Ciencia, conciencia y experiencia. MINISTERIO DE SANIDAD, SERVICIOS SOCIALES E IGUALDAD.

Álvarez, M., Becerra, M., \& Meneses, F. (2004). El desarrollo social y afectivo en los niños de primer ciclo básico., Universidad Mayor, Santiago.

Badinter, E. (2003). Fausse route: Odile Jacob.

Badinter, E. (20IO). Le Conflit-la femme et la mère: Éditions Flammarion.

Barriuso, L., De Miguel, M., \& Sánchez, M. (2007). Lactancia materna: factor de salud. Recuerdo histórico Maternal breastfeeding: health factor. Historical memory. An. Sist. Sanit. Navar, 30(3), 383-39I.

Becerril Rodríguez, E. (20I2). La teoría del apego en las diferentes etapas de la vida: los vínculos afectivos que establece el ser humano para la supervivencia.

Berger, P., \& Luckmann, T.(2003). La construcción social de la realidad. Buenos Aires.

Báez, J., \& de Tudela, P. (2007). Investigación cualitativa: ESIC Editorial.

Campuzano, M. (2004). Los grupos en las instituciones. La Psicoterapia De Grupo En Las Instituciones/group Psychotherapy in the Institutions: Psychoanalysis Y Psicodrama: Alterrnativas Complementarias, 3I.

Canóniga Pizarro, R. (2005). Embarazo de Emociones. Educación. 
Chóliz, M. (2005). Psicología de la emoción: el proceso emocional. Universidad de Valencia, España.[Links].

Damasio, A. (2005). En busca de Spinoza. Neurobiología de la emoción y los sentimientos. Barcelona: Crítica.

Damasio, A. R. (2000). Sentirlo que sucede: cuerpo y emoción en la fábrica de la conciencia: Andrés Bello.

De Dios Aguado, M., \& Gallego Moreno, M. F. (2017). "Dar el pecho: ir contracorriente”. Investigación cualitativa en grupos de Lactancia materna, 388-396. Retrieved from http://www.faecap.com/publicaciones/show/libro-de-actas-xcongreso-faecap-20I7

De la Salud, M. (2003). Estrategia mundial para la alimentación del lactante y del niño pequeño.

Dettwyler, K. A. (1987). Breastfeeding and weaning in Mali: cultural context and hard data. Social Science E Medicine, 24(8), 633-644.

Didierjean-Jouveau, C.-S. (2003). L'allaitement est-il compatible avec le féminisme? Spirale(3), I39-I47.

d'Eaubonne, F., Merchant, C., \& Hottell, R. (1974). Le temps de l'écoféminisme. The Time For Ecofeminism.

Embarazo, P.y.P.,padres, R. p. m.y., \& Andalucía.,J.d. Consejería de Salud. Dirección General de Salud Pública y Participación. Dep. Legal: SE-2.924/o6.

Fernández de Sanmamed Santos, M. (2000). Adecuación de las normas de publicación en revistas científicas a las investigaciones cualitativas. Atención primaria, 25(7), 502-504.

García, M. J. B. (2006). Iniciativa hospitales amigos de los niños. Medicina naturis$t a(\mathrm{Io}), 550-560$.

García, M. J. B., Lainez, M. C. T., \& Coarasa, A. O. (2006). VÍA LÁCTEA 20 AÑOS DE AYUDA DE MADRE A MADRE. Zaragoza.

González, C. (2006). Un regalo para toda la vida. Guia de lactancia materna. Ed. Temas de Hoy.

Ibáñez, J. (1979). Más allá de la sociología: el grupo de discusión: teoría y crítica: Siglo XXI de España Editores.

Jackson, C., \& Pearson, R. (1998). Feminist visions of development: gender analysis and policy: Routledge.

Jiménez, M. L. V. (2006). Emociones positivas. Papeles del psicólogo, 27(I), 9-17.

Lazarus, R. S. (1993). From psychological stress to the emotions: A history of changing outlooks. Annual review of psychology, 44(I), I-22. 
Macadam, P.S., \& Dettwyler, K. A. (1995). Breastfeeding: biocultural perspectives: Transaction Publishers.

Massó Guijarro, E.(2013). Lactancia materna y revolución, o la teta como insumisión biocultural: calostro, cuerpo y cuidado. Dilemata(II), 169-206.

Mateo Rodríguez, I. (2000). El grupo focal como técnica de investigación cualitativa en salud: diseño y puesta en práctica. Atención primaria, 25(3), I8I-I86.

Materna, A. L. (Ed.) (2005). Claves para amamantar con éxito.

Melgar del Corral, G., Villar de la Fuente, M. C., de Dios Aguado, M., \& Gallego Moreno, M. F. (20I7). "Ir contracorriente": investigación cualitativa en grupos de lactancia materna. Rev. iberoam. Educ. investi. Enferm. 7(2):2I-3I. (7 (2)), 2I-3I.

Moscovici, S. (1986). Pensamiento y vida social. Psicología social y problemas sociales. Psicología social II. Barcelona: Paidós.

Nieto del Mármol, S. (2012). Situación y actitudes del activismo prolactancia materna en España a partir de los acontecimientos provocados por la publicación del reportaje "Madre o vaca" en el dominical Magazine de El Mundo el I7 de octubre de 2010.

Pediatria, A. E.d. (2008). Manual de lactancia materna: Ed. Médica Panamericana.

Pérez,M.P.(I999). A PROPÓSITO DE LAS REPRESENTACIONES SOCIALES. APUNTES TEÓRICOS, TRAYECTORIA Y ACTUALIDAD. Recuperado de http://biblioteca. clacso. edu. ar/ar/libros/cuba/cips/caudaleso5/Caudales/ ARTICULOS/Articu losPDF/02Po75. $p d f$.

Righard, L., \& Alade, M. O. (I990). Effect of delivery room routines on success of first breast-feed. The Lancet, 336(8723), I105-IIо7.

Scheper-Hughes, N. (1997). La muerte sin llanto: violencia y vida cotidiana en Brasil ( $\mathrm{I}^{\mathrm{a}}$ ed.). Barcelona: Ariel.

Sordini, N. (20I0). Representaciones sociales de la lactancia materna.

Trillo Siaba, T. (I982). Breve historia de Yepes. Temas Toledanos(I9).

Uriarte, A. G. (2006). Estados emocionales en el postparto. Medicina Naturista(ı), $483-487$.

Vilalonga, C. A. (2010). Ecofeminisme: Dona i Naturalesa. Revista Taula. Quaderns de pensament, $2009(42), \mathrm{I} 27-\mathrm{I} 36$.

Wilhelm, S. L., Flanders Stepans, M. B., Hertzog, M., Callahan Rodehorst, T. K., \& Gardner, P. (2006). Motivational interviewing to promote sustained breastfeeding. Journal of Obstetric, Gynecologic, E Neonatal Nursing, 35(3), 340-348.

Zamora Pasadas, M., \& Cañamero Pascual, I. (2008). Lactancia Materna (F. A. S.L Ed. primera edición ed.). 


\section{ANEXOS}

\subsection{ANEXO 1. PERFIL TIPO DE LOS GRUPOS DE DISCUSIÓN}

Grupos Rural: GDI y GD2.

\begin{tabular}{|l|l|c|c|c|c|c|c|c|c|}
\hline \multicolumn{2}{|c|}{ MIEMBRO No } & $\mathbf{1}$ & $\mathbf{2}$ & $\mathbf{3}$ & $\mathbf{4}$ & $\mathbf{5}$ & $\mathbf{6}$ & $\mathbf{7}$ & $\mathbf{8}$ \\
\hline \multirow{2}{*}{ Permanen. } & 3-5 & & $\mathrm{X}$ & & & & $\mathrm{X}$ & & $\mathrm{X}$ \\
\hline & Más 5 visitas & $\mathrm{X}$ & & $\mathrm{X}$ & $\mathrm{X}$ & $\mathrm{X}$ & & $\mathrm{X}$ & \\
\hline \multirow{2}{*}{ Origen } & "Foráneas & & $\mathrm{X}$ & $\mathrm{X}$ & $\mathrm{X}$ & & & & \\
\hline \multirow{2}{*}{ Paridad } & Oriundas & & & & & $\mathrm{X}$ & $\mathrm{X}$ & $\mathrm{X}$ & \\
\hline & Inmigrantes & $\mathrm{X}$ & & & & & & & $\mathrm{X}$ \\
\hline \multirow{2}{*}{ Duración } & Multi & $\mathrm{X}$ & $\mathrm{X}$ & & & & & & \\
\cline { 2 - 11 } & Primi & & & $\mathrm{X}$ & $\mathrm{X}$ & $\mathrm{X}$ & $\mathrm{X}$ & $\mathrm{X}$ & $\mathrm{X}$ \\
\hline & Menos de 4 meses & & & $\mathrm{X}$ & & $\mathrm{X}$ & & $\mathrm{X}$ & $\mathrm{X}$ \\
\hline
\end{tabular}

Grupos Urbano: $G D_{3}$ y $G D_{4}$.

\begin{tabular}{|l|l|l|l|l|l|l|l|l|l|}
\hline \multicolumn{2}{|c|}{ MIEMBRO No } & $\mathbf{1}$ & $\mathbf{2}$ & $\mathbf{3}$ & $\mathbf{4}$ & $\mathbf{5}$ & $\mathbf{6}$ & $\mathbf{7}$ & $\mathbf{8}$ \\
\hline \multirow{2}{*}{ Permanen. } & $3-5$ & & $\mathrm{X}$ & & & & $\mathrm{X}$ & & $\mathrm{X}$ \\
\hline & Más 5 visitas & $\mathrm{X}$ & & $\mathrm{X}$ & $\mathrm{X}$ & $\mathrm{X}$ & & $\mathrm{X}$ & \\
\hline Origen & Españolas & & $\mathrm{X}$ & $\mathrm{X}$ & $\mathrm{X}$ & $\mathrm{X}$ & $\mathrm{X}$ & $\mathrm{X}$ & \\
\hline \multirow{2}{*}{ Paridad } & Inmigrantes & $\mathrm{X}$ & & & & & & & $\mathrm{X}$ \\
\hline & Multi & $\mathrm{X}$ & $\mathrm{X}$ & & & & & & \\
\hline \multirow{2}{*}{ Duración } & Primi & & & $\mathrm{X}$ & $\mathrm{X}$ & $\mathrm{X}$ & $\mathrm{X}$ & $\mathrm{X}$ & $\mathrm{X}$ \\
\hline & Menos de 4 meses & & & $\mathrm{X}$ & & $\mathrm{X}$ & & $\mathrm{X}$ & $\mathrm{X}$ \\
\hline
\end{tabular}




\subsection{ANEXO 2. MODELO DE "FICHA DE CAPTADOR FINAL" GD No ${ }^{o}$ : Miembro n. $^{\circ} \mathrm{I}$}

\section{Características de la persona a contactar:}

Mujer que haya acudido al taller de apoyo a la lactancia materna de Yepes después del nacimiento de su hijo/a, que hable correctamente el español y que no sea profesional sanitaria.

- Que haya asistido más de 5 días al taller.

- Que sea inmigrante.

- Que tenga más de 1 hijo/a.

- Que haya dado L. M. más de 4 meses.

Se trata de una investigación realizada por la Universidad de Castilla-La Mancha sobre la lactancia materna.

Nombre de la persona citada:

Teléfono

Por favor conserva este original para saber a quién has citado a la reunión y llámeme al teléfono .......................... para facilitarme los datos de la persona citada.

La parte inferior de la ficha debes dársela a la persona invitada para que le sirva como recordatorio de la reunión.

Recuerda anotarle tu teléfono en la parte de abajo para que pueda llamarte si tiene algún problema.

Información sobre la reunión

Se trata de participar junto con otras 7 mujeres en una reunión para hablar, discutir y opinar sobre la lactancia materna. 
La reunión durará aproximadamente una hora y media y lo hablado será de carácter anónimo. Junto con lo que se diga en otras reuniones parecidas, formará la base de una investigación de la Universidad.

La reunión tendrá lugar en: ......

Fecha y hora: ......

Preguntar por: ......

Te agradecemos de antemano tu colaboración.

Tfno. de la persona que te invitó:

Por favor, comunica cualquier incidencia o imprevisto que te surja a la persona que te ha invitado. 


\subsection{ANEXO 3. GUÍA DE DISCUSIÓN ENTREVISTAS GRUPALES}

\section{INTRODUCCIÓN:}

Presentación preceptor

- Agradecimiento. Valoración esfuerzo de participar

- Tiempo estimado

Tema: se trata de hablar de la lactancia materna.

- Garantía de anonimato

- Consentimiento verbal de grabación y motivo.

- Presentar al observador

- Dinámica de grupo

- Arranque: opinión de la lactancia materna. Experiencia de L.M.

\section{GUÍA TEMÁTICA:}

1.1. EXPECTATIVAS QUE TENÍAN SOBRE LOS TALLERES DE APOYO A LA L.M.

1.2. Qué se busca en el taller: Seguridad, pautas y protocolos de L.M., asesoramiento y supervisión profesional o técnica del cuidado y otros temas relacionados

\subsubsection{Expectativas frustradas}

\subsection{VIVENCIAS QUE TIENEN SOBRE LOS TALLERES DE APOYO A LA L.M.}

1.3.1. El taller como espacio de intercambio de experiencias en L.M.

1.3.2. El taller como espacio de relación

1.3.3. La utilidad práctica del taller de L.M. (peso y otros,...)

1.3.4. Sobre el profesional que lo coordina

\subsubsection{Propuestas de mejora}

1.3.6. Valoración de recursos, estructura, espacio, horario, etc.

1.3.7. El momento de dejar de asistir al taller. 


\subsection{CONCEPTO DE L.M.}

1.4.1. Influencia de cuestiones sociales y culturales sobre la L.M.:

1.4.2. la leche materna

1.4.2.1. imagen de la mujer

1.4.3. Emociones y L.M.

1.4.4. La lactancia materna como "técnica"

1.4.5. L.M. y maternidad y papel femenino.

1.4.6. L.M. y entorno familiar y doméstico

1.4.7.L.M. y el lactante

1.4.8. Conocer cuáles son los condicionantes para el inicio y el mantenimiento de la L.M.

1.4.9. Beneficios e inconvenientes de L.M.

1.4.10. Visión sobre la L.M. y los sanitarios:

1.4.11. Contradicciones

1.4.12. Visión de la enfermera en L.M.

1.4.13. Visión de otros profesionales en la L.M.

1.4.14. El tema del enganche por el pecho

1.4.15. La lactancia materna como objeto de atención sanitaria (medicalización, la mujer como objeto obstétrico y ginecológico, el juicio del/la sanitario/a sobre L.M....) 
7.4.ANEXO 4. GUÍA DE ENTREVISTA A PROFESIONALES

7.4.1. GUÍA DE ENTREVISTA A PROFESIONAL DE ENFERMERÍA EN ATENCIÓN PRIMARIA CON EXPERIENCIA EN TALLERES DE L.M.

\section{INTRODUCCIÓN:}

Agradecimiento. Valoración esfuerzo de participar

- Tiempo estimado

- Tema: se trata de hablar de la lactancia materna. En base a su experiencia. También como centro...

- Garantía de anonimato. Consentimiento verbal de grabación y motivo

- Arranque: experiencia de trabajo en apoyo lactancia materna

\section{GUÍA TEMÁTICA:}

\section{EXPECTATIVAS QUE TIENEN LAS MUJERES QUE ASISTEN A LOS TALLERES DE APOYO A LA L.M.}

1.1. Qué buscan en el taller: seguridad, pautas y protocolos de L.M., Asesoramiento y supervisión profesional o técnica del cuidado y otros temas relacionados

1.2. Por qué no vienen algunas.

1.3. Evolución en el tiempo de los talleres

1.4. Qué viven en el taller las mujeres

\section{La L.M.}

2.1. Condicionantes para el inicio

2.2. Condicionantes para el mantenimiento de la L.M.

2.3. Cuándo dejarlo

2.4. Beneficios e inconvenientes de L.M.

2.5. La familia en la L.M.

2.6. El trabajo y la L.M.

2.7. El entorno social en la L.M.

2.8. Asociaciones y L.M. 


\section{SANITARIOS Y L.M.}

3.1. Propuestas de mejora de los talleres

3.2. Sobre el profesional que coordina el taller

3.3. Valoración de recursos, estructura, espacio, horario, etc., del taller

3.4. Visión de otros profesionales en la L.M.

3.5. Visión sobre la L.M. y el hospital

\subsubsection{GUÍA DE ENTREVISTA A PROFESIONAL ENFERMERÍA EN ATENCIÓN HOSPITALARIA. NEONATOLOGÍA}

\section{INTRODUCCIÓN:}

Agradecimiento. Valoración esfuerzo de participar

- Tiempo estimado

- Tema: se trata de hablar de la lactancia materna. En base a su experiencia. Garantía de anonimato. Consentimiento verbal de grabación y motivo

\section{GUÍA TEMÁTICA:}

\section{La L.M.}

- Condicionantes para el inicio de la L.M. en el hospital

- La influencia de la familia en el inicio de la L.M.

- El entorno social en la L.M.

- Asociaciones y L.M.

\section{SANITARIOS Y L.M.}

- Visión sobre la L.M. y el hospital

- El/la enfermero/a y la L.M. en el hospital

- Visión de otros profesionales en la L.M.

- Propuestas de mejora de la L.M. en el hospital 


\section{LECTURA INICIAL: primeras impresiones}

2. Elaboración de esquema de codificación: planilla de análisis según objetivos y variables

\section{ELABORACIÓN MATRIZ INICIAL}

3.1. Elaboración de libro de códigos iniciales (se completará en el proceso de codificación y recodificación)

\subsection{CICLO DE CODIFICACIÓN INICIAL (SEGMENTACIÓN del texto).}

\subsection{Organización de codificación:}

\subsubsection{Nombrar responsable de codificación}

\subsubsection{Equipo de Codificadores}

3.4. Elaboración de tabla de familias de documentos según variables

3.5. Distribuir documentos entre codificadoras Se decide que habrá 3 codificadoras, que codificarán todos los documentos

3.6. Selección de pasajes significativos (citas) por cada codificadora

El proceso podrá comenzar en cuanto se cuente con el libro de códigos y la matriz corregida. Se propone empezar por el documento GDY2

3.7. Asignación INMEDIATA de códigos a las citas

3.7.1. Citas A PRIORI, deductiva o Cerrada (del "libro de códigos" o la matriz)

3.7.2.Abierta (emergentes). Las nuevas que creáis que hay que incluir. Se marcarán con asterisco y se propondrán posibles códigos para incluir en el libro de códigos

3.8. Elaboración inmediata de "notas de análisis"

3.8.1.En las notas se incluirá las letras $\mathrm{T}, \mathrm{M}, \mathrm{C}$ o $\mathrm{A}$, según tipologías:

3.8.2. T: Teóricos (donde se registra la estructura teórica)

- M: Metodológicos habla del método (entrevista, EG, etcétera) 
- C: Conceptual, registran detalles de los "códigos"

- A: Analítico o de reflexión, nota de análisis propiamente

- Volcado de citas con códigos a tabla EXCELL

3.9. Reuniones de selección de análisis por objetivos o códigos

\section{RECODIFICACIÓN (CATEGORIZACIÓN INICIAL)}

4.9.1. Relación entre códigos agrupamiento en "familias" de códigos

4.9.2. Listado de PROTOCATEGORÍAS coincidentes con los capítulos del estudio

\section{CATEGORIZACIÓN E INTERPRETACIÓN}

5.1. Descripción de categorías

5.2. Redaccón de resultados de cada categoría, en forma de narración teórica apoyada en las citas ordenadas

5.3. Relación entre categorías y resultados generales

5.4. Explicación general de resultados

5.5. Búsqueda del sentido

6. VERIFICACIÓN (CIRCULARIDAD) 
7.6. ANEXO 6. LIBRO DE CÓDIGOS INDUCTIVOS (INICLALES)

\begin{tabular}{|c|c|c|}
\hline 1 & CÓDIGO & TALLER \\
\hline 1.1 & EXP. & $\begin{array}{l}\text { EXPECTATIVAS QUE TENÍAN SOBRE LOS } \\
\text { TALLERES DE APOYO A LA L.M. (GENERAL) }\end{array}$ \\
\hline 1.1.1 & SEG & Seguridad \\
\hline 1.1.2 & PAUTAS & Pautas y protocolos de L.M. \\
\hline 1.1.3 & ASESO & Asesoramiento prof/técnica \\
\hline 1.1.4 & OTRO & Otros \\
\hline 1.1.5 & FRUS & Expectativas frustradas \\
\hline 1.2 & VIVENC & $\begin{array}{l}\text { VIVENCIAS QUE TIENEN SOBRE LOS } \\
\text { TALLERES DE APOYO A LA L.M. }\end{array}$ \\
\hline 1.2.1 & INTER EXP & $\begin{array}{l}\text { El taller como espacio de intercambio de experiencias en } \\
\text { L.M. }\end{array}$ \\
\hline 1.2.2 & RELAC & El taller como espacio de relación \\
\hline 1.2.3 & UTIL & La utilidad práctica del taller de L.M. (peso y otros) \\
\hline 1.2.4 & PROF COORD & Sobre el profesional que lo coordina \\
\hline 1.2.5 & EXPO. & Exposición física y emocional \\
\hline 1.2.6 & P. MEJORA & Propuestas de mejora \\
\hline 1.2.7 & RECURS & Valoración de recursos, estructura, espacio, etcétera \\
\hline 1.2.8 & MOMENT & El momento de dejar de asistir al taller. \\
\hline 2 & & CONCEPTO DE L.M. \\
\hline 2.1 & SOCIO CULT & $\begin{array}{l}\text { INFLUENCIA DE CUESTIONES SOCIALES Y } \\
\text { CULTURALES SOBRE LA L.M.: }\end{array}$ \\
\hline 2.1.1 & LECHE M & La leche materna \\
\hline 2.2 . & IMAGEN M & Imagen de la mujer \\
\hline 2.3 & EMO & EMOCIONES Y L.M. \\
\hline 2.3.1 & DEPEN & Dependencia \\
\hline 2.4 & TECNI & LA LACTANCIA MATERNA COMO “TÉCNICA” \\
\hline 2.5 & L.M. FEMENI & L.M.Y MATERNIDAD Y PAPEL FEMENINO \\
\hline 2.6 & FAMILIA & L.M.Y ENTORNO FAMILIAR Y DOMÉSTICO \\
\hline 2.7 & LACTANTE & L.M.Y EL LACTANTE \\
\hline 2.8 & $\begin{array}{l}\text { CONDICIONA } \\
\text { L.M. }\end{array}$ & $\begin{array}{l}\text { CONOCER CUÁLES SON LOS } \\
\text { CONDICIONANTES EXTERNOS PARA EL } \\
\text { INICIO DE LA L.M. }\end{array}$ \\
\hline 2.9 & MANTENI & $\begin{array}{l}\text { CONOCER CUÁLES SON LOS } \\
\text { CONDICIONANTES EXTERNOS PARA EL } \\
\text { MANTENIMIENTO }\end{array}$ \\
\hline
\end{tabular}




\begin{tabular}{|l|l|l|}
\hline 2.10 & BENEF-INCO & BENEFICIOS E INCONVENIENTES DE L.M. \\
\hline 2.11 & SANITARIO & VISIÓN SOBRE LA L.M.Y LOS SANITARIOS \\
\hline 2.11 .1 & CONTRAD & Contradicciones \\
\hline 2.11 .2 & ENF & Visión de la enfermera en L.M. \\
\hline 2.11 .3 & OTRO PROF & Visión de otros profesionales en la L.M. \\
\hline 3 & & VARIABLES \\
\hline 3.1 & MULTI & Multípara \\
\hline 3.2 & PRIMI & Primípara \\
\hline 3.3 & INMIG & Inmigrante \\
\hline 3.4 & FORANEA & Foránea \\
\hline 3.4 & DURA L.M. & Duración de la L.M. \\
\hline 3.5 & PERMA & Permanencia en el taller \\
\hline
\end{tabular}




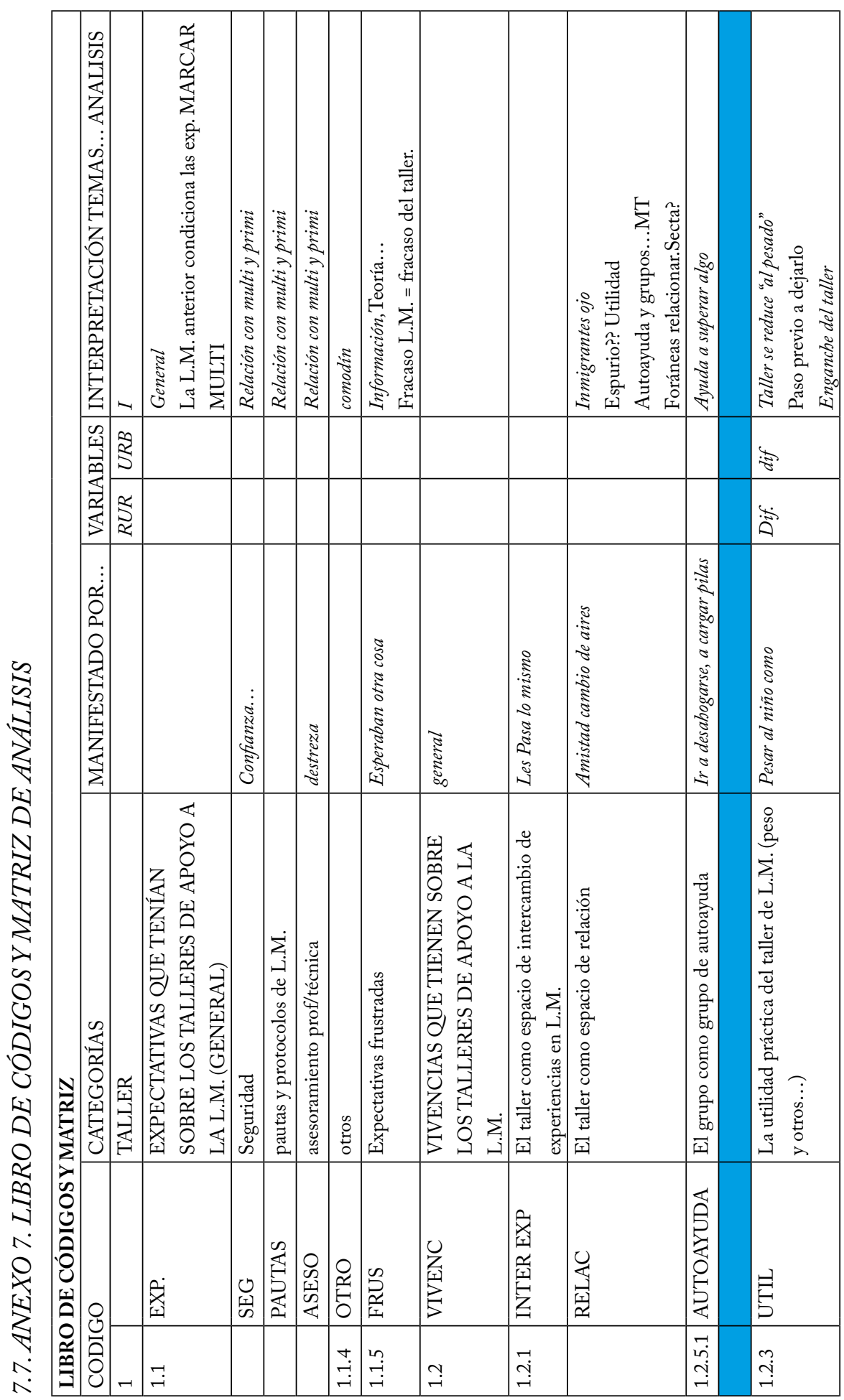




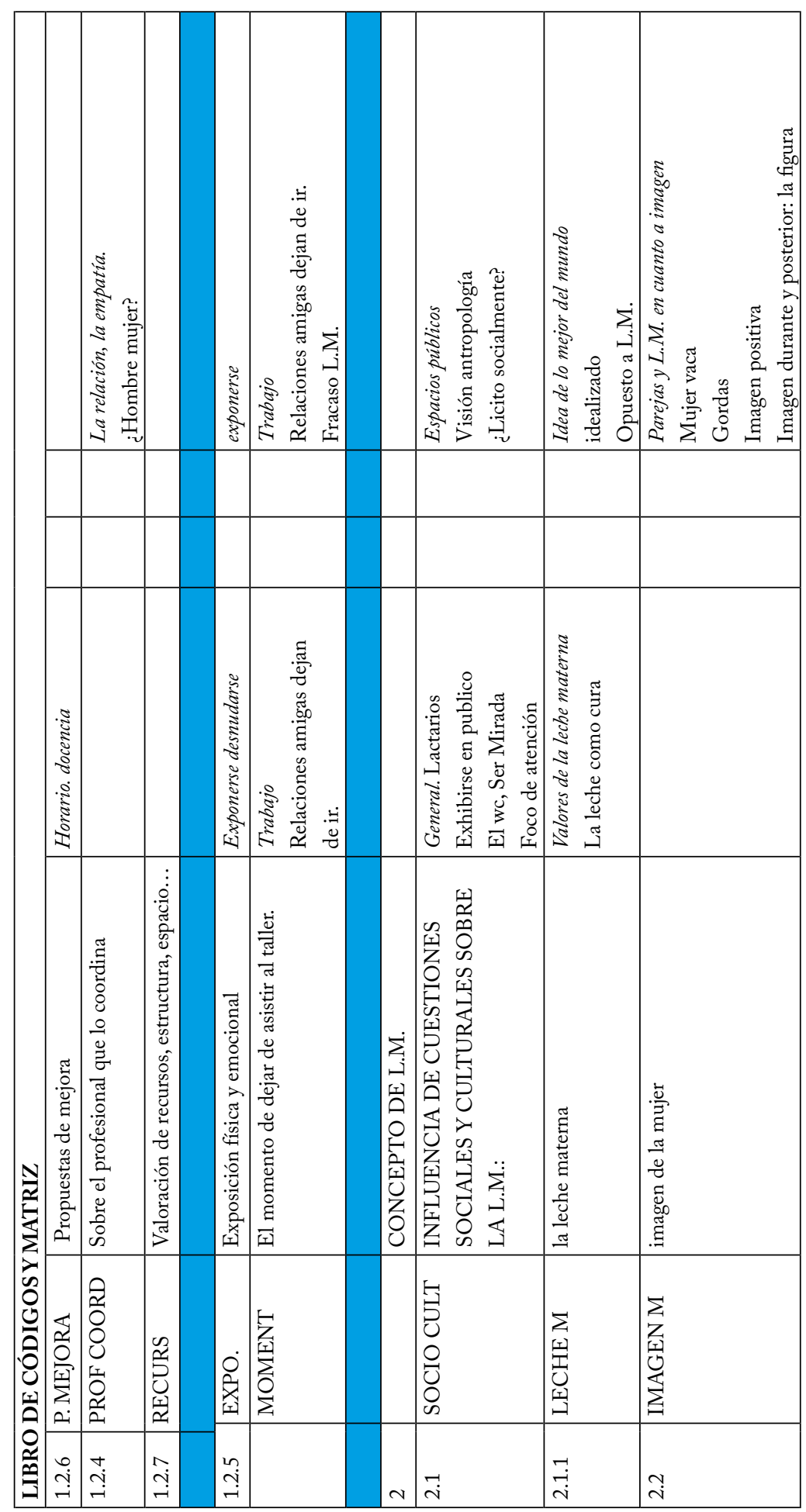




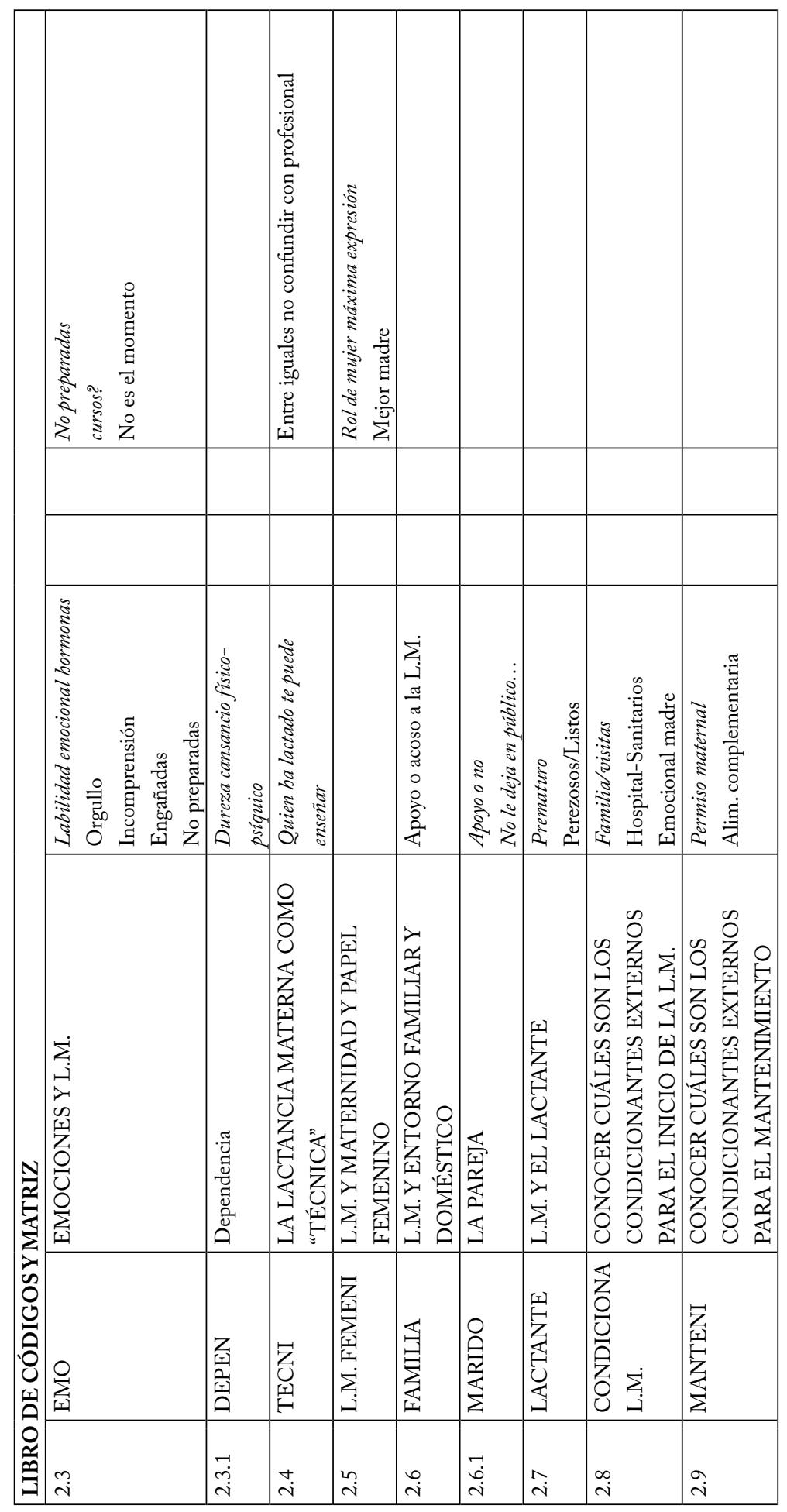




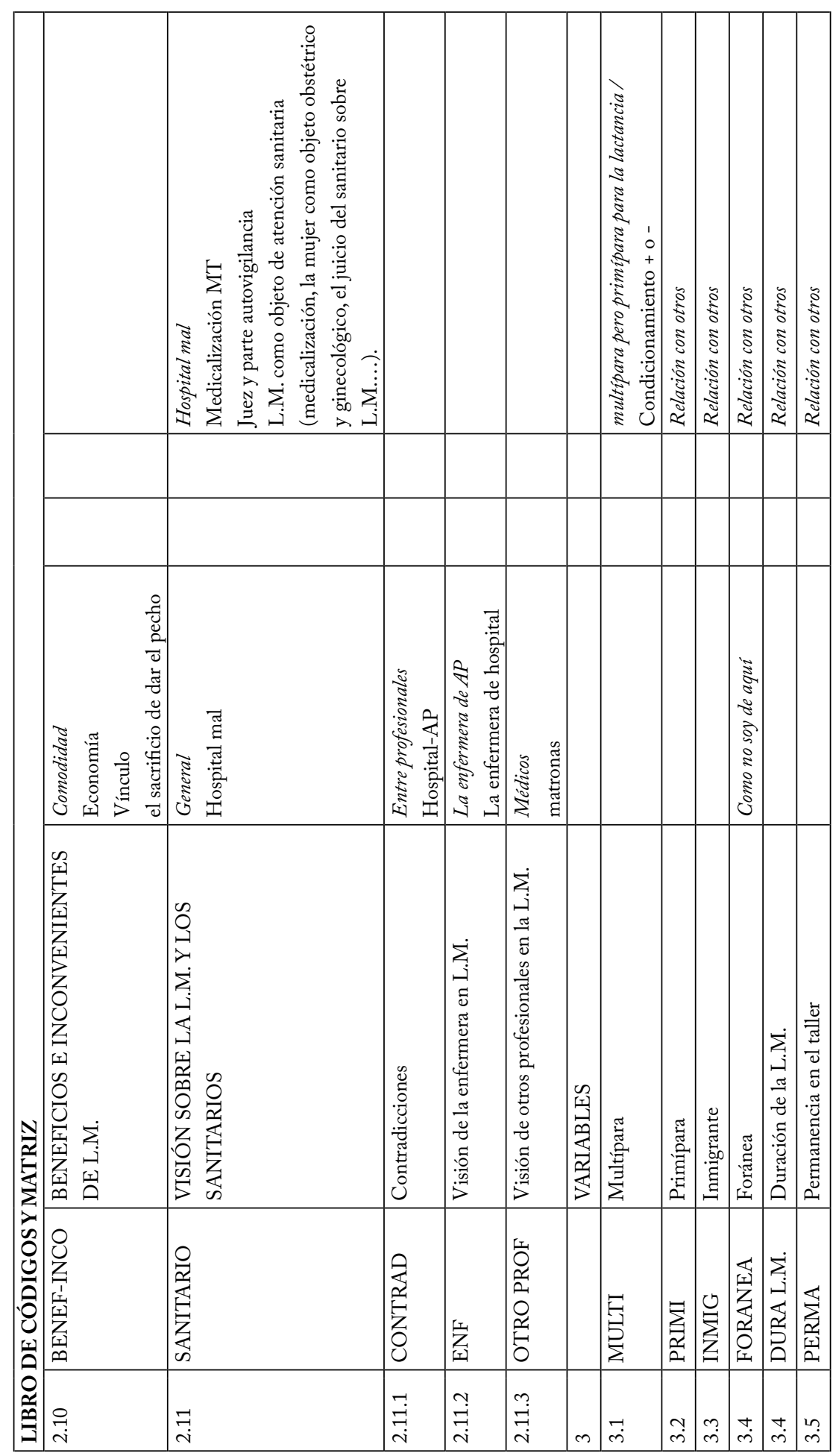


Ilustración 1. Pirámide de Población de ZBS Yepes (Toledo)........ 31

Ilustración 2. Pirámide de Población de ZBS Sta. M.a de Benquerencia (Toledo) …….............................................. 32

Ilustración 3. Pirámide de Población de ZBS de Fuensalida (Toledo).................................................................. 33

Ilustración 4. Esferas de la L.M................................................... 67

Ilustración 5. Cambios en la Visión de la lactancia........................ $\quad 72$

Ilustración 6. Tensiones Madre-hijo/a.......................................... $\quad 92$

Ilustración 7. Beneficios e inconvenientes de la L.M..................... 95

Ilustración 8. Tensiones familiares. ............................................... 110

Ilustración 9. Tensiones con la pareja............................................ 117

Ilustración 10. Tensiones en el ámbito sanitario............................. 128

Ilustración 11. Tensiones sociales.................................................. 143

Ilustración 12. Evolución de los Grupos...................................... 145

Ilustración 13. Tensiones en la Lactancia Materna........................ 153 


La lactancia materna en la actualidad se enfrenta a importantes dificultades sociales, laborales y familiares que hacen que las cifras de prevalencia materna estén muy por debajo de las recomendaciones de expertos y autoridades. Por este motivo la promoción de la LM ha empezado a ser una labor que se desarrolla en el ámbito de la salud. En España actualmente se ensayan diferentes formas y estilos de realizar esta labor.

El estudio realizado mediante metodología cualitativa, mediante grupos de discusión con madres participantes en diferentes "grupos de apoyo a la lactancia materna" de la provincia de Toledo, analiza desde sus puntos de vista, el funcionamiento de estos grupos y las dificultades que deben superan durante la lactancia.

Así, el estudio ofrece claves que permitirán al profesional de la salud orientar su labor de promoción de la lactancia natural hoy. 